\title{
DISTRIBUIÇÃO DE TENSÕES GERADAS POR PRÓTESES ESPLINTADAS OU INDIVIDUALIZADAS SOBRE IMPLANTES COM REABILITAÇÕES EM DIFERENTES REBORDOS. ANÁLISE PELO MÉTODO DOS ELEMENTOS FINITOS
}

Tese apresentada à Faculdade de Odontologia de Ribeirão Preto da Universidade de São Paulo, para obtenção do título de Doutor no Programa de Reabilitação Oral.

Área de concentração: Reabilitação Oral

Orientador: Profa. Dra. Maria da Glória Chiarello de Mattos

VERSÃO ORIGINAL 


\section{AUTORIZO A REPRODUÇÃO E DIVULGAÇÃO DO TEOR TOTAL OU PARCIAL DESTE TRABALHO POR QUALQUER MEIO CONVENCIONAL OU ELETRÔNICO, PARA FINS DE ESTUDO E PESQUISA, DESDE QUE CITADA A FONTE.}

Ficha catalográfica elaborada pela Biblioteca Central do Campus USP - Ribeirão Preto

Toniollo, Marcelo Bighetti

Distribuição de tensões geradas por próteses esplintadas ou individualizadas sobre implantes com reabilitações em diferentes rebordos. Análise pelo método dos elementos finitos. Ribeirão Preto, 2014.

144 p. : il. ; $30 \mathrm{~cm}$

Tese de Doutorado, apresentada à Faculdade de Odontologia de Ribeirão Preto/USP. Área de Concentração: Reabilitação Oral.

Orientador: Mattos, Maria da Glória Chiarello. 


\section{FOLHA DE APROVAÇÃO}

Marcelo Bighetti Toniollo

Tese apresentada à Faculdade de Odontologia de Ribeirão Preto, da Universidade de São Paulo, para obtenção do título de Doutor.

Área de Concentração: Reabilitação Oral

Aprovado em:

\section{Banca Examinadora:}

1) Prof.(a). Dr.(a):

Instituição:

Julgamento Assinatura:

2) Prof.(a). Dr.(a).:

Instituição:

Julgamento:

Assinatura:

3) Prof.(a). Dr.(a).:

Instituição:

Julgamento:

Assinatura: 

Dedicatórias 



\section{Dedico este trabalho...}

...a Deus e minha querida $\mathcal{M}$ ãe Rainha, meus protetores e guardiões de todos os dias, a quem recorro nos momentos de tristeza e/ou momentos de alegria. A devoção por ti tem me dado mais sabedoria e calma nos momentos de escolha por qual caminho seguir. A fé e força para continuar, sempre em frente, também vêm de vós!

...a meus pais Gilson Hélio Toniollo e Elizabeth Maria Bighetti Toniollo, e minha irmã Patrícia Bighetti Toniollo, os quais são os responsáveis por toda minha formação e conceito do que é ter uma família ideal, do que é ser amado em todos os momentos, do que é ser sempre apoiado e estimulado a continuar batalhando por aquilo que julgo correto e digno. Vocês são as pessoas pelas quais busco me tornar uma pessoa melhor e realizada, de sucesso pessoal e profissional!

...a Andrea Sayuri Silveira Dias Terada, por estar sempre ao meu lado, me acompanhando, estimulando e ajudando! Sua presença, amor e companhia ajudaram muito nesse momento de crescimento e conquista! 

Agradecimentos 



\section{Agradecimentos especiais...}

...à Profa. Dra. Maria da Glória Chiarello de Mattos, minha orientadora e amiga, que tem me acompanhado e orientado desde os primeiros anos de graduação! Devo grande parte de minha formação profissional a ti, pelos corretos conceitos de dignidade, lealdade, trabalho e sensatez! Saiba que sua forma de exercer a profissão e posicionamento pessoal e profissional me serviu de exemplo muito positivo durante todos esses anos de formação! Obrigado pela convivência sempre espontânea e sadia, na qual pude crescer sempre, e me tornar um grande amigo e admirador de sua pessoa. Só tenho a agradecer pelas oportunidades, pelo incentivo e confiança depositados. Devo toda a construção de minha pós-graduação a você, já que tem me orientado desde o mestrado, além das iniciações científicas! Sou muito agradecido pela forma como tem me acompanhado por todos esses anos, pela sua dedicação, amizade e colaboração em todos os sentidos!!!

..à responsável técnica pelo Laboratório de Metrologia, e agora doutora, Ana Paula Macedo, minha grande "tutora" e amiga durante todo o período de pós-graduação. Não é novidade que sua participação em todo o período de minha pós-graduação foi de fundamental importância. Seus ensinamentos como engenheira e domínio da metodologia utilizada me guiaram da melhor forma possível para a finalização dos trabalhos neste período todo. Já o fiz inúmeras vezes, mas não me canso em the agradecer pela sua dedicação, respeito, humildade e delicadeza durante esses anos de convívio! Fica aqui, mais uma vez, meu grande respeito, admiração e agradecimento infinito pela sua ajuda, parceria, convívio e amizade! Orgulho-me muito em ter trabalhado com você e em ser seu amigo! Nossa ilustre frase algumas vezes ao nos despedirmos ficará sempre em minha memória destes tempos: "Tudo certo, mas nada resolvido!".

...aos meus familiares, que sempre me apoiaram e foram grandes entusiastas a cada obstáculo transposto nesta caminhada. 

Agradecimentos...

...ao Prof. Dr. Valdemar Mallet da Rocha Barros, Diretor da Faculdade de Odontologia de Ribeirão Preto - USP, pela oportunidade proporcionada.

...à Profa. Dra. Cláudia Helena Lovato da Silva, Chefe do Departamento de Materiais Dentários e Prótese da Faculdade de Odontologia de Ribeirão Preto - USP, pela oportunidade proporcionada e pela convivência.

...à Profa. Dra. Fernanda de Carvalho Panzeri de Souza, Coordenadora do Curso de Pós-graduação em Reabilitação Oral da Faculdade de Odontologia de Ribeirão Preto - USP, pela oportunidade proporcionada e pela convivência.

...à Profa. Dra. Renata Cristina Silveira Rodrigues e ao Prof. Dr. Ricardo Faria Ribeiro, pelo companheirismo, amizade e valiosa ajuda com o presente trabalho. Saibam que a parceria neste grupo de trabalho foi de grande aprendizado, satisfação e crescimento. Sem vossa ajuda, colaboração, avaliação e experiência este trabalho não teria a mesma qualidade.

...ao Prof. Dr. Antônio Carlos Shimano e ao Laboratório de Bioengenharia do Departamento de Biomecânica, Medicina e Reabilitação do Aparelho Locomotor da FMRP, pelo apoio e parceria. 
...às secretárias do Departamento de Materiais Dentários e Prótese Ana Paula Xavier, Fernanda Talita de Freitas e Regiane de Cássia Tirado Damasceno, e às secretárias do serviço de pós-graduação Isabel Cristina Galino Sola e Regiane Cristina Moi Sacilotto, pela paciência, ajuda e dedicação para conosco.

...aos técnicos de laboratório Eduardo, Fernando, Godói, Henrique, Júlio, Lício, Marcelo, Paulo Sérgio, Paulinho e Serginho pela convivência e ajuda no dia-a-dia.

...a todos os amigos mestrandos e doutorandos que propiciaram um ambiente de trabalho agradável, harmônico e produtivo. Vocês ficarão para sempre em minha memória dos bons tempos da pós-graduação.

...a todos os professores que ministraram e conduziram as disciplinas da pós-graduação.

...à Capes pelo apoio financeiro por meio da bolsa por período de 24 meses durante o doutorado.

...a todos que contribuíram direta ou indiretamente para que mais essa etapa em minha vida pudesse ser cumprida, meus sinceros agradecimentos. 
Resumo 

TONIOLLO, M.B. Distribuição de tensões geradas por próteses esplintadas ou individualizadas sobre implantes com reabilitações em diferentes rebordos. Análise pelo método dos elementos finitos. Ribeirão Preto, 2014. 144p. Tese (Doutorado em Reabilitação Oral). Faculdade de Odontologia de Ribeirão Preto, Universidade de São Paulo.

\section{RESUMO}

O emprego dos implantes ósseointegráveis na odontologia moderna tem conquistado destaque nas reabilitações de forma crescente. Em casos de perda óssea vertical severa, a qual se faz bastante presente em áreas posteriores mandibulares, o uso de implantes curtos e de diâmetro reduzido se faz necessário. Para que a reabilitação mantenha o plano oclusal nivelado, utiliza-se próteses sobre implantes com proporção coroa/implante aumentada, sendo importante avaliar se há sobrecarga das estruturas de suporte, e se convém a esplintagem da infraestrutura reabilitadora. Um dos métodos utilizados atualmente para análise de distribuição de tensões na odontologia é o método dos elementos finitos. Assim, este estudo teve o objetivo geral de comparar o desempenho biomecânico de próteses, esplintadas (PSIE) ou individualizadas (PSII), sobre implantes cone Morse de comprimento regular e curto, em área posterior de mandíbula. Foram usados modelos geométricos tridimensionais de implantes regulares $-\varnothing 4 \times 11 \mathrm{~mm}$ e curtos - $\varnothing 4 \times 5 \mathrm{~mm}$ alojados em rebordos representativos do hemi-arco mandibular esquerdo posterior envolvendo o dente 34 adjacente ao espaço anodôntico, desenhados no programa SolidWorks 2007. Os 8 grupos experimentais foram: grupo controle E (3 implantes regulares reabilitados com PSIE), grupo 1E (2 implantes regulares e 1 curto reabilitados com PSIE), grupo 2E (1 implante regular e 2 curtos reabilitados com PSIE) e grupo 3E (3 implantes curtos reabilitados com PSIE); grupo controle I (3 implantes regulares reabilitados com PSII), grupo 1 ( 2 implantes regulares e 1 curto reabilitados com PSII), grupo 2 I (1 implante regular e 2 curtos reabilitados com PSII) e grupo 3I (3 implantes curtos reabilitados com PSII); As alturas dos pilares usados foram $3,5 \mathrm{~mm}$ para implantes regulares e $0,8 \mathrm{~mm}$ para implantes curtos. Foram simuladas forças oblíquas $\left(45^{\circ}\right.$ - linguo-vestibular) de $365 \mathrm{~N}$ em molares e $200 \mathrm{~N}$ em prémolares. Análises qualitativas e quantitativas da distribuição de tensões máximas e mínimas principais (ossos cortical e esponjoso) e tensão equivalente de von Mises (implantes, componentes e infraestruturas) foram feitas por meio do programa AnsysWorkbench10.0. Os resultados obtidos permitiram concluir que o uso de PSIE propiciou uma série de vantagens e benefícios com relação à distribuição de tensões nos elementos envolvidos no sistema, sendo benéfica a todos os grupos experimentais do presente estudo, notoriamente ao grupo com presença apenas de implantes curtos, diminuindo as tensões no osso circunjacente aos implantes, principalmente em sua abrangência. Também diminuiu as tensões na superfície dos implantes, na área de transmucoso dos pilares/componentes, na região interna das infraestruturas e sua abrangência ao osso circunjacente aos implantes curtos nos grupos com implantes regulares e curtos. No entanto, nesse mesmo contexto, gerou maior tensão ao osso circunjacente aos implantes regulares intermediários comparativamente aos grupos individualizados. Também favoreceu a diminuição das tensões ao osso circunjacente ao dente adjacente, 
quando na presença de proporção coroa/implante aumentada. O uso PSII apresentou-se vantajosa na diminuição das tensões na parte superior dos pilares e na área de conexão entre coroas, além do grupo controle, apenas com implantes regulares e próteses de proporção normal, sendo viável sua utilização neste contexto frente às vantagens clínicas não oferecidas pelas próteses esplintadas.

Palavras-Chave: implantes dentários, prótese dentária fixada por implante, cerâmica, análise de elementos finitos. 
Albstract 

TONIOLLO, M.B. Stress distribution generated by splinted or individualized implant prostheses with rehabilitation in different edges. A finite element analysis. Ribeirão Preto, 2014. 144p. Tese (Doutorado em Reabilitação Oral). Faculdade de Odontologia de Ribeirão Preto, Universidade de São Paulo.

\section{ABSTRACT}

The use of dental implants in modern dentistry has gained prominence in oral rehabilitations. In cases of severe vertical bone loss, which is very much present in mandibular posterior areas, the use of short implants and reduced diameter is necessary. To maintain the occlusal plane level rehabilitation it is necessary the use of prostheses with increased crown/implant ratio, and it is important assess whether there is overhead of supporting structures, and befits splinting the rehabilitating infrastructure. One of the methods currently used to analyze the stress distribution in dentistry is the finite element method. Thus, this study has the overall objective to compare the biomechanical performance of prostheses, splinted (PSIE) or individualized (PSII) over Morse taper implants of regular and short length in the posterior area of the mandible. It were used three-dimensional geometric models of regular implants - $\varnothing 4 \times 11 \mathrm{~mm}$ and short implants - $\varnothing 4 \times 5 \mathrm{~mm}$ housed in representative edges of the posterior left mandibular hemi-arch tooth involving 34 teeth, designed in SolidWorks 2007 program. The 8 experimental groups were: control group E (3 regular implants rehabilitated with PSIE ), group 1E (2 regular and 1 short implants rehabilitated with PSIE) , 2E group (1 regular implant and 2 short implants rehabilitated with PSIE) and 3E group (3 short implants rehabilitated with PSIE); control group I (3 regular implants rehabilitated with PSII), group 1 ( 2 regular and 1 short implants rehabilitated with PSII), 2 I group (1 regular implant and 2 short implants rehabilitated with PSII) and $3 \mathrm{I}$ Group (3 short implants rehabilitated with PSII); The pillars heights used for regular implants were of $3.5 \mathrm{~mm}$ and 0.8 $\mathrm{mm}$ for the short implants. Oblique forces ( $45^{\circ}$ linguo-vestibular) were simulated in molars $(365 \mathrm{~N})$ and premolars $(200 \mathrm{~N})$. Qualitative and quantitative analysis of the distribution of maximum and minimum principal stresses (cortical and cancellous bone) and von Mises equivalent stress (implants, components and infrastructure) were made through the software AnsysWorkbench10.0. The results showed that the use of PSIE provided advantages and benefits regarding the stresses distribution in the elements involved in the system, being beneficial to all experimental groups of this study notoriously in the group with only short implants, reducing stresses in the surrounding bone to implants, especially in coverage. Also decreased the stresses on the implants surface, in the transmucosal abutments area, in the inner region of the infrastructure and its reach to the surrounding bone to short implants in groups with regular and short implants. However, in that respect, generated higher stresses to the surrounding bone of intermediate implants compared to the individualized groups. Also favoring a decrease of the stresses to surrounding bone adjacent to the tooth, in the presence of increased crown/implant ratio. The use PSII 
showed to be advantageous in reducing stresses on top of the abutments and the area of connection between crowns, and in the control group, only with regular implants and prostheses of normal crown/implant ratio, so it can be used in this context facing the clinical advantages not offered by splinted prostheses.

Keywords: dental implantation, dental prosthesis implant-supported, ceramics, finite element analysis. 
Sumário

=



1. INTRODUÇÃO

1.1. Implantodontia na atualidade ......................................................... 29

1.2. Fatores associados aos implantes dentários........................................ 29

1.3. Relação do complexo implante e prótese sobre implante com suas adjacências x Implante cone Morse..................................................... $\quad 30$

1.4. Uso de implantes com comprimento reduzido..................................... $\quad 32$

1.5. Esplintagem ou individualização das próteses sobre implantes?............. 33

1.6. Implantes curtos $x$ Esplintagem ou Individualização................................ $\quad 35$

1.7. Análise pelo método dos elementos finitos............................................ 36

1.8. Biomecânica dos implantes curtos $\mathrm{x}$ cone Morse $\mathrm{x}$ próteses sobre implantes esplintadas ou individualizadas e com proporção coroa/implante aumentada............................................................ 38

2. REVISÃO DA LITERATURA................................................................. 41

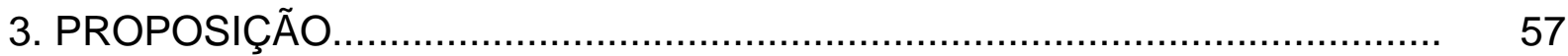

4. MATERIAIS E MÉTODOS..................................................................... 61

4.1. Geometria das estruturas................................................................. $\quad 70$

4.1.1. Implantes e componentes...................................................... $\quad 70$

4.1.2. Osso e estruturas adjacentes, dente natural e próteses sobre implantes

4.2. Desenvolvimento dos modelos de elementos finitos............................... 71

4.3. Carregamento..................................................................... 72

4.4. Simulações, obtenção das imagens e padronização das escalas............ 73

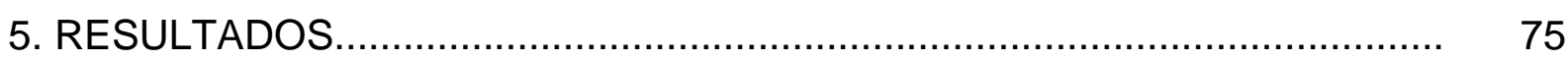

5.1. Analisando o osso cortical................................................................. 83

5.2. Analisando o osso esponjoso............................................................ 95

5.3. Analisando os implantes e componentes............................................. 105

5.4. Analisando as infraestruturas.......................................................... 109

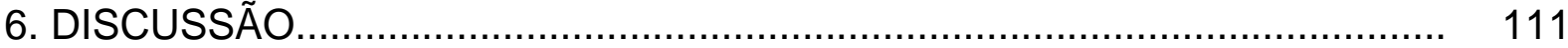

6.1. Tensões e suas interferências à interface osso/implante................................................................... 113

6.2. Esplintagem e individualização e seus efeitos no tecido ósseo................ 113 
6.3. Esplintagem e individualização e seus efeitos à infraestrutura, implantes e componentes de suporte.

6.4. Proporção coroa/implante................................................................ 123

6.5. Sugestões e possibilidades futuras................................................... 126

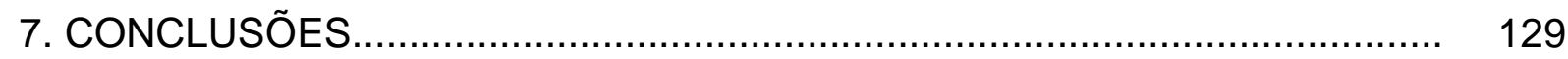

8. REFERÊNCIAS BIBLIOGRÁFICAS.......................................................... 133 
1. Introdução 



\section{INTRODUCÃ̃O}

\subsection{Implantodontia na atualidade}

O uso de implantes dentários para resolução de casos no meio odontológico tem sido cada vez mais crescente e inevitável (Toniollo et al., 2012a). Tais implantes possuem inúmeras e variadas características desde seus tipos de tratamento de superfície, comprimentos, diâmetros, tipos de plataformas e configurações internas e externas.

Tal tratamento, que pode ser aplicado às maxilas e/ou mandíbulas parcialmente ou totalmente desdentadas, tem-se mostrado bastante satisfatório, com elevados índices de sucesso e aplicabilidade extremamente viável (Carlsson e Carlson, 1994; Ekfeldt et al., 1994; Henry et al., 1996; Eckert et al., 2000; Goodacre et al., 2003).

\subsection{Fatores associados aos implantes dentários}

O uso dos implantes ósseointegráveis necessita de correta avaliação e indicação, já que são inúmeros os fatores associados ao seu adequado funcionamento. Estudos mostram conclusões básicas em que o implante considerado "ótimo" é aquele que gera integração dos fatores material, físico, químico, mecânico, biológico e econômico (Steigenga et al., 2003; Pierrisnard et al., 2003).

Além disso, fatores de suma importância como volume e densidade óssea, comprimento e área de superfície do implante e tipos de cargas oclusais presentes também devem ser considerados (Holmgren et al., 1998; Eskitascioglu et al., 2004; Lin et al., 2008), a fim de se promover adequada e efetiva ósseointegração. Não bastasse, as próteses implantossuportadas, que 
são os elementos instalados sobre os implantes, também desempenham função tão importante quanto os pinos de sustentação. $O$ material de recobrimento de tais próteses, bem como o material que compõe sua infraestrutura, a anatomia oclusal composta de maiores ou menores angulações (Kaukinen et al., 1996), suas dimensões em relação ao implante, entre outros fatores, também podem ser preponderantes no sucesso ou fracasso do trabalho reabilitador.

\subsection{Relacão do complexo implante e prótese sobre implante com}

\section{suas adjacências x Implante cone Morse}

Todo o complexo implante e prótese sobre implante receberá e transmitirá as forças tensionais, sejam elas de tração, compressão, deflexão, cisalhamento, entre outras, diretamente para a estrutura de suporte em que se situa: o osso. De acordo como essas cargas incidem na prótese sobre implante e conforme elas se dissipam ao longo do mesmo, haverá distintas distribuições das tensões no osso (Falcón-Antenucci et al., 2008). Tal distribuição varia de acordo com vários fatores, alguns inerentes ao osso, e outros inerentes ao implante.

O tecido ósseo apresenta diferentes densidades, espessuras e qualidades (Sahin et al.,2002; Okumura et al., 2010). Resultados na literatura apontam nível médio máximo de tensão para o osso cortical, julgado como prejudicial, girando em torno de $167 \mathrm{MPa}$, o que representaria o seu limiar entre o estado elástico e plástico. Isso se traduziria, clinicamente, em possível começo de reabsorção óssea e/ou processo de remodelagem (Teixeira et al. 2010). Tal valor serve como referência aos dados obtidos por ensaios ou 
estudos com tensões e deformações. O nível cervical de posicionamento do implante no osso também é de fundamental importância, já que isso terá relacionamento direto na dissipação das forças nas primeiras espiras do implante no tecido circunjacente, tanto em osso cortical como em osso esponjoso (Toniollo et al., 2012b).

Com relação ao implante, há influência de fatores como diâmetro, comprimento, desenho de superfície, entre outros (Chun et al., 2002; Pierrisnard et al., 2003; Geng et al., 2004; Verri et al., 2007; Baggi et al., 2008). Os tipos de conexão entre implante e prótese sobre implante também variam, sendo que as mais conhecidas e usadas são hexágonos externo e interno. Mais recentemente a conexão interna do tipo cone Morse vem sendo destacada diante de várias vantagens, entre elas, a de minimizar contaminação bacteriana entre implante e prótese sobre implante (Tesmer et al., 2009). Assim, esta relação entre tais elementos que envolvem a reabilitação tem seus efeitos não desejáveis minimizados, preservando de forma mais eficiente a saúde do tecido ósseo e gengival que circundam o implante (Dibart et al., 2005).

Além disso, a conexão cone Morse é citada como mais favorável para previsibilidade estética, apresentando qualidades biológicas, clínicas e biomecânicas superiores por conta da diminuição da emenda (gap) entre implante e componente protético, com menor comunicação do interior do implante com o meio externo (Thomé et al., 2011). A junção cone Morse promove selamento mais eficiente diante da penetração bacteriana, por meio de redução da dimensão do microgap (1 a $3 \mu \mathrm{m}$ ) na interface pilar/implante, contribuindo para um nível mínimo de inflamação no tecido peri-implantar 
(Dibart et al., 2005).

Com esse sistema há também menor risco de afrouxamento do parafuso protético (Schwarz, 2000; Mangano et al., 2010). Thomé et al. (2011) mostraram de forma muito interessante, por meio de simulação com elementos finitos, que após carregamento sobre o componente protético de um implante cone Morse, há o efeito de proteção às roscas do parafuso que une o pilar e o implante, sendo tal fato justificativa plausível à menor soltura e fratura destes parafusos, acarretando assim menores complicações protéticas neste tipo de conexão interna.

Bozkaya et al. (2004), analisando diferentes conexões protéticas, também puderam observar a vantagem dos implantes cone Morse com relação à dissipação de forças de forma mais favorável no osso peri-implantar em situações de cargas não axiais. Portanto estes fatores são primordiais para o alto índice de sucesso e longevidade das peças protéticas e maior previsibilidade de manutenção das condições peri-implantares.

\subsection{Uso de implantes com comprimento reduzido}

Diâmetro e comprimento dos implantes e seus efeitos no osso circunjacente também tem sido estudado, porém ainda não está totalmente claro o limite e a situação ideal de suas inter-relações.

Há pouco tempo a única alternativa viável para se reabilitar um paciente com debilidade óssea, principalmente em altura, era a realização de cirurgias avançadas de reconstrução óssea. Atualmente, os implantes de comprimento abaixo de $8 \mathrm{~mm}$ tornaram possível evitar que os pacientes passem por procedimentos cirúrgicos de alta complexidade e morbidade, tais como 
enxertos ósseos extensos, lateralização de nervo alveolar inferior e distrações osteogênicas (das Neves et al., 2006; Morand e Irinakis, 2007; Ogawa et al., 2010).

Os implantes denominados como curtos é um tanto quanto subjetivo (das Neves et al., 2006). Alguns autores definem implantes curtos como aqueles menores que $7 \mathrm{~mm}$ (Johns et al., 1992; Friberg et al., 2000). Já outros autores os definem como sendo menores que 10 mm (Tawil e Younan, 2003; Weng et al., 2003).

Apesar da dúvida sobre a previsibilidade a longo prazo dos implantes curtos, por meio do seu uso é possível obter boas taxas de sucesso. Porém de fato existem várias hesitações sobre seu emprego clínico na atividade diária (das Neves et al., 2006). Mesmo assim, avaliação de seu comportamento a longo prazo permite concluir que se faz interessante o uso desses implantes, havendo necessidade de diâmetro mínimo como $4 \mathrm{~mm}$ para bom desempenho biomecânico (já que seu comprimento é reduzido e há necessidade da compensação pelo aumento do diâmetro), além de uso por meio de protocolo específico em ossos de baixa densidade e qualidade inferior (das Neves et al., 2006).

\subsection{Esplintagem ou individualizacão das próteses sobre implantes?}

Dúvidas ainda pairam sobre os profissionais da área com relação à esplintagem ou individualização das próteses implantossuportadas, principalmente quando estas se encontram sobre implantes curtos.

É sabido que a distribuição de tensões pode variar de acordo com o planejamento da reabilitação sobre implantes. Barão et al. (2009) mostraram 
diferenças entre dentaduras totais e overdentures implanto-retidas por sistema barra-clipe ou o'ring, em que este último induziu menores tensões no sistema, contrariamente aos resultados obtidos por Tabata et al. (2010).

Estudos de acompanhamento a longo prazo com o uso de implantes curtos têm demonstrado bons resultados, mesmo com reabilitações individualizadas (Lindh et al., 1998; Fugazzotto et al., 2004), tal como Grossmann et al. (2005), que fizeram uma série de considerações a respeito, defendendo a ideologia de que há situações específicas para se unir os implantes por meio das próteses implantossuportadas para que realmente se tenha vantagens significativas, como por exemplo em situações de desdentamentos totais ou em que a oclusão não permita guias excursivos e desoclusões favoráveis. Além disso, Nissan et al. (2010) obtiveram resultados controversos na literatura, em que, por meio de metodologia com uso de strain gauges posicionados na cervical dos implantes, mostraram valores de tensão significativamente maiores para as próteses esplintadas comparativamente às próteses individualizadas.

Por outro lado, Guichet et al. (2002), por meio de estudos com fotoelasticidade, notaram melhor dissipação das tensões em próteses sobre implantes esplintadas comparadas às próteses individualizadas, já que o contato excessivo entre as coroas individualizadas pode gerar situação de adaptação não-passiva, além de se configurar como procedimento de difícil ajuste, clinicamente. Sahin et al. (2002) concluíram que o tratamento com implantes é otimizado quando estes são posicionados em osso denso, número de implantes de suporte é aumentado e quando a reabilitação é em forma de prótese fixa. Wang et al. (2002), Huang et al. (2005) e Yokoyama et al. (2005) 
por meio de análise com elementos finitos, também notaram melhores níveis de tensão com o uso de próteses esplintadas. Misch et al. (2006) também realizaram vasto estudo de acompanhamento clínico, chegando a conclusão de que a esplintagem de implantes curtos em áreas posteriores é bem indicada para a preservação da reabilitação, associando-a a um bom controle oclusal e de distribuição de forças. Menani et al. (2011) concluíram por meio de análise fotoelástica que próteses sobre implantes esplintadas e com cobertura de cerâmica promovem melhor distribuição das tensões ao redor dos implantes.

\subsection{Implantes curtos $x$ Esplintagem ou Individualização}

Há na literatura certa controvérsia com relação à opção em se esplintar ou não as reabilitações sobre implantes a fim de se diminuir as tensões geradas. O conceito de que esplintagem das próteses implantossuportadas diminua as tensões ainda é incerto e pouco fundamentado em evidências bem conceituadas, e deve ser revisto, sendo que a relevância clínica dos variados achados na literatura ainda apontam para a necessidade de maiores estudos (Nissan et al., 2010). Dúvidas existem com relação à necessidade de se esplintar as próteses implantossuportadas quando do uso de implantes de comprimento curto, e até mesmo sobre implantes de comprimento regular.

Das Neves et al. (2006) e Thomé et al. (2011) relataram que, com o uso dos implantes curtos do tipo cone Morse, principalmente em áreas sujeitas à grandes cargas, a esplintagem pode ser recomendada visando o aumento da possibilidade de sucesso do caso a longo prazo. Thomé et al. (2011) mostraram alguns casos reabilitados, entre eles um caso de acompanhamento por 2 anos de total sucesso, com implantes cone Morse de comprimento 
médio, e próteses individualizadas. Apesar disso, os autores sugerem mais estudos a serem realizados para melhor compreensão de casos clínicos como esse, pois implantes esplintados e parafusados tem mais tempo de acompanhamento clinico descrito na literatura. A indicação deste tipo de procedimento deve ser planejada previamente do ponto de vista cirúrgico e reabilitador de forma com que não existam espaços para erros.

Alguns estudos têm explorado a variação do comprimento e diâmetro dos implantes, porém levando-se em conta situação ideal no tamanho da coroa e nivelamento ósseo (Huang et al., 2005; Bergkvist et al.,2008; Nissan et al., 2010; Menani et al., 2011). Esses dois elementos são de fundamental importância no resultado final e prognóstico da reabilitação. Deve-se levar em conta que, seguido das perdas dentárias sempre há perda de tecido ósseo, tanto em altura como em espessura, e, inevitavelmente, isso leva a necessidade de reabilitações com próteses sobre implantes de dimensões maiores, com coroas mais amplas no sentido gengivo-oclusal. Além disso, também como consequência da perda óssea, há necessidade em se optar por implantes mais curtos e de menor diâmetro, diminuindo ainda mais a área de suporte e podendo levar a sobrecarga de todo o sistema.

\subsection{Análise pelo método dos elementos finitos}

Para a avaliação deste tipo de interação entre tecido ósseo e superfície do implante, tem-se usado a análise dos elementos finitos, que tem a capacidade de quantificar o grau de tensão que ocorre aos elementos envolvidos na dissipação da carga exercida sobre a prótese sobre implante.

A análise dos elementos finitos foi criada no início de 1960 para 
solucionar problemas estruturais na indústria aeroespacial, porém tem sido usado na resolução de casos em outras inúmeras áreas, inclusive a odontológica. Em 1977, Weinstein foi o primeiro a usar a análise dos elementos finitos em implantes odontológicos. Daí em diante modificações e melhorias foram realizadas e outros inúmeros autores passaram a usar tal artifício em seus estudos (Akça e Cehreli, 2006; Geng et al., 2008; Barão et al., 2009; Tabata et al., 2010; Toniollo et al., 2012a).

Tal metodologia é uma técnica de interação numérica computadorizada para determinar deslocamento, fadiga e tensões, por meio de modelo prédesenhado com dimensões praticamente idênticas à realidade, podendo-se assim reproduzir padrões de alta fidelidade. Então, exporta-se o modelo para programa específico que, para ser processado, é necessário a descrição das características de todas as estruturas e elementos envolvidos no contexto da reabilitação, como por exemplo o módulos de elasticidade e coeficiente de Poisson de cada estrutura (Cunha et al., 2008). Assim, tornam-se possíveis simulações das mais variadas situações, podendo-se prever e visualizar 0 desempenho biomecânico de todos os elementos envolvidos no processo, principalmente em situações críticas e limítrofes, como é o caso do presente estudo, envolvendo implantes curtos, reduzido diâmetro e reabilitados com próteses implantossuportadas esplintadas e individualizadas.

Presume-se que, entendendo-se a teoria básica, método, aplicação e limitações das análises dos elementos finitos em implantes dentários, o clínico torna-se mais bem preparado para interpretar os resultados dos estudos e extrapolá-los às situações clínicas (Geng et al., 2001).

A análise dos elementos finitos tem se mostrado como efetiva 
ferramenta computacional que se adapta do campo da engenharia à biomecânica dos implantes dentários. Com sua ajuda, muitos designs e novos projetos têm sido desenvolvidos e poderão ser aplicados a potenciais sistemas de implantes no futuro, trazendo constantes inovações e mudanças. Por meio de seu uso é possível observar e interpretar as forças tensionais geradas nos implantes e osso de suporte trazendo à realidade clínica situações mais seguras de uso e aplicabilidade, visando menor incidência de problemas como falhas dos pilares, parafusos e propriamente nos implantes. Mudanças das características dos implantes e do tipo de reabilitação tende a evitar ou reduzir tais falhas promovendo a distribuição de tensões mais efetiva.

\subsection{Biomecânica dos implantes curtos $x$ cone Morse $x$ próteses} sobre implantes esplintadas ou individualizadas e com proporcão coroa/implante aumentada

O tamanho das coroas das próteses sobre implantes deve influenciar diretamente nas forças de alavanca e torcionais, principalmente sobre pilares de implantes curtos. Tipos de conexão de implantes do tipo hexágono externo e hexágono interno já foram bastante estudadas, no entanto o tipo de conexão interna cone Morse, de desenvolvimento mais recente, é a mais promissora com relação a todas as suas vantagens e vem ganhando maior destaque na literatura mundial. Além disso, este estudo visa implementar outra situação que não se encontra na literatura: coroas implantossuportadas sendo submetidas a cargas de incidência não só axiais, mas também oblíquas, e, o mais importante, de dimensões aumentadas a fim de se manter o plano oclusal homogêneo frente ao desnível ósseo, usando-se modelos não-simplificados. 
O principal intuito é observar como tais próteses implantossuportadas de proporção coroa/implante aumentada se comportam sobre implantes extremamente curtos, os quais recebem a tarefa de dissipar toda a incidência da carga oclusal no osso circunjacente, e analisar as possíveis diferenças entre tal dissipação das tensões em comparação aos implantes regulares em infraestruturas esplintadas ou individualizadas. 



\section{Revisão da Literatura}





\section{REVISÃO DA LITERATURA}

Isidor, em 1996, avaliou, em macacos, a perda de osso periimplantar devido à carga oclusal excessiva ou acúmulo de placa. Foram usados 5 tipos de implantes na mandíbula de 4 macacos, sendo posicionados 2 implantes em cada um dos segmentos laterais e 1 implante na área frontal. Cada macaco recebeu 2 dispositivos cimentados abrangendo pré-molares e molares no lado direito e esquerdo da maxila, respectivamente. 6 meses pós-inserção uma prótese parcial fixa foi feita sobre 2 implantes em um dos segmentos laterais. A prótese esteve em contato supra-oclusal com o dispositivo antagonista. Parte dos implantes eram higienizados, e parte não. 5 dos 8 implantes com contato oclusal excessivo perdeu a ósseointegração (4.5 a 15.5 meses após a instalação da prótese em supra-oclusão). Nenhum dos implantes com placa acumulada foi perdido, embora uma média de $1.8 \mathrm{~mm}$ de osso foi perdido depois de 18 meses.

Lindh et al. (1998) realizaram meta-análise de implantes envolvidos em edentulismo parcial, suportando próteses fixas e coroas individualizadas. Foram analisados 66 estudos, publicados entre 1986 e 1996, envolvendo 570 próteses sobre implantes unitárias e 2116 próteses fixas sobre implantes. A taxa de sucesso encontrada foi de $97.5 \%$ para as primeiras, e $93.6 \%$ para as segundas, em período de 1 a 8 anos.

Yang et al. (1999) analisaram, por meio dos elementos finitos, o efeito da esplintagem em próteses parciais fixas sobre os níveis de tensão em dentes e estruturas de suporte. Os autores observaram uma redução das tensões e deflexão nas estruturas de suporte quando uma prótese parcial fixa foi fabricada e dentes foram esplintados juntamente. O aumento do número de 
elementos esplintados não revelou uma diminuição proporcional no nível de tensão periodontal. Concentração de tensão foi observada nos conectores das próteses e na dentina cervical próximo aos conectores. Os autores concluíram que o aumento da esplintagem não compensa os problemas mecânicos da prótese suficientemente.

Guichet et al. (2002) avaliaram o efeito da esplintagem e da intensidade do contato interproximal na transferência de cargas em próteses sobre implante. Os autores padronizaram diferentes espaços entre as coroas implantossuportadas e avaliaram as tensões por meio de modelos fotoelásticos. Também foram feitos modelos com próteses esplintadas. Os resultados mostraram que o contato excessivo entre as coroas aumentaram as tensões nos implantes. Além disso, as próteses esplintadas dissiparam de melhor forma as tensões nos implantes. Os autores concluíram que o contato excessivo entre as coroas individualizadas pode gerar situação de adaptação não-passiva. Além disso, próteses sobre implantes esplintadas exibiram melhor dissipação das tensões comparadas às próteses individualizadas.

Naert et al. (2002a) objetivaram prever o resultado de tratamentos com restaurações sobre implantes em edentulismo parcial, levando em conta a interdependência dos implantes e o efeito de diversas variáveis de confusão. Foram avaliados 1212 implantes em maxila e 744 em mandíbula, em 660 pacientes. A taxa de sucesso foi de $91.4 \%$ para todos os implantes, e $95.8 \%$ para as restaurações num período de 16 anos. Fatores como comprimento curto do implante, elevado número de implantes por paciente, baixo número de implantes por próteses e implantes combinados com enxerto ósseo, apresentam um risco maior de falha. A idéia de não esplintar os implantes é 
promissora, mas necessita de maiores estudos antes de aceitá-la totalmente.

Naert et al., ainda em 2002b, avaliaram a perda óssea marginal ao redor de implantes instalados em espaços edêntulos parciais. Os implantes avaliados foram divididos em 3 grupos: 235 unitários, 398 associados a dentes e 1022 suportando prótese fixa. Os implantes foram posicionados tanto em maxila como em mandíbula, em área anterior e posterior. Não foi encontrada diferença significante na perda de nível ósseo entre os grupos, tanto anterior como posterior.

Sahin et al. (2002) avaliaram por meio de uma revisão de literatura a influência de forças funcionais no sistema biomecânico de próteses implantossuportadas. Artigos relatando controle de forças oclusais em implantes dentários, influência da qualidade do osso, tipo de próteses e materiais e número de implantes de suporte foram analisados. Os autores concluíram que o tratamento é otimizado quando os implantes são posicionados em osso denso, número de implantes de suporte é aumentado e quando é usada uma prótese fixa.

Wang et al. (2002) analisaram o efeito de materiais de recobrimento das próteses sobre implantes, além de sua esplintagem ou não, sobre as tensões no osso peri-implantar, por meio de análise tridimensional de elementos finitos. Os materiais de recobrimento foram resina, liga de ouro ou porcelana. Os autores obtiveram que a esplintagem das coroas reduziu as tensões, além da resina induzir maiores tensões.

Fugazzotto et al. (2004), realizaram análise sobre as taxas de sucesso e falha encontradas no tratamento reabilitador em área maxilar de molares, com implantes de $9 \mathrm{~mm}$ de comprimento ou menores, e reabilitados com coroas 
individuais. Foi avaliado um total de 970 implantes acompanhados em função por um período de 84 meses. A taxa total média de sucesso foi de $95.1 \%$. Os autores concluíram que implantes de $7 \mathrm{~mm}$ e $9 \mathrm{~mm}$ de comprimento podem ser reabilitados com coroas individuais, com sucesso, na área referida.

Grossmann et al. (2005) fizeram uma série de considerações a respeito, defendendo a ideologia de que há situações específicas para se unir os implantes por meio das próteses implantossuportadas para que realmente se tenha vantagens significativas, como por exemplo em situações de desdentamentos totais ou em que a oclusão não permita guias excursivos e desoclusões favoráveis.

Huang et al. (2005) avaliaram, por meio da análise tridimensional de elementos finitos, a distribuição de tensões em próteses esplintadas ou não com diferentes tipos de implantes (plataforma padrão, plataforma ampla ou 2 implantes na porção posterior). Os autores obtiveram melhores resultados, para a porção posterior, usando-se implante de plataforma ampla e 2 implantes, diminuindo a tensão tanto para reabilitação esplintada como para não esplintada. Com o uso de implantes de plataforma padrão, os resultados foram idênticos tanto para próteses esplintadas como para não esplintadas. Já no uso de implantes com plataforma ampla e 2 implantes posteriores, o uso de reabilitação esplintada diminuiu as tensões encontradas em $25 \%$.

Rokni et al., em 2005, avaliaram a proporção coroa-raiz com o uso de implantes curtos reabilitados em áreas parcialmente desdentadas. Foram analisados 199 implantes em 74 pacientes, sendo classificados de acordo com o comprimento (curto - 5 ou $7 \mathrm{~mm}$ - e longo - 9 ou $12 \mathrm{~mm}$ ) e área de superfície (pequena e grande). Outro dado coletado foi a proporção coroa-raiz, tendo em 
media 1.5 , tendo $78.9 \%$ dos implantes uma proporção entre 1.1 e 2 . Os resultados mostraram que nem a proporção coroa-raiz, nem a área de superfície dos implantes afetaram a estabilidade do nível da crista óssea. No entanto, o comprimento do implante e a situação de esplintagem ou não dos mesmos pareceu influenciar no nível da crista óssea. Implantes longos tiveram menor controle da crista óssea ( $0.2 \mathrm{~mm}$ a mais de perda) do que os implantes curtos. Implantes esplintados também mostraram menor controle da crista óssea ( $0.2 \mathrm{~mm}$ a mais de perda) do que implantes não esplintados. Os autores concluíram que os implantes longos e/ou esplintados podem resultar em maior perda da crista óssea.

Yokoyama et al. (2005) analisaram a tensão gerada em osso de mandíbula desdentada suportando estrutura sobre implantes única ou em partes. Os autores utilizaram análise tridimensional por elementos finitos com 8 implantes e 1 ou mais estruturas. Forças verticais e oblíquas foram direcionadas nas áreas oclusais das estruturas a fim de simular os contatos em máxima intercuspidação e contatos de trabalho, assim como guia-canino e desoclusão em grupo. Os resultados mostraram que a estrutura única gerou menores valores de tensão no osso peri-implantar, seguida da estrutura em duas partes separada na região mediana. Para a estrutura em três partes, que foi separada entre canino e pré-molar, a tensão foi menor quando o canino no lado de trabalho foi carregado do que os dentes posteriores. Os autores concluíram que dividir a estrutura em mais partes causa mais tensão ao redor dos implantes. Além disso, a desoclusão em guia-canino para estruturas únicas e em 3 partes foi benéfica.

Isidor (2006) realizou uma ampla revisão da literatura enfocando a 
influência de forças no osso peri-implantar. $O$ autor, de acordo com seus estudos, afirmou que o osso reage de diferentes formas frente às cargas oclusais, sendo que isso também é dependente das características dos diferentes tipos de ossos e suas propriedades. O autor cita que estudos com fotoelasticidade e análise tridimensional pelo método dos elementos finitos mostraram que quando um implante é submetido à carga oclusal, a tensão é transferida no osso com a máxima tensão na porção mais coronal do osso suporte. Além disso, o estudo mostrou que, também se usando análise por elementos finitos, cargas não-axiais em implantes são mais danosas aos implantes orais do que as cargas axiais, resultando em maiores níveis de tensão no osso peri-implantar. Isidor citou também que as cargas oclusais têm sido estudadas, porém apresentam grande variância, podendo ir de $380 \mathrm{~N}$ até $1000 \mathrm{~N}$.

Misch et al. (2006) avaliaram a taxa de sobrevida/sucesso de implantes menores de $10 \mathrm{~mm}$ de comprimento posicionados na região posterior parcialmente desdentada, considerando o uso de uma abordagem com preocupação biomecânica a fim de se minimizar a tensão na interface osso/implante. Os autores realizaram avaliação retrospectiva de 273 pacientes com 745 implantes de $7 \mathrm{~mm}$ ou $9 \mathrm{~mm}$ de comprimento, em uso por período de 1 a 5 anos. A preocupação biomecânica envolveu a esplintagem das próteses sobre implantes sem forças em cantilever, restaurando com proteção mútua ou guia de desoclusão por canino. Os autores encontraram uma taxa de sucesso de $98.9 \%$, concluindo que implantes de curto comprimento são viáveis a serem empregados nestas áreas e os métodos citados a fim de se diminuir tensões é bastante apropriada. 
Blanes et al. (2007) avaliaram a influência da proporção coroa-implante e diferentes tipos de tratamentos com próteses sobre implante no comportamento da crista óssea ao redor de implantes em região posterior. Um total de 192 implantes ITI foram posicionados em área de pré-molares e molares de 83 pacientes parcialmente desdentados. Todos os implantes foram restaurados com próteses metalocerâmicas, fixas ou unitárias. Foram feitas análises radiográficas padronizadas pela técnica de paralelimetria. Foram criados 3 grupos com relação à proporção: (a) 0-0.99, (b) 1-1.99 e (c) _2. Um total de 51 implantes (26.5\%) mostraram uma proporção clínica igual a ou maior que 2. Neste grupo, 3 implantes falharam, resultando num total de $94.1 \%$ de sucesso. A perda de crista óssea foi de 0.34-0.27 mm para (a), 0.03$0.15 \mathrm{~mm}$ para (b) e 0.02-0.26 mm para (c). Os autores concluíram que as restaurações sobre implantes com proporções coroa-implante entre 2 e 3 são satisfatórias para áreas posteriores de mandíbula

Weber e Sukotjo (2007) realizaram revisão sistemática a fim de determinar as evidências científicas existentes sobre a influência dos desenhos das próteses sobre os resultados a longo prazo da terapia com implantes em pacientes parcialmente desdentados. Foram feitas uma série de perguntas envolvendo variados aspectos. Quanto ao tipo cimentada ou parafusada não houve diferença estatisticamente significante na taxa de sucesso dos tratamentos. Quanto ao tipo de prótese, também não houve diferença estatisticamente significante entre próteses fixas, unitárias ou estruturas envolvendo implante e dente natural. Os autores concluíram que as evidências obtidas nesta revisão foram insuficientes para estabelecer qualquer tipo de afirmação. 
Bergkvist et al. (2008) estudaram, por meio de análise dos elementos finitos, a distribuição de tensão no osso circunjacente a implantes com próteses esplintadas ou não esplintadas. Os resultados mostraram tensões notadamente menores no osso circunjacente aos implantes esplintados do que nos implantes individualizados. Os autores concluíram que, do ponto de vista biomecânico, e por meio da análise de elementos finitos, a esplintagem reduz os eventuais danos no tecido ósseo, indo de encontro às observações clínicas.

Barão et al. (2009) realizaram análise pelo método dos elementos finitos comparando a distribuição de tensões em dentaduras totais e overdentures implanto-retidas com diferentes sistemas de attachment. Foram construídos 4 modelos de mandíbula edêntula: grupo A (controle - dentadura total), grupo B (overdenture retida por 2 implantes esplintados com sistema barra-clipe), grupo C (overdenture retida por 2 implantes não esplintados com sistema o'ring) e grupo D (overdenture retida por dois implantes esplintados com sistema barraclipe e dois o'rings distais). A simulação foi realizada pelo programa Ansys, com carregamento vertical de $100 \mathrm{~N}$ aplicado no incisivo central. A menor tensão máxima principal ( $\mathrm{MPa}$ ) foi encontrada no grupo $\mathrm{A}$, seguida pelos grupos C, D e B. A mesma tendência ocorreu para a distribuição de tensão no osso cortical. Implantes não esplintados associados com sistema de attachment o'ring mostraram a menor tensão máxima principal entre os grupos estudados. Além disso, o sistema de attachment o'ring também melhorou a distribuição de tensão quando associado com o sistema de attachment barraclipe.

Jofre et al. (2010) analisaram o efeito da esplintagem de mini-implantes na perda de osso marginal em overdentures mandibulares, por meio de modelo 
biomecânico e estudo clínico randomizado. Por meio de análise de elementos finitos com modelos matemáticos os autores compararam as tensões ao redor de dois mini-implantes, tanto esplintados por barra como individualizados. $\mathrm{Na}$ parte clínica do experimento, os autores realizaram o posicionamento de 90 mini-implantes na parte anterior de mandíbulas em 45 pacientes, os quais foram randomizados e distribuídos em 2 grupos, com implantes individualizados tipo bola e esplintados por barra. Avaliou-se a perda óssea por meio de análise radiográfica e comparou-se por 5, 10, 15 e 24 meses após implantação. A análise pelos elementos finitos mostrou maior tensão mínima principal em osso ao redor de mini-implantes individualizados. $\mathrm{Na}$ análise clínica, houve maior perda óssea marginal para os implantes individualizados tipo bola, após 2 anos de acompanhamento. Os autores concluíram que os mini-implantes esplintados diminuíram os níveis de tensão no osso circunjacente, justificando também assim a sua menor perda de osso marginal. Lan et al. (2010) analisaram, por meio de estudo tridimensional de elementos finitos, as tensões em osso com variadas inclinações de implantes e coroas esplintadas em região posterior de mandíbula. Oito implantes foram divididos em três tipos de inclinações: implantes paralelos, implantes com ápices convergentes e implantes com ápices divergentes. Os resultados mostraram que o principal fator a afetar as tensões no osso foi o tipo de oclusão/carga em comparação com a inclinação dos implantes. As tensões foram especialmente maiores associando-se inclinação distal dos implantes com as cargas. Os autores concluíram também que o posicionamento dos implantes com inclinação distal deve ser evitado em áreas mandibulares posteriores. 
Nissan et al. (2010) constataram que na literatura há uma grande controvérsia com relação à opção em se esplintar ou não as próteses implantossuportadas a fim de se diminuir as tensões geradas. Seguindo este contexto, os autores analisaram a transferência de forças e distribuição de tensões em próteses sobre implantes do tipo cimentadas esplintadas ou não. Os resultados, por meio dos strain gauges posicionados na cervical dos implantes, mostraram valores de tensão significativamente maiores para as próteses esplintadas comparativamente às próteses não esplintadas. Já posicionando os strain gauges nas margens das próteses, houve mais tensão para as próteses não esplintadas. Os autores concluíram que o conceito de que esplintagem das próteses implantossuportadas diminua as tensões deve ser revisto, e que a relevância clínica destes achados necessita de maiores estudos.

Tabata et al., em 2010, estudaram por meio de análise pelo método dos elementos finitos comparação entre implantes unidos e individuais na distribuição de tensão em osso mandibular suportando overdenture. Foram construídos dois modelos usando o programa Ansys para duas situações: sistema barra-clipe usando dois implantes conectados; sistema o'ring suportado por dois implantes separados. Ambas as situações simulou mandíbula desdentada suportando overdenture, com carga de $100 \mathrm{~N}$. Os resultados mostraram menor tensão máxima principal para o sistema barraclipe do que para o sistema o'ring. Os autores concluíram que o sistema barraclipe foi mais favorável na distribuição de tensões nos tecidos de suporte periimplantares.

Urdaneta et al. (2010) analisaram o efeito da proporção coroa-implante 
aumentada em implantes unitários. A proposta conhecida na literatura sempre foi a de que coroas com grandes alturas poderiam levar a maiores tensões na crista óssea e consequente perda óssea e outras possíveis complicações. Assim, tais autores avaliaram o efeito da proporção coroa-implante aumentada em reabilitações sobre implantes unitárias. Foi realizado estudo retrospectivo por aproximadamente 2 anos, com pacientes que possuíam ao menos um implante Bicon reabilitado com prótese cimentada. Foram avaliados ao todo 326 implantes Bicon, com uma duração média de avaliação de 70.7 meses. A média da proporção coroa-implante foi 1.6 (variando entre 0.79 a 4.95). 16\% das próteses tinham proporção maior ou igual a 2. As reabilitações com proporção até 4.95 não levaram a um risco maior de perda de crista óssea ou aumento nas taxas de falhas. Os autores concluíram que a proporção coroaimplante aumentada teve associação com complicações protéticas, porém não houve efeito significante na perda dos níveis de crista óssea de próteses sobre implantes unitárias no presente estudo.

Menani et al. (2011) pesquisaram o comportamento biomecânico de próteses sobre implantes cimentadas cerâmica e plástica, esplintadas e não esplintadas, em implantes cone Morse, por meio de análise fotoelástica. Os autores observaram que a cimentação causou tensões entre os implantes. Além disso, as próteses esplintadas distribuíram as tensões de forma mais uniforme no momento da força aplicada. Próteses com cobertura de cerâmica apresentaram melhores resultados dos que com cobertura de resina. Os autores concluíram que próteses sobre implantes esplintadas e cerâmicas promovem melhor distribuição das tensões ao redor dos implantes.

Thomé et al. (2011) analisaram o comportamento mecânico da junção 
interna em implantes dentários do tipo cone Morse. Resultados de testes experimentais não destrutivos, acompanhamentos de casos clínicos, assim como revisão crítica da literatura, permitiram discutir a importância do efeito de embricamento mecânico na interface cônica implante/pilar típica dos implantes cone Morse, e sua principal consequência como efeito protetor às roscas do parafuso. Discussões foram direcionadas para o comportamento biomecânico deste sistema e seu reflexo no sucesso de casos clínicos acompanhados longitudinalmente, gerando boa previsibilidade a longo prazo no uso de tais implantes. Tais autores ainda relataram que com o uso dos implantes curtos do tipo cone Morse, principalmente em áreas sujeitas a grandes cargas, a esplintagem pode ser recomendada visando o aumento da possibilidade de sucesso do caso a longo prazo. Thomé et al. (2011) mostraram alguns casos reabilitados, entre eles um caso de acompanhamento por 2 anos de total sucesso, com implantes cone Morse de comprimento médio, e próteses individualizadas. Apesar disso, os autores sugerem mais estudos a serem realizados para melhor compreensão de casos clínicos como esse, pois implantes esplintados e parafusados tem mais tempo de acompanhamento clinico descrito pela literatura. A indicação deste tipo de procedimento deve ser planejada previamente do ponto de vista cirúrgico e reabilitador de forma com que não existam espaços para erros.

Lops et al. (2012) analisaram implantes curtos em regiões parcialmente desdentadas de maxila e mandíbula por meio de estudo retrospectivo de 10 a 20 anos. Os autores observaram que o uso dos implantes curtos de $8 \mathrm{~mm}$ de comprimento suportando próteses fixas apresentaram taxas de sucesso aceitáveis e sem diferença estatisticamente significante para os implantes de 
comprimento regular, tanto para regiões posteriores como anteriores.

Bal et al. (2013) estudaram, por meio de análise de elementos finitos, a distribuição de tensões geradas por próteses maxilares anteriores esplintadas e não esplintadas suportadas por implantes de zircônia e titânio. A análise permitiu afirmar que as tensões no grupo de próteses esplintadas foram menores do que as não esplintadas, sendo que as tensões se concentraram ao redor cervical dos implantes. Os autores relataram que tais tensões foram levemente maiores para as próteses não esplintadas no osso cortical, tanto para implantes de zircônia como de titânio.

Kim et al. (2014) estudaram, por meio de análise tridimensional de elementos finitos, implantes curtos em área posterior de maxila, em rebordos residuais de diferentes alturas $(13 \mathrm{~mm}, 7 \mathrm{~mm}, 6 \mathrm{~mm}, 5 \mathrm{~mm}$ e $4 \mathrm{~mm})$. Foram usados implantes de $4,5 \times 11 \mathrm{~mm}$ e $6 \times 5,7 \mathrm{~mm}$. As cargas oclusais foram de $187 \mathrm{~N}$ em angulação de 30 graus. Os resultados analisados em tensões de von Mises mostraram que os grupos envolvendo implantes curtos e maior quantidade óssea gerou menores tensões.

Queiroz et al., em 2014, realizaram estudo clínico a fim de avaliar a taxa de sobrevivência de implantes curtos posicionados em região posterior de mandíbula, por meio de frequência de ressonância. O objetivo principal foi comparar a estabilidade mecânica dos implantes curtos com os implantes de comprimento regular na área referida. Total de 23 pacientes receberam 48 implantes curtos $(5 \times 5,5 \mathrm{~mm}$ e $5 \times 7 \mathrm{~mm})$ e 42 implantes regulares $(4 \times 10 \mathrm{~mm}$ e 4x11,5 mm) em região posterior mandibular. Realizou-se análise com frequência de ressonância em T0 (logo após colocação dos implantes), T1 (depois de 15 dias), T2 (depois de 30 dias), T3 (depois de 60 dias) e T4 (depois 
de 90 dias). Os resultados mostraram que no T4 houve $100 \%$ de sucesso aos implantes regulares e $87.5 \%$ de sucesso aos implantes curtos, sem diferença significativa entre os tempos T1, T2, T3 e T4. Total de 6 implantes curtos foram perdidos. Os autores concluíram que a sobrevivência dos implantes curtos foi menor que dos implantes regulares, mas se configuram como opção viável a serem utilizados em áreas de severa reabsorção óssea. Destacaram também a importância em alertar os pacientes com relação a isso, e evitar desapontamentos. 
3. Proposição 



\section{PROPOSICÃO}

Este estudo teve o objetivo geral de comparar, qualitativa $e$ quantitativamente, o desempenho biomecânico, por meio da análise dos elementos finitos, de próteses metalocerâmicas, parafusadas, esplintadas e individualizadas, sobre implantes cone Morse de comprimento regular e curto, em área posterior de mandíbula.

Os objetivos específicos foram:

- Comparar as tensões geradas nos diferentes rebordos reabilitados com implantes cone Morse de comprimento regular e curto, tanto nos implantes, componentes e infraestrutura de suporte, como no osso circunjacente, tendo como variação o uso de próteses sobre implantes esplintadas ou individualizadas.

- Avaliar a influência da proporção coroa/implante sobre a distribuição de tensões nas estruturas circunjacentes, estando elas esplintadas ou individualizadas e associadas aos implantes regulares e/ou curtos. 



\section{Materiais e Métodos}





\section{MATERIAIS E MÉTODOS}

Foram usados implantes do tipo cone Morse com diâmetro de $4 \mathrm{~mm}$, variando-se seus comprimentos. Assim sendo, os implantes usados, da marca Neodent, tiveram as seguintes configurações: regular, $\varnothing 4,0 \times 11,0 \mathrm{~mm}$ (Titamax CM Cortical) e curto, $\varnothing$ 4,0 x 5,0 mm (Titamax WS Cortical), todos de superfície porosa e cilíndricos.

Os pilares/componentes usados foram de $3,5 \mathrm{~mm}$ de altura para os implantes de 11,0 mm de comprimento (os implantes foram posicionados $2 \mathrm{~mm}$ infra-ósseo como recomendado pelo fabricante) e de 0,8 $\mathrm{mm}$ de altura para os implantes de 5,0 mm de comprimento (os implantes foram posicionados ao nível ósseo como recomendado pelo fabricante).

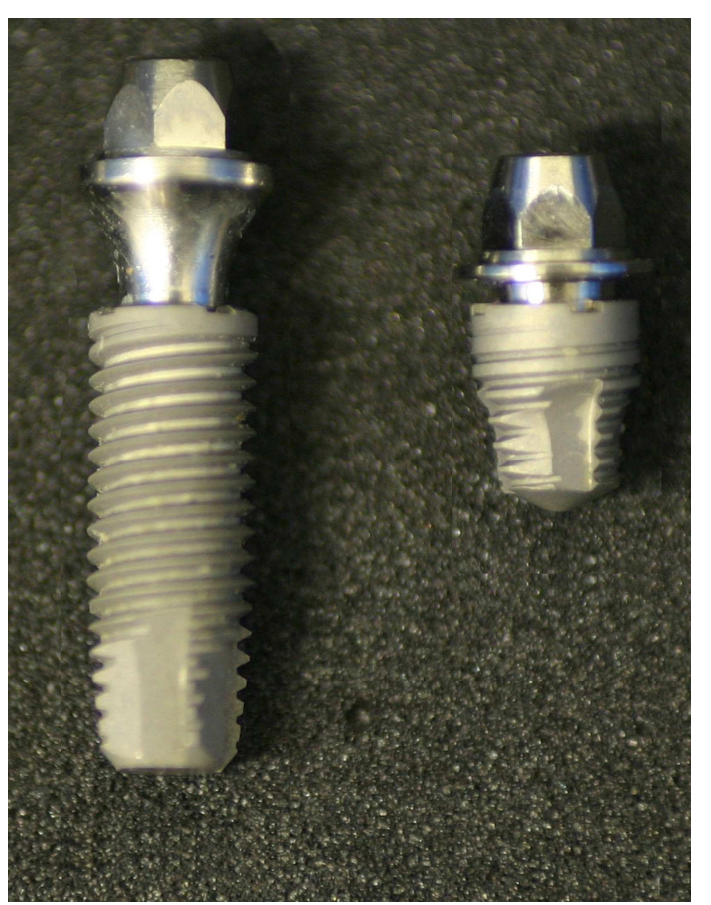

Figura 1: implantes regular e curto com seus respectivos pilares

Também foram usados cilindros calcináveis GT (Neodent - Curitiba Brasil), anti-rotacionais para as próteses individualizadas e rotacionais para as próteses esplintadas. 
Foi realizada a aferição de todas as medidas dos implantes e seus componentes por meio do Projetor de Perfil Modelo 6C (Nikon, Kanagawa, Japão) e da Lupa Estereoscópica Modelo S8AP0 (Leica, Microsystems, Hurbrugg, Suíça) assistida pelo Programa Leica Application Suite V3.6. A reprodução gráfica dos modelos de todos os elementos necessários, assim como bloco ósseo em que foram inseridos, foi realizada por meio do programa SolidWorks 2007 (Corporation, Massachusetts,EUA). Em todos os modelos foi posicionado o dente 34 , gerando ponto de contato com a prótese adjacente, e suas respectivas estruturas (ligamento periodontal, esmalte, dentina e polpa). Os modelos desenhados foram exportados para 0 programa AnsysWorkbench 10.0 (Swanson, Analysis Systems, Inc., Houston, USA), no qual foram atribuídas as características específicas de cada estrutura (Tabela 1), cargas aplicadas, geração da malha e então realizaram-se as simulações pelo método dos elementos finitos. Todos os materiais foram considerados isotrópicos, homogêneos e linearmente elásticos. 
Tabela 1: Valores das propriedades mecânicas referentes a cada estrutura e respectivas referências

\begin{tabular}{|c|c|c|c|}
\hline Estrutura & $\begin{array}{c}\text { Módulo de } \\
\text { Elasticidade/Young } \\
\text { (MPa) }\end{array}$ & $\begin{array}{c}\text { Coeficiente } \\
\text { de Poisson } \\
(v) \\
\end{array}$ & Referências \\
\hline Polpa & 2,07 & 0,45 & Rubin et al., 1983 \\
\hline Dentina & 18600,00 & 0,31 & Ko et al., 1992 \\
\hline Esmalte & 41000,00 & 0,30 & $\begin{array}{l}\text { Rubin et al., 1983; } \\
\text { Ko et al., } 1992\end{array}$ \\
\hline $\begin{array}{l}\text { Ligamento } \\
\text { periodontal }\end{array}$ & 68,90 & 0,45 & $\begin{array}{l}\text { Ko et al., 1992; } \\
\text { Reinhardt et al., } \\
\text { 1983; }\end{array}$ \\
\hline Osso trabecular & 1370,00 & 0,30 & $\begin{array}{l}\text { Ko et al., 1992; } \\
\text { Sertgoz, } 1997\end{array}$ \\
\hline Osso cortical & 13700,00 & 0,30 & $\begin{array}{l}\text { Ko et al., 1992; } \\
\text { Papavasiliou et al., } \\
\text { 1996; Assif et al., } \\
1996\end{array}$ \\
\hline Mucosa & 19,60 & 0,30 & $\begin{array}{l}\text { Ko et al., 1992; } \\
\text { Reinhardt et al., } 1983\end{array}$ \\
\hline Implante (Ti) & 110000,00 & 0,35 & $\begin{array}{l}\text { Çiftçi e Canay, 2000; } \\
\text { Pierrisnard et al., } \\
\text { 2003; Monteith, } \\
\text { 1993; }\end{array}$ \\
\hline $\begin{array}{c}\text { Estrutura de } \\
\text { CoCr }\end{array}$ & 218000,00 & 0,33 & $\begin{array}{l}\text { Anusavice, 2003; } \\
\text { Craig, } 1997\end{array}$ \\
\hline Resina & 7000,00 & 0,20 & Craig, 1997 \\
\hline $\begin{array}{l}\text { Porcelana } \\
\text { feldspática }\end{array}$ & 82800,00 & 0,35 & Sertgoz, 1997 \\
\hline
\end{tabular}


Foram construídos 8 grupos experimentais:

- $\quad$ Grupo controle E: rebordo residual sem desnível ósseo, com 3 implantes de $11 \mathrm{~mm}$ de comprimento nas regiões do 35,36 e 37, reabilitados com próteses sobre implantes esplintadas (Figura 2).
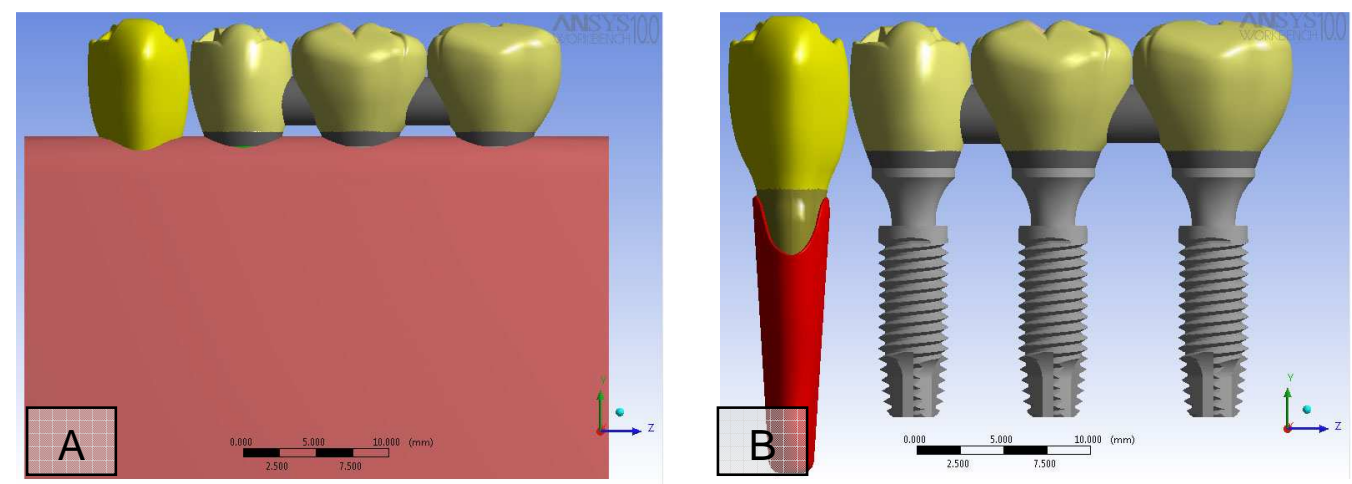

Figura 2: grupo controle E, A - com mucosa e ossos cortical e esponjoso, $B$ - sem mucosa e ossos cortical e esponjoso

- $\quad$ Grupo 1E: desnível ósseo na região de ausência do dente 37, com 1 implante de $11 \mathrm{~mm}$ na região do 35, 1 implante de $11 \mathrm{~mm}$ na região do 36 e 1 implante de $5 \mathrm{~mm}$ na região do 37 , reabilitados com próteses sobre implantes esplintadas (Figura 3).
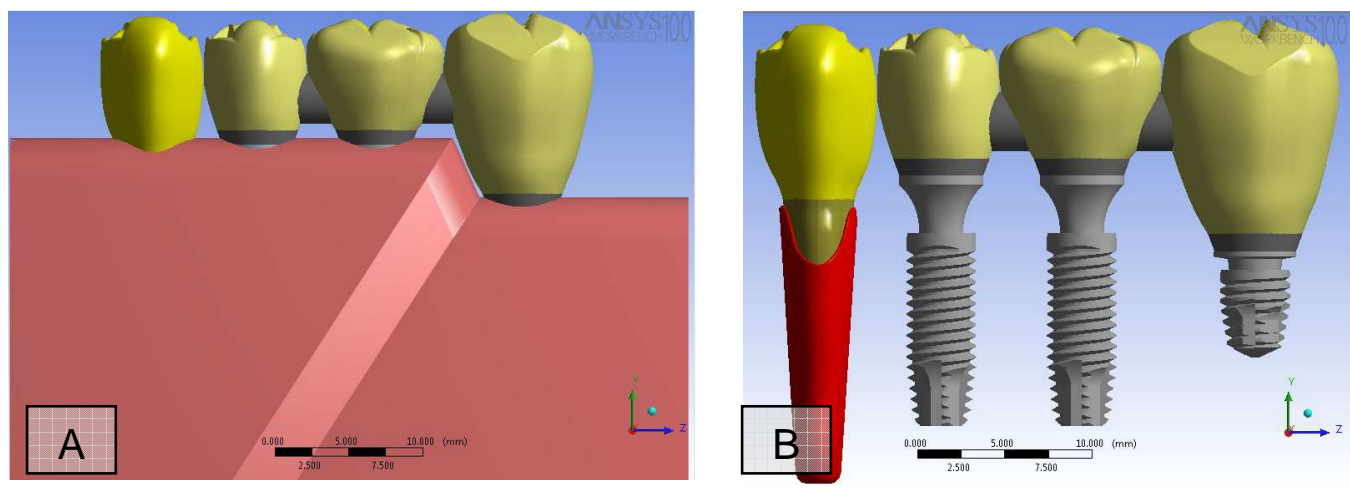

Figura 3: grupo 1E, A - com mucosa e ossos cortical e esponjoso, B sem mucosa e ossos cortical e esponjoso 
- $\quad$ Grupo 2E: desnível ósseo na região de ausência dos dentes 36 e 37, com 1 implante de $11 \mathrm{~mm}$ na região do 35 e 2 implantes de $5 \mathrm{~mm}$ na região do 36 e 37, reabilitados com próteses sobre implantes esplintadas (Figura 4).
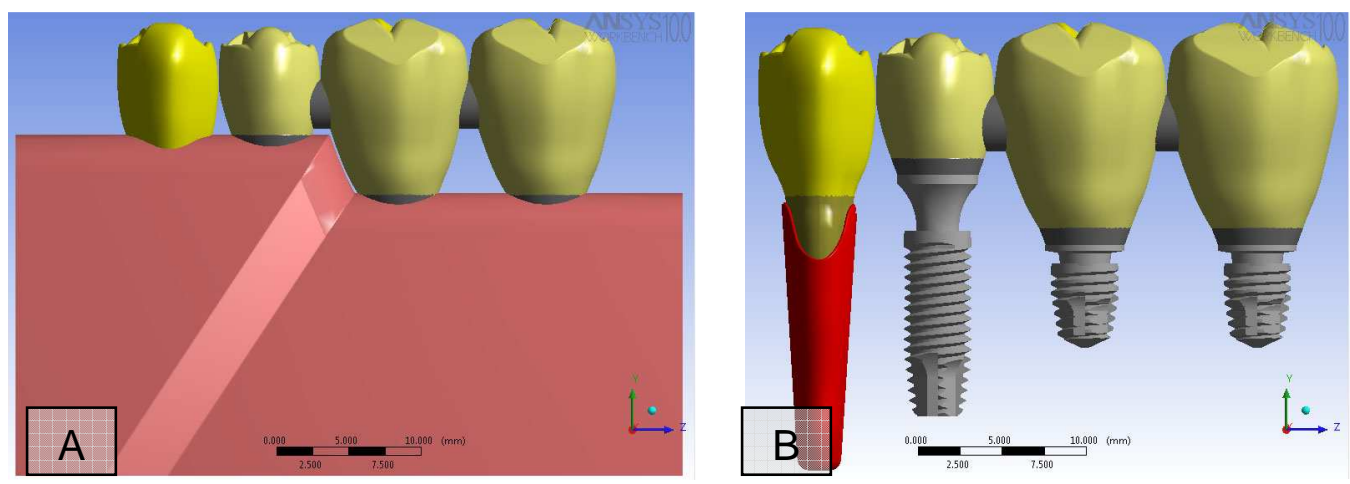

Figura 4: grupo 2E, A - com mucosa e ossos cortical e esponjoso, B sem mucosa e ossos cortical e esponjoso

- $\quad$ Grupo 3E: desnível ósseo na região dos dentes 35, 36 e 37, com 3 implantes de $5 \mathrm{~mm}$ nas regiões do 35,36 e 37 , reabilitados com próteses sobre implantes esplintadas (Figura 5).
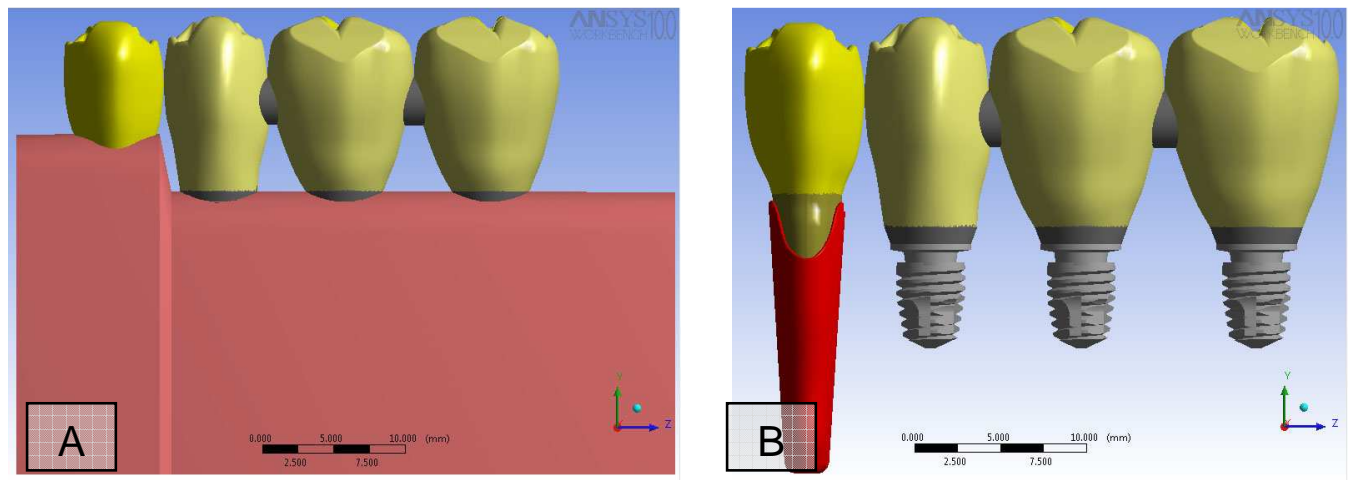

Figura 5: grupo 3E, A - com mucosa e ossos cortical e esponjoso, B sem mucosa e ossos cortical e esponjoso 
- $\quad$ Grupo controle I: rebordo residual sem desnível ósseo, com 3 implantes de $11 \mathrm{~mm}$ de comprimento nas regiões do 35,36 e 37, reabilitados com próteses sobre implantes individualizadas (Figura 6).
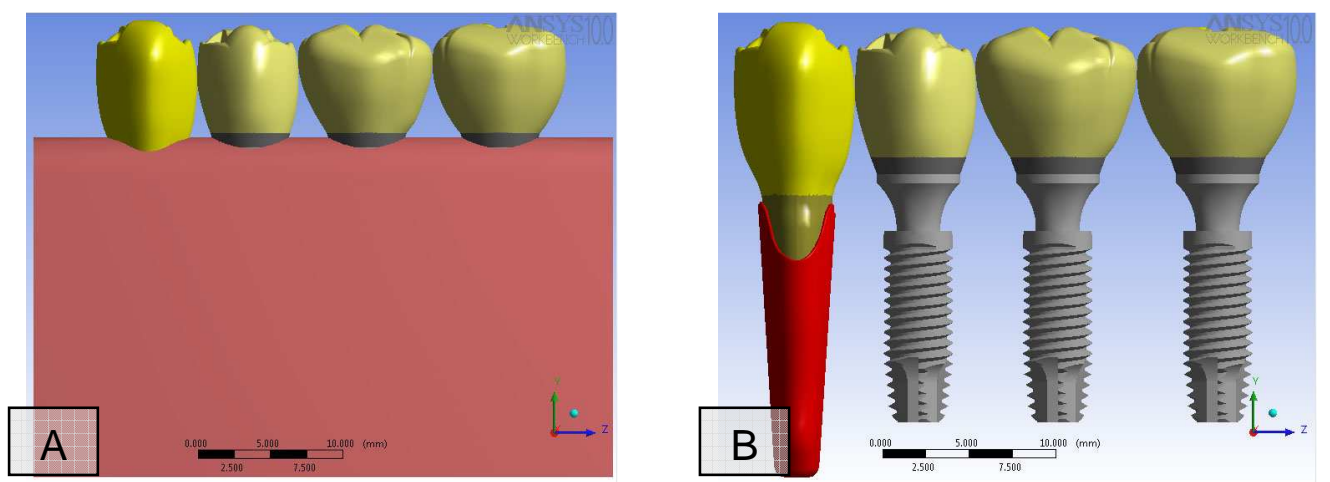

Figura 6: grupo controle I, A - com mucosa e ossos cortical e esponjoso, B - sem mucosa e ossos cortical e esponjoso

- Grupo 11: desnível ósseo na região de ausência do dente 37, com 1 implante de $11 \mathrm{~mm}$ na região do 35,1 implante de $11 \mathrm{~mm}$ na região do 36 e 1 implante de $5 \mathrm{~mm}$ na região do 37, reabilitados com próteses sobre implantes individualizadas (Figura 7).
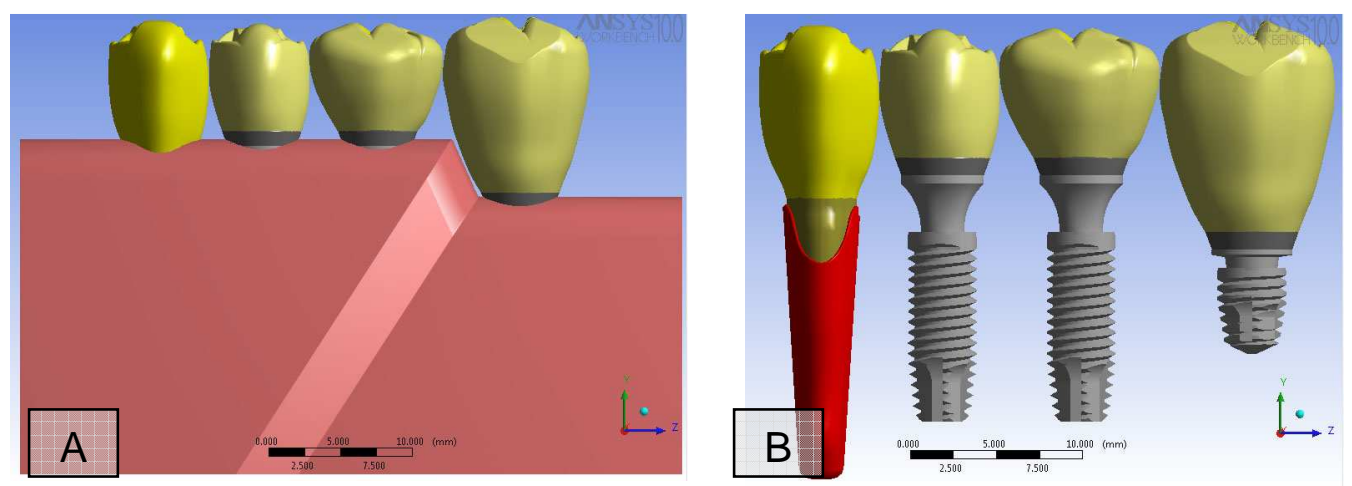

Figura 7: grupo 11, A - com mucosa e ossos cortical e esponjoso, B sem mucosa e ossos cortical e esponjoso 
- $\quad$ Grupo 21: desnível ósseo na região de ausência dos dentes 36 e 37, com 1 implante de $11 \mathrm{~mm}$ na região do 35 e 2 implantes de $5 \mathrm{~mm}$ na região do 36 e 37 , reabilitados com próteses sobre implantes individualizadas (Figura 8).
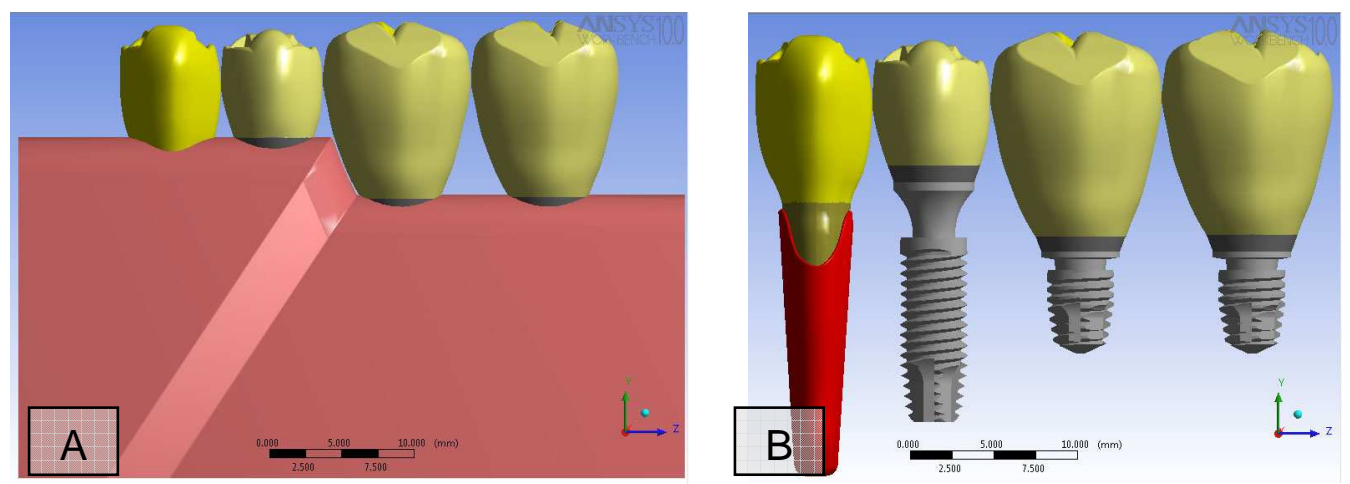

Figura 8: grupo 2I, A - com mucosa e ossos cortical e esponjoso, B sem mucosa e ossos cortical e esponjoso

- $\quad$ Grupo 3I: desnível ósseo na região dos dentes 35, 36 e 37, com 3 implantes de $5 \mathrm{~mm}$ nas regiões do 35,36 e 37 , reabilitados com próteses sobre implantes individualizadas (Figura 9).
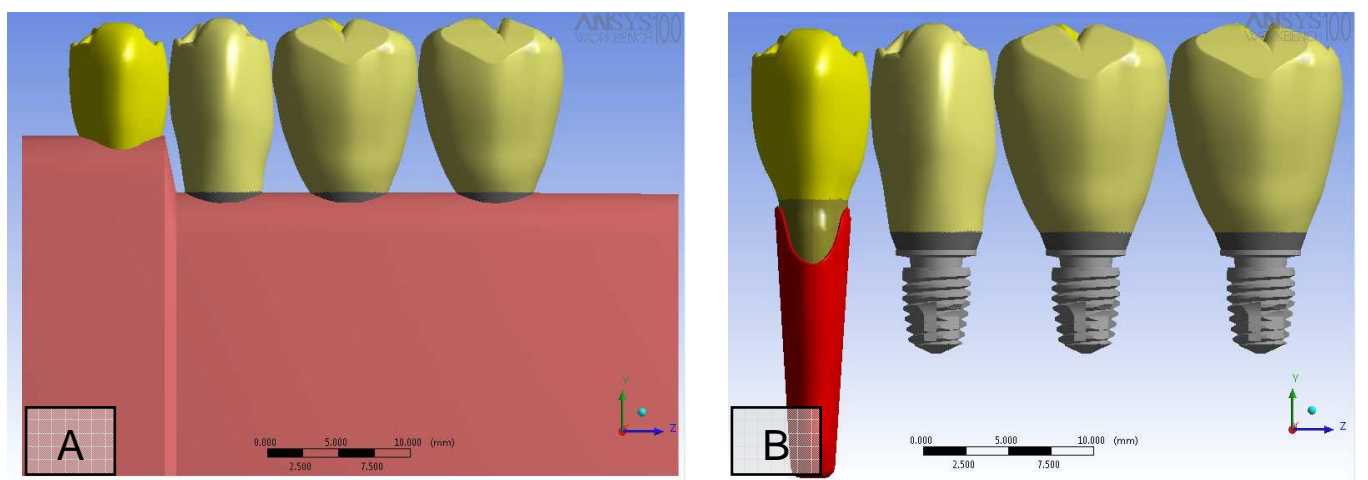

Figura 9: grupo 3l, A - com mucosa e ossos cortical e esponjoso, B sem mucosa e ossos cortical e esponjoso 


\subsection{Geometria das estruturas}

\subsubsection{Implantes e componentes}

Os implantes foram posicionados sobre a mesa de dupla coordenada do Projetor de Perfil Modelo 6C e foram aferidas todas as medidas necessárias. $\mathrm{Na}$ Lupa Estereoscópica Modelo S8AP0 por meio do Programa Leica Application Suite V3.6 obteve-se também medidas complementares às do Projetor de Perfil . Usou-se dois exemplares de cada comprimento de implante para aferição das medidas e a média de tais valores foi obtida, empregando-a na confecção dos modelos virtuais tridimensionais no programa SolidWorks 2007 (Corporation, Massachusetts, USA.).

\subsubsection{Osso e estruturas adjacentes, dente natural e próteses sobre}

\section{implantes}

Foi representado o hemi-arco mandibular esquerdo posterior envolvendo o dente 34 adjacente ao espaço anodôntico. As dimensões de todos os elementos e estruturas relativas ao estudo, como medidas médias mésiodistais e gengivo-oclusais das coroas das próteses sobre implantes e dos dentes, osso cortical, ligamento periodontal e fibromucosa foram baseadas em estudos específicos e relatos na literatura (Wang et al., 2002; Yokoyama et al.,2005; Jofre et al., 2010).

As medidas gengivo-oclusais das próteses sobre implante variaram em cada modelo de acordo com o posicionamento de tais coroas no bloco ósseo e em relação ao desnível ósseo, o qual foi fixado em $4 \mathrm{~mm}$ no sentido gengivooclusal (vertical), para manterem-se assim no alinhamento oclusal.

O volume das próteses sobre implantes (de dimensão natural ou 
aumentada) não variou de forma muito significativa, mas sim sua proporção vertical coroa-implante (Tabela 2). Nos grupos esplintados foi adotada a união entre as próteses de forma circular para que fosse possível a padronização de tal elemento em todos os grupos de forma homogênea e tornar sua reprodução de forma fidedigna em todos os modelos. Além disso, tal união teve de ser feita em secção circular para que não interferisse com tecido mole circunjacente. $O$ diâmetro da secção circular foi de aproximadamente $3,4 \mathrm{~mm}$, baseado no padrão de cera utilizado para tal pelos protéticos na rotina diária de laboratório.

Tabela 2: Grupos experimentais, respectivos implantes e proporções coroa/implante (C/I)

\begin{tabular}{ccccc}
\hline & \multicolumn{4}{c}{ Segmento posterior esquerdo mandibular } \\
\hline \multirow{2}{*}{$\begin{array}{c}\text { Grupos } \\
\text { experimentais }\end{array}$} & $\mathbf{3 4}$ & $\mathbf{3 5}$ & $\mathbf{3 6}$ & $\mathbf{3 7}$ \\
\cline { 2 - 5 } $\begin{array}{c}\text { Grupos } \\
\text { Controle E e I }\end{array}$ & $4 \times 11$ & Implante $\mathbf{( m m )}$ & \\
\hline Grupos 1E e 1I & $(\mathrm{C} / \mathrm{l}: 1)$ & $(\mathrm{C} / \mathrm{l}: 1)$ & $4 \times 11$ \\
& $4 \times 11$ & $4 \times 11$ & $(\mathrm{C} / \mathrm{l}: 1)$ \\
\hline Grupos 2E e 2I & $(\mathrm{C} / \mathrm{l}: 1)$ & $(\mathrm{C} / \mathrm{l}: 1)$ & $(\mathrm{C} / \mathrm{l}: 2,8)$ \\
& $4 \times 11$ & $4 \times 5$ & $4 \times 5$ \\
& $(\mathrm{C} / \mathrm{l}: 1)$ & $(\mathrm{C} / \mathrm{l}: 2,8)$ & $(\mathrm{C} / \mathrm{l}: 2,8)$ \\
\hline Grupos 3E e 3I & $4 \times 5$ & $4 \times 5$ & $4 \times 5$ \\
& $(\mathrm{C} / \mathrm{l}: 2,8)$ & $(\mathrm{C} / \mathrm{l}: 2,8)$ & $(\mathrm{C} / \mathrm{l}: 2,8)$ \\
\hline \hline
\end{tabular}

\subsection{Desenvolvimento dos modelos de elementos finitos}

Os modelos criados no programa SolidWorks 2007 (Corporation, Massachusetts, USA) foram exportados para o programa AnsysWorkbench10.0 a fim de serem atribuídas as propriedades mecânicas inerentes a cada estrutura (módulo de elasticidade e coeficiente de Poisson), definir as condições de contorno (pontos de fixação do modelo) e realizar o carregamento oclusal e a geração da malha de elementos finitos (Figura 10). 

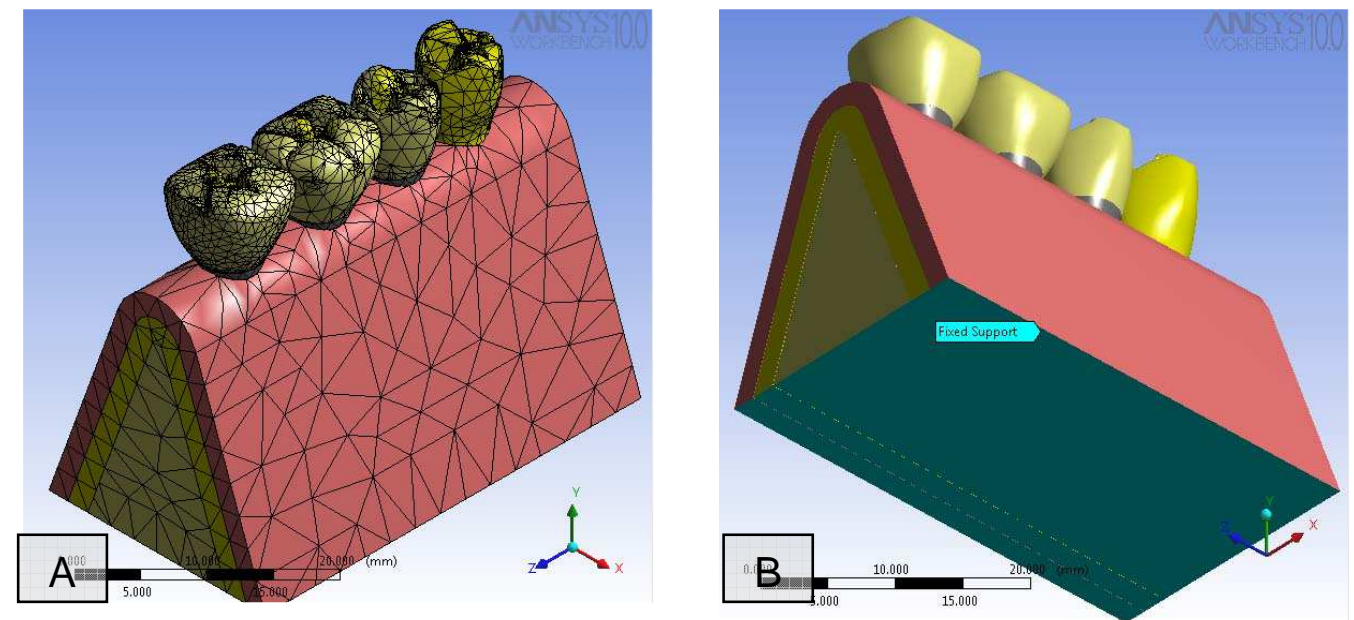

Figura 10: grupo controle I, A - com malha de elementos finitos gerada, $B$ - condições de contorno

\subsection{Carregamento}

O carregamento de forças foi realizado nas pontas de cúspides e fundos de sulcos de todos os elementos, em todos os modelos, com componentes verticais e horizontais, resultando em forças oblíquas no sentido línguovestibular (em torno de $45^{\circ}$ de inclinação) com intensidade de $365 \mathrm{~N}$ para os molares e $200 \mathrm{~N}$ para os pré-molares (Shillingburg et al., 1997; Cosme et al., 2005; Isidor, 2006; Toniollo et al., 2012a), o que seriam cargas fisiológicas consideradas de intensidade média (Figura 11). 


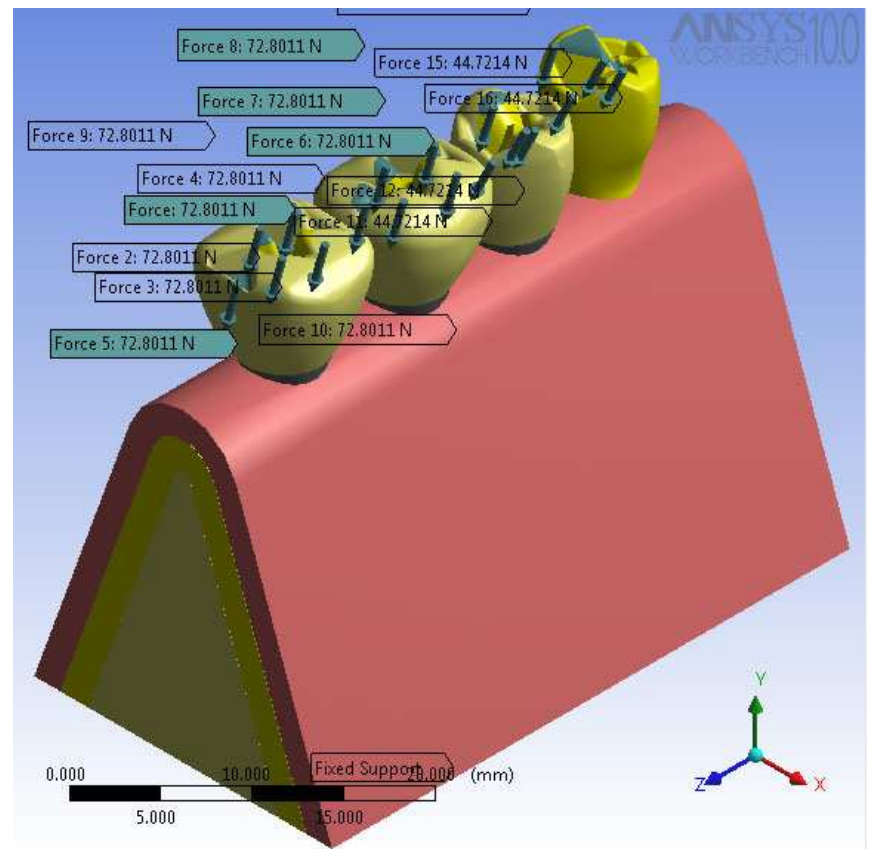

Figura 11: carregamento de forças oblíquas

\subsection{Simulações, obtencão das imagens e padronização das escalas}

Depois de gerada a malha de elementos finitos, realizados os carregamentos e atribuições de todas as características específicas dos materiais e estruturas presentes no estudo, além das restrições quanto ao movimento, foram geradas as simulações no programa AnsysWorkbench10.0 (Swanson, Analysis Systems, Inc., Houston, USA).

Os resultados analisados nos diferentes grupos foram: Tensão Equivalente de Von Mises (TEVM) para as estruturas de comportamento dúctil (implantes, componentes e infraestruturas); Tensão Mínima Principal (TMiP) e Tensão Máxima Principal (TMaP) para as estruturas de comportamento nãodúctil (ossos cortical e esponjoso).

Estudos e relatos na literatura, especialmente na área de engenharia de materiais, indica a melhor aplicabilidade do critério de von Mises aos materiais de comportamento dúctil, tal como os metais. Já para os materiais de comportamento friável, os melhores resultados e análises se configuram por 
meio das tensões principais máximas e mínimas (von Mises, 1913; Akça e Cehreli, 2006; Fereguetti e Martins, 2008).

Por convenção, a tensão máxima principal (TMaP) é positiva e representa a máxima tração na região de análise. A tensão mínima principal (TMiP) é negativa e representa a máxima compressão na região de análise, sendo que a determinação desses valores normais de pico num sistema de implante dentário e nos tecidos pode fornecer dados valiosos com relação aos sítios de potencial fratura do implante e atrofia do osso (Misch, 2007)

A partir daí, imagens com escalas padronizadas foram obtidas, a fim de tornar possíveis as comparações qualitativa e quantitativamente entre os modelos experimentais.

Foram realizados conjuntos de imagens confrontando os grupos correspondentes, tanto individualizados como esplintados. Observou-se externa e internamente aos ossos cortical e esponjoso, tanto para as TMaP como para as TMiP (foram ocultados os implantes e componentes para melhor visualização dos resultados nos ossos). Já para os implantes e respectivos componentes foram analisadas as tensões (TEVM) na face vestibular de cada grupo experimental. Para as infraestruturas foram analisadas as tensões na superfície interna, também do lado vestibular (Quadros 1 a 24). 


\section{Resultados}





\section{RESULTADOS}

Os resultados estão apresentados em forma de montagens comparativas das imagens, juntamente das respectivas legendas padronizadas, do Quadro 1 ao Quadro 24, sendo possível a comparação qualitativa entre os grupos experimentais. Para cada grupo, individualizado e esplintado, também foram identificados os valores médios das tensões observadas, a fim de possibilitar as comparações quantitativas. 

Quadro 1: TMaP Osso Cortical - Grupo controle

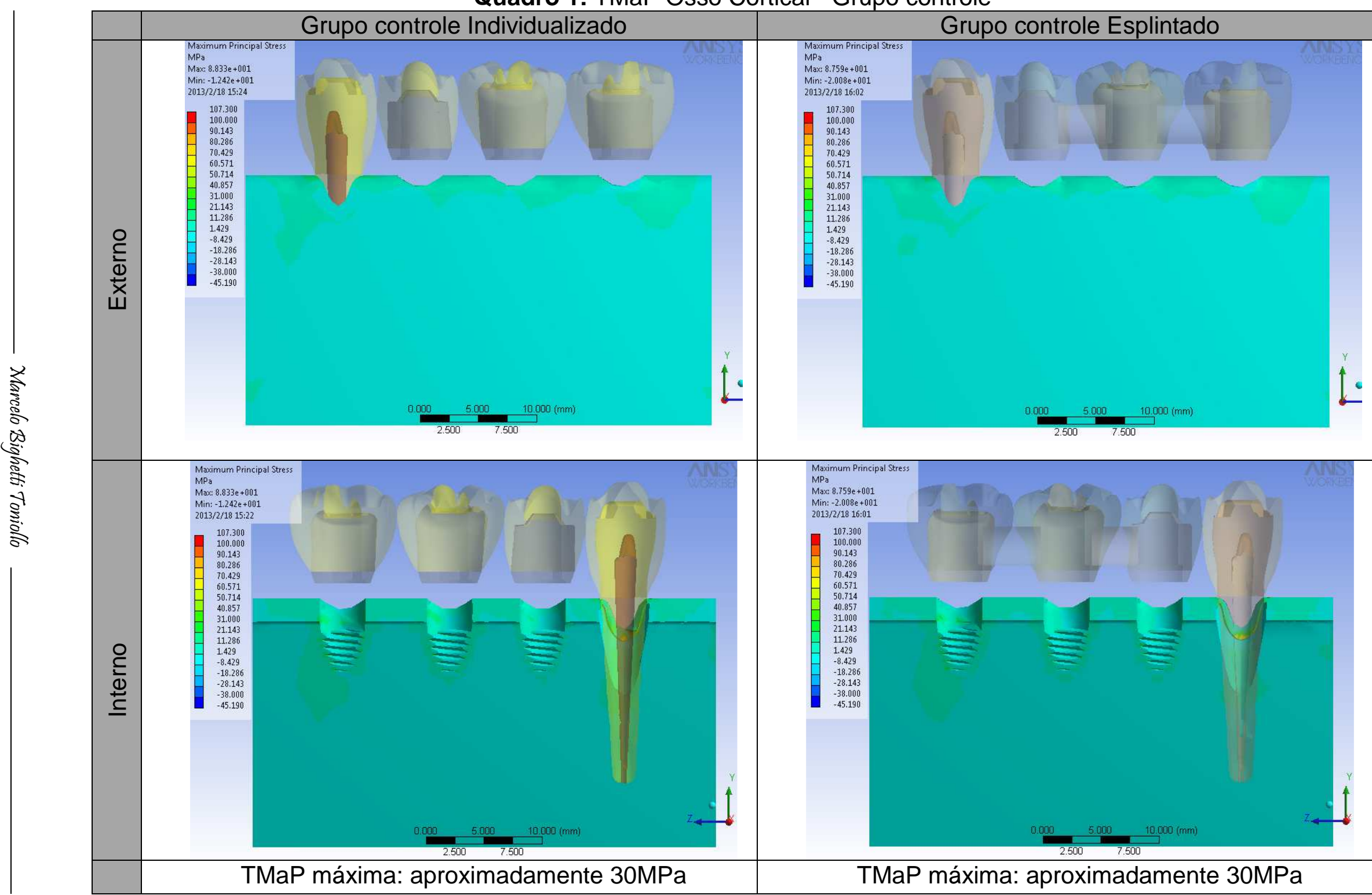


Quadro 2: TMaP Osso Cortical - Grupo 1

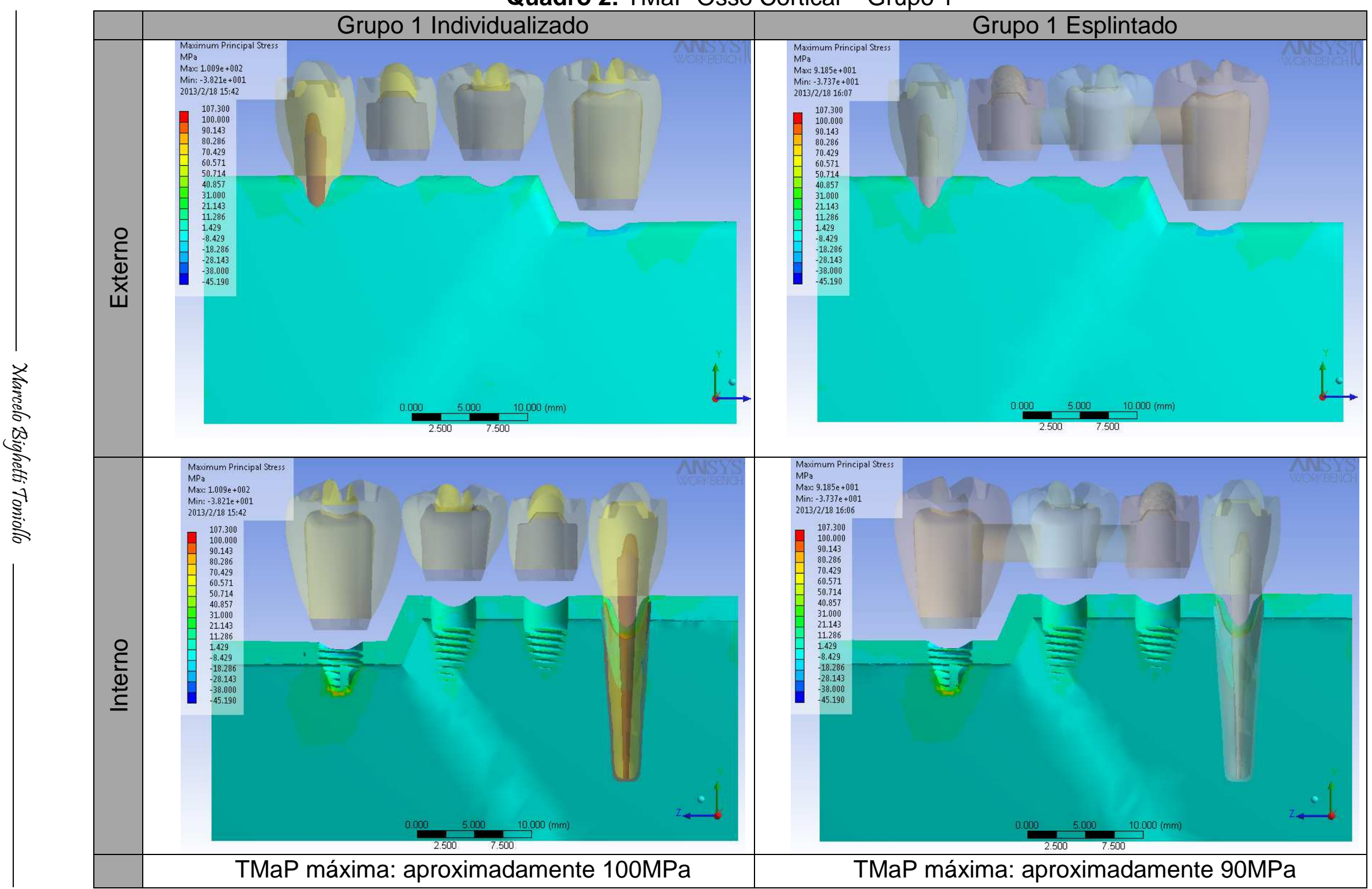


Quadro 3: TMaP Osso Cortical - Grupo 2

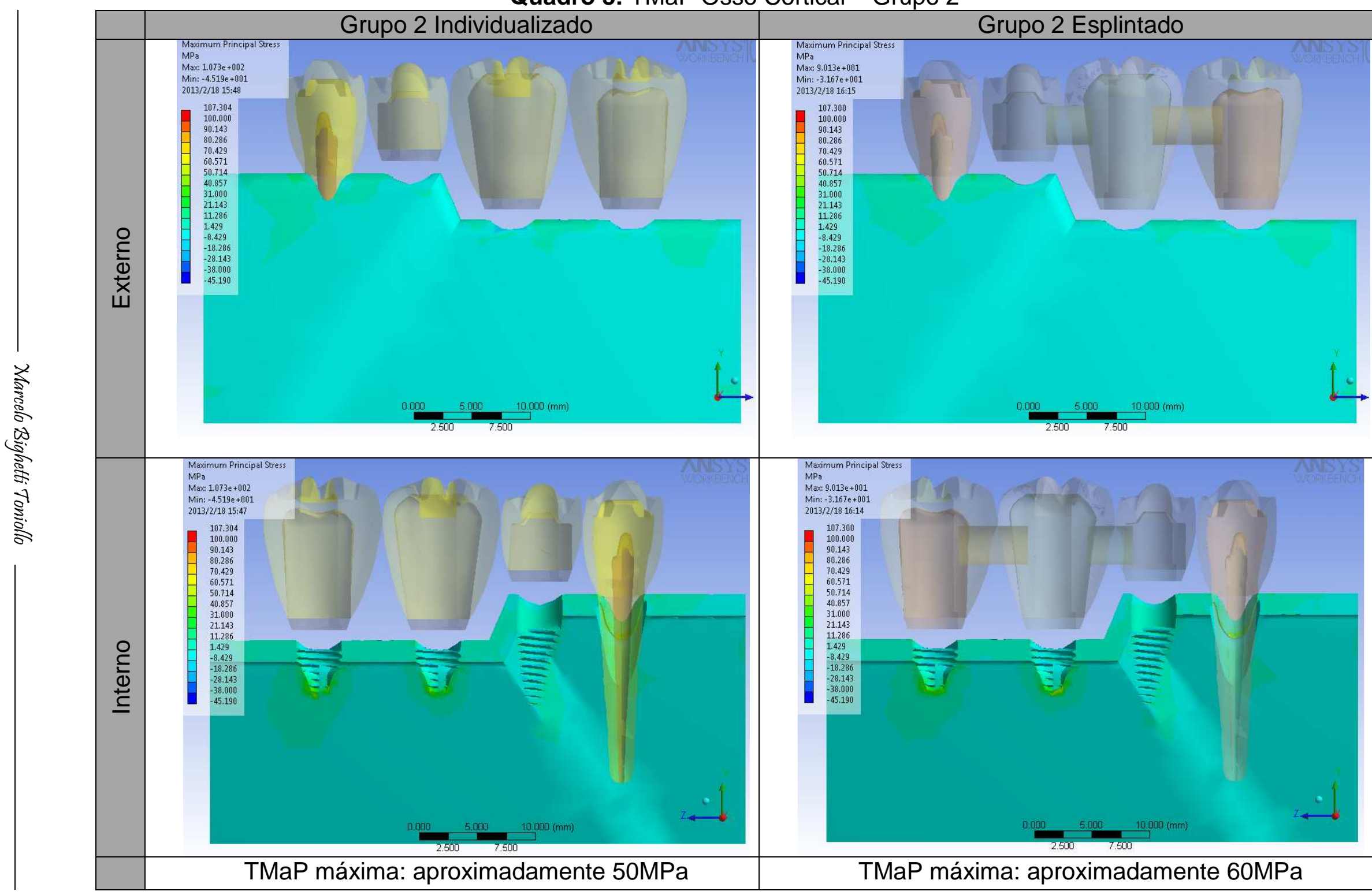


Quadro 4: TMaP Osso Cortical - Grupo 3

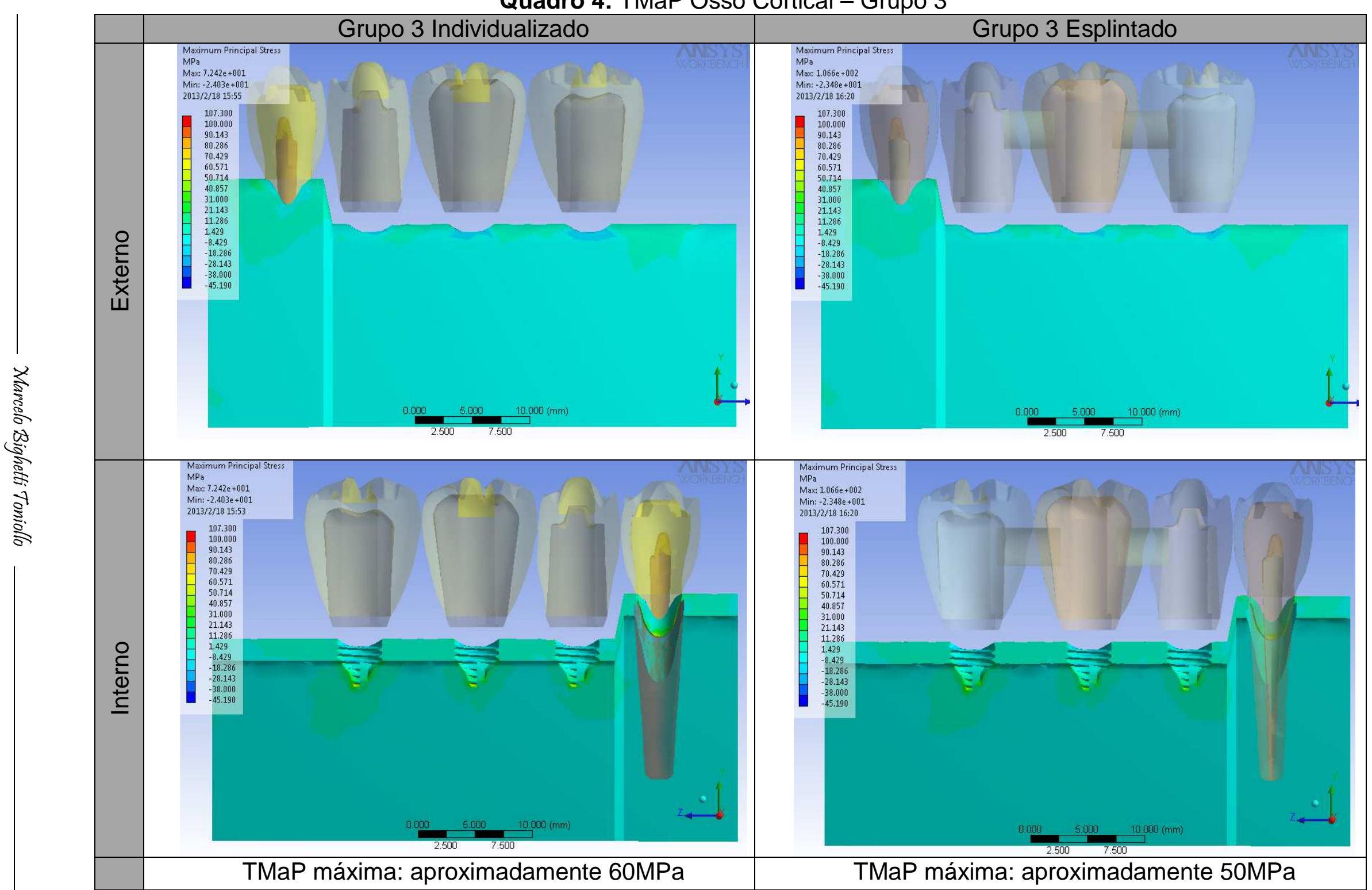




\subsection{Analisando o osso cortical:}

TMaP osso cortical externo:

- nos grupos controle, com as próteses individualizadas observou-se pequena área com maiores tensões (de tração) em abrangência circunjacente aos implantes e dente (Quadro 1).

- nos grupos $1 \mathrm{E}$ e 1l, houve maior tensão em abrangência no implante intermediário das próteses esplintadas (Quadro 2).

- nos grupos 2E e 2l, praticamente as mesmas tensões de tração para as próteses esplintadas e individualizadas (Quadro 3).

- nos grupos 3E e 3I, praticamente as mesmas tensões de tração para as próteses esplintadas e individualizadas (Quadro 4).

TMaP osso cortical interno:

- nos grupos controle, praticamente as mesmas tensões de tração para as próteses esplintadas e individualizadas (Quadro 1).

- nos grupos $1 \mathrm{E}$ e 11 , maior tensão no osso circunjacente às próteses individualizadas - $100 \mathrm{MPa}$ contra $90 \mathrm{MPa}$, na área apical do implante curto (Quadro 2).

- nos grupos 2E e 2l, houve maior tensão nos implantes extremos (mais anterior e mais posterior) para o grupo de próteses individualizadas. Porém houve maior tensão no implante intermediário para o grupo de próteses esplintadas $-60 \mathrm{MPa}$ contra $50 \mathrm{MPa}$, na área apical do implante curto intermediário (Quadro 3).

- nos grupos 3E e 3I, houve maior tensão (de tração) no osso cortical 
84 | Resultados

interno do grupo de próteses individualizadas - 60MPa contra 50MPa, na área apical dos implantes curtos (Quadro 4). 
Quadro 5: TMiP Osso Cortical - Grupo 1

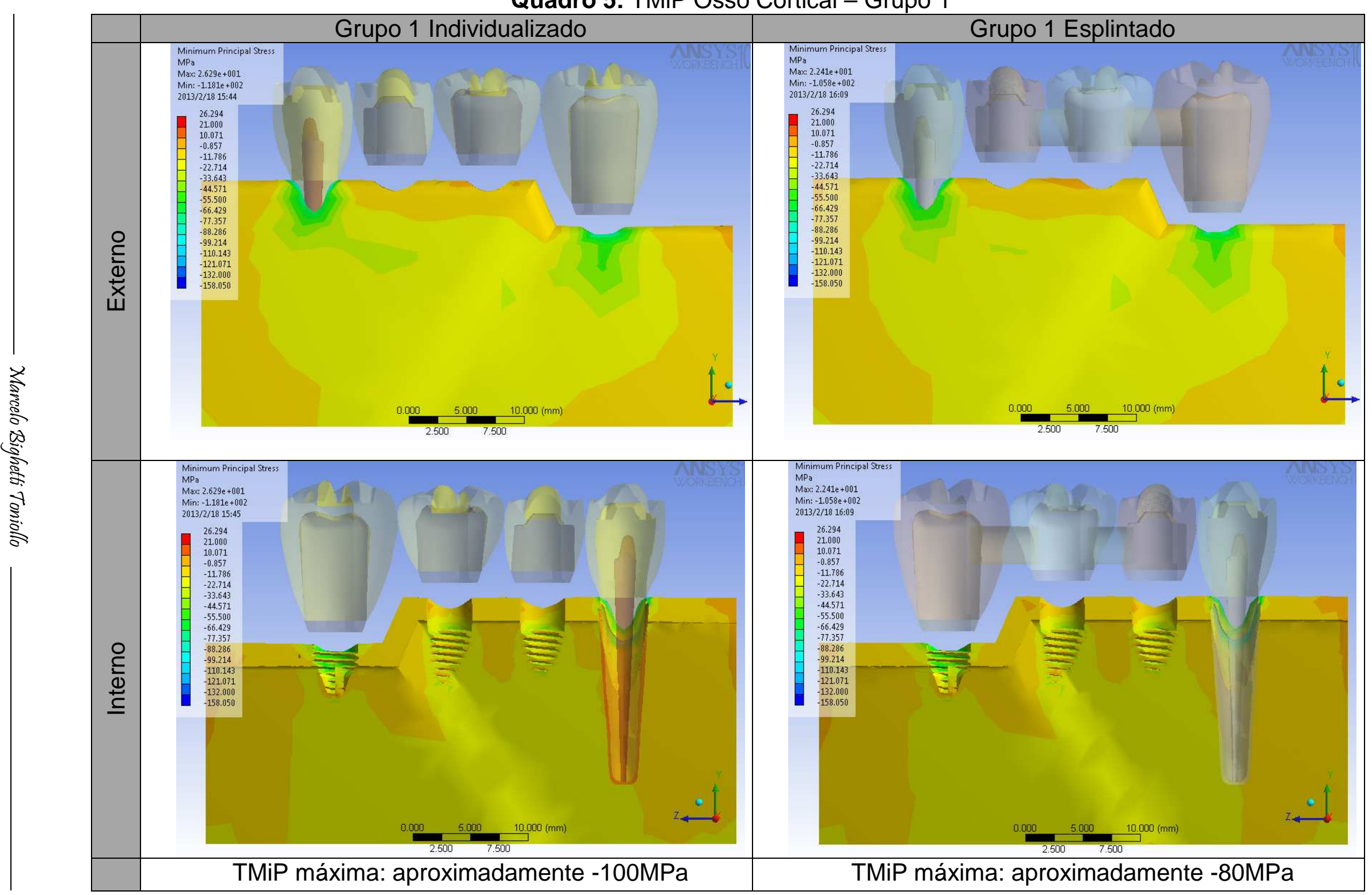


Quadro 6: TMiP Osso Cortical - Grupo 2

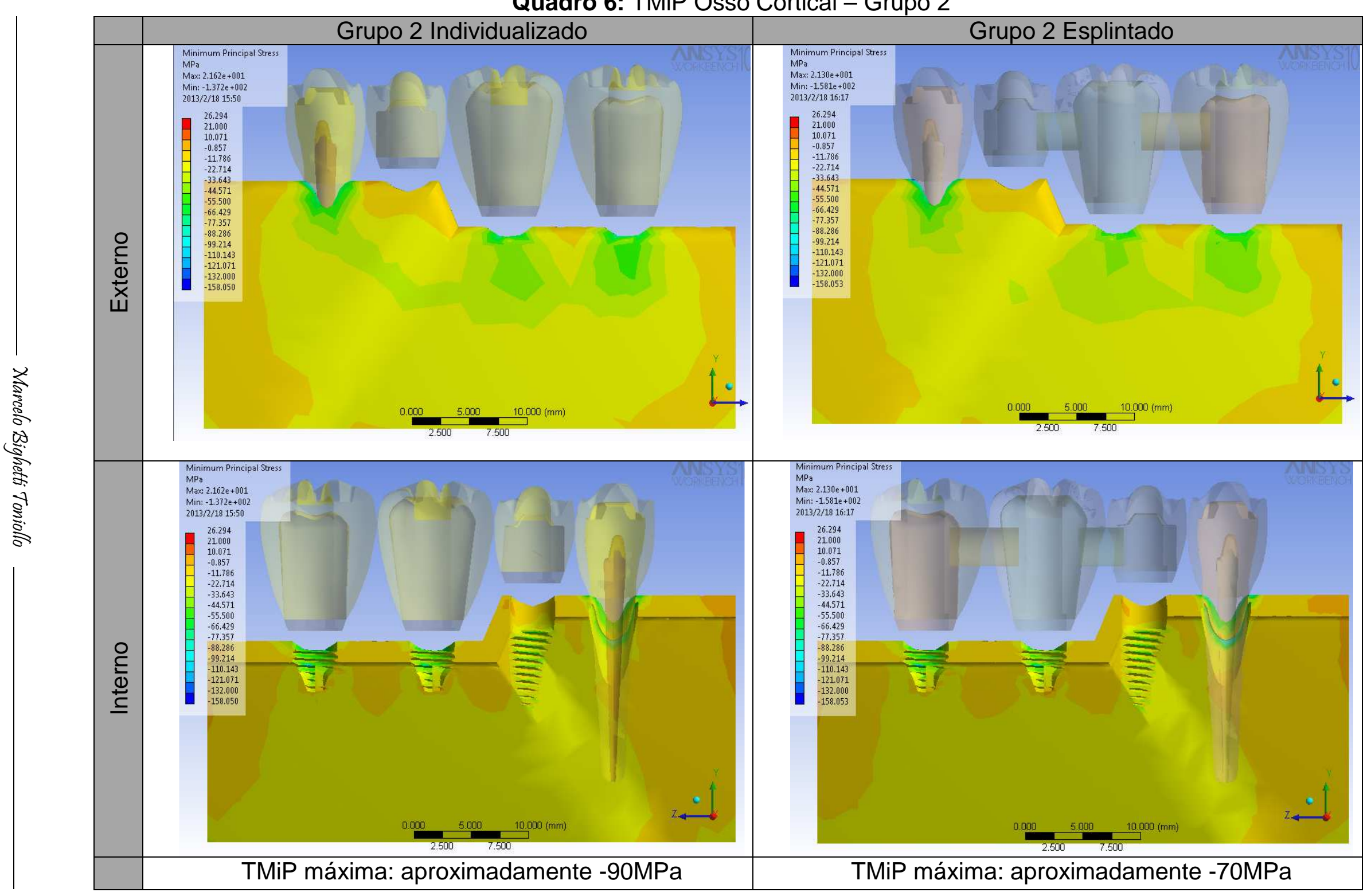


Quadro 7: TMiP Osso Cortical - Grupo 3

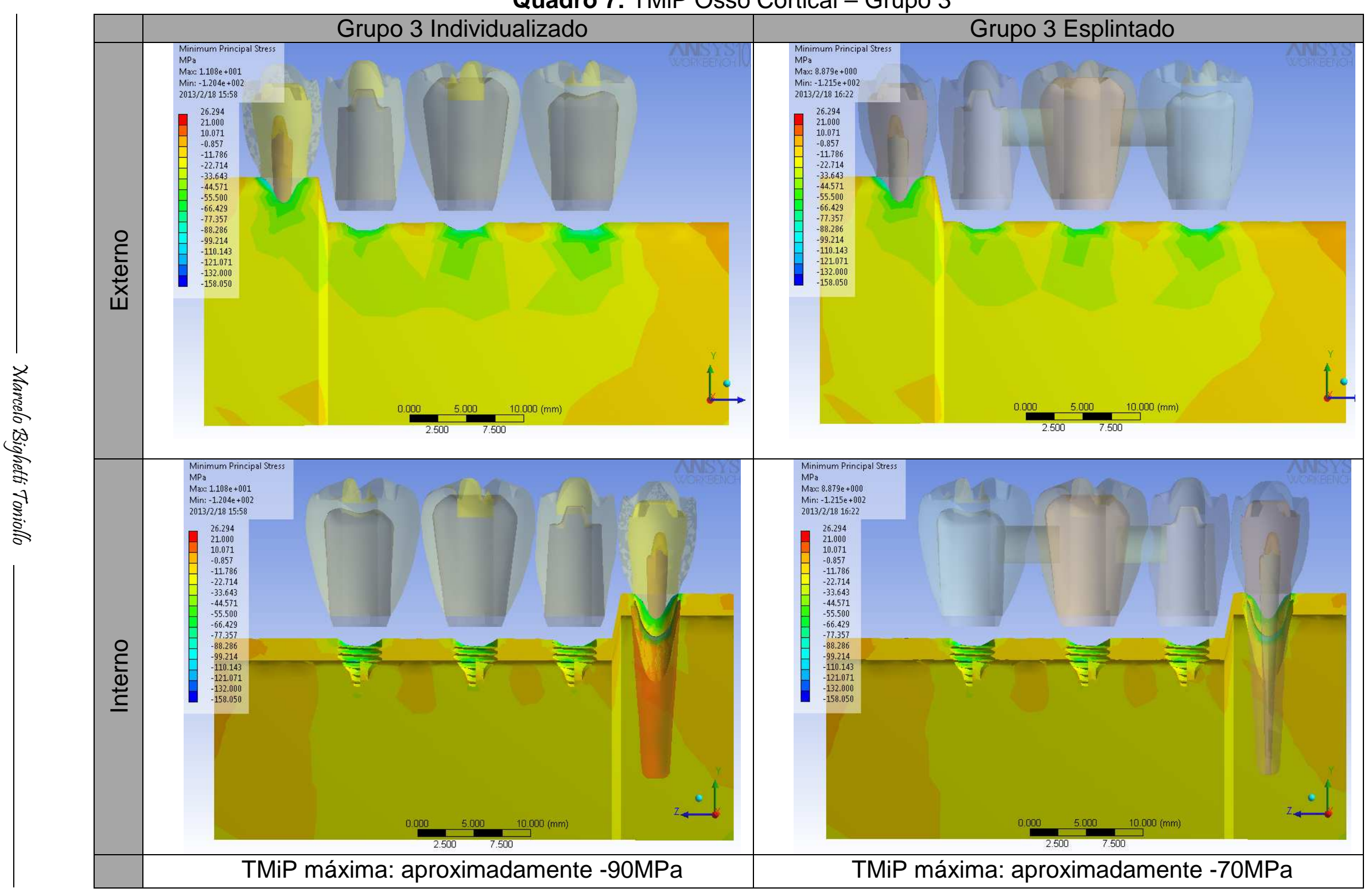


Quadro 8: TMiP Osso Cortical - Grupo controle

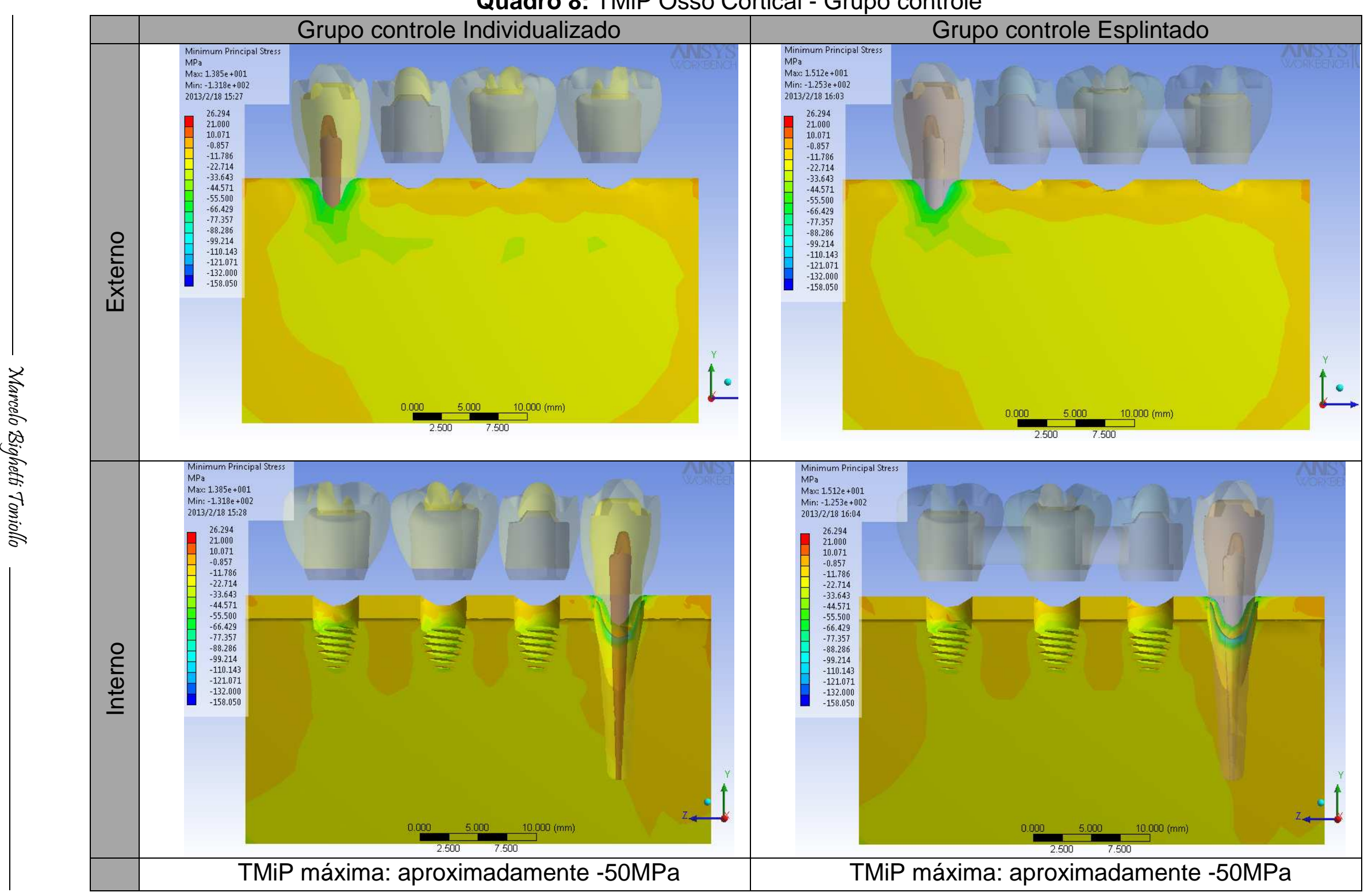


$\underline{\text { TMiP osso cortical externo e interno: }}$

- nos grupos com a presença de ao menos 1 implante curto foi benéfica a esplintagem das próteses sobre implantes, já que há a geração de menores tensões no osso adjacente a esses implantes (-80MPa, contra $100 \mathrm{MPa}$ ), além de menores tensões circunjacente ao dente. Isso pode ser notado claramente ao se analisar as TMiP no osso cortical dos grupos 1E e 1I, 2E e 2I e 3E e 3I (Quadros 5, 6 e 7), principalmente com relação à abrangência das tensões.

- já nos grupos controle, contendo apenas próteses com proporção coroa/implante igual a 1 , houve menor TMiP no osso extremamente circunjacente ao dente para as próteses individualizadas (Quadro 8).

- para as tensões de TMiP no osso circunjacente aos implantes regulares, houve equivalência de valores tanto para as próteses individualizadas quanto esplintadas (Quadros 5, 6 e 8). 

Quadro 9: TMaP Osso Esponjoso - Grupo controle

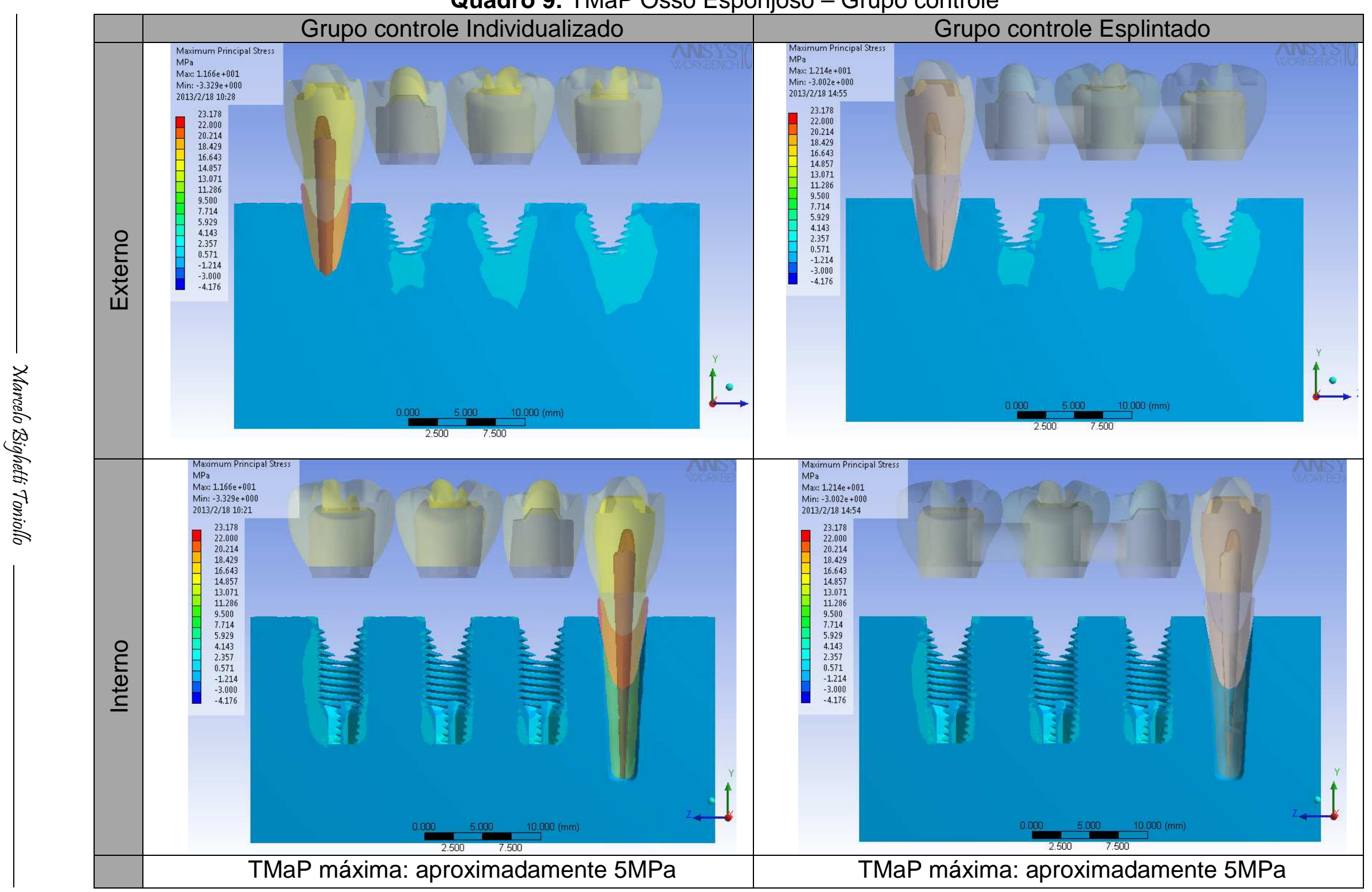


Quadro 10: TMaP Osso Esponjoso - Grupo 1

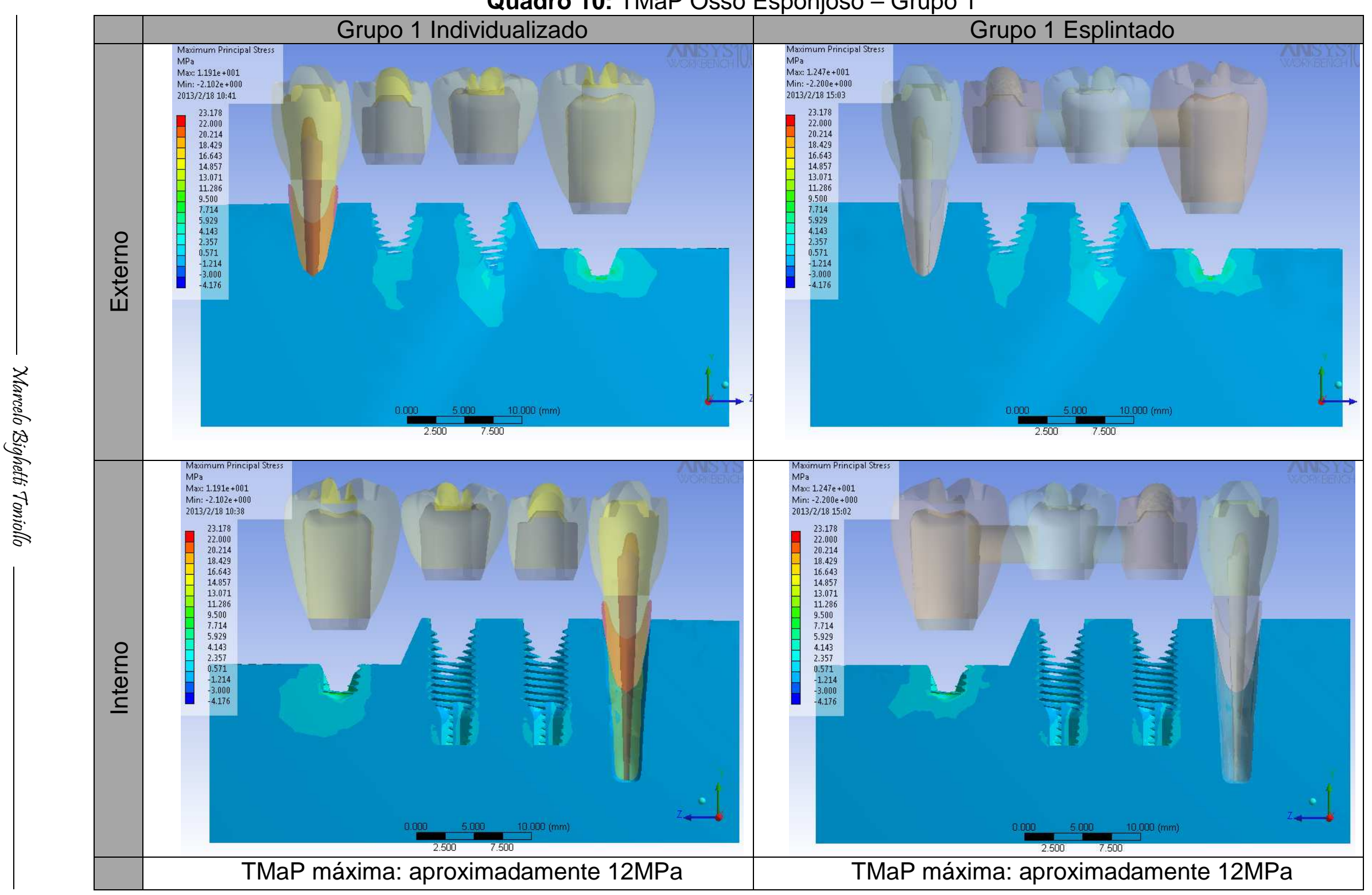


Quadro 11: TMaP Osso Esponjoso - Grupo 2

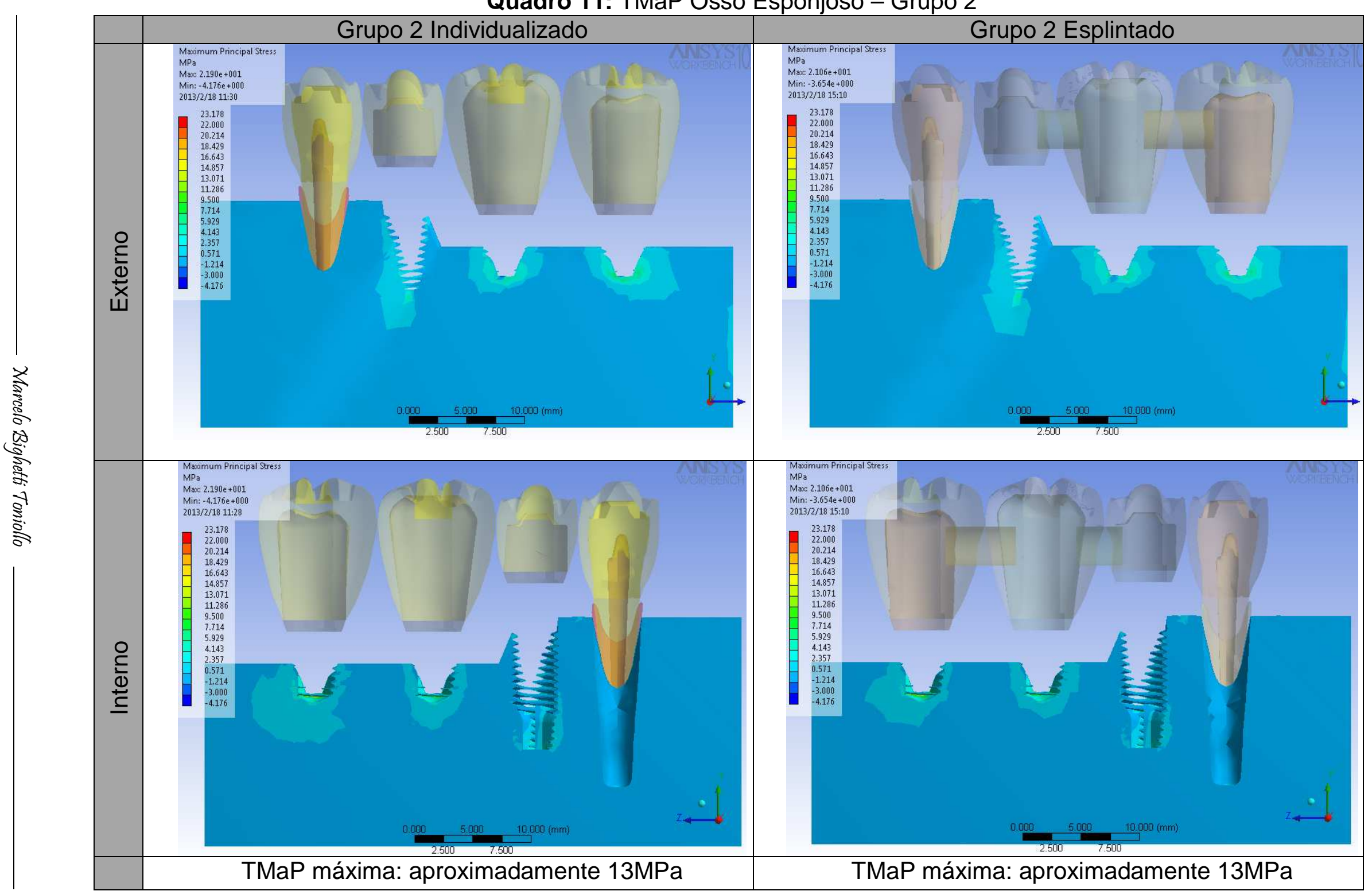


Quadro 12: TMaP Osso Esponjoso - Grupo 3

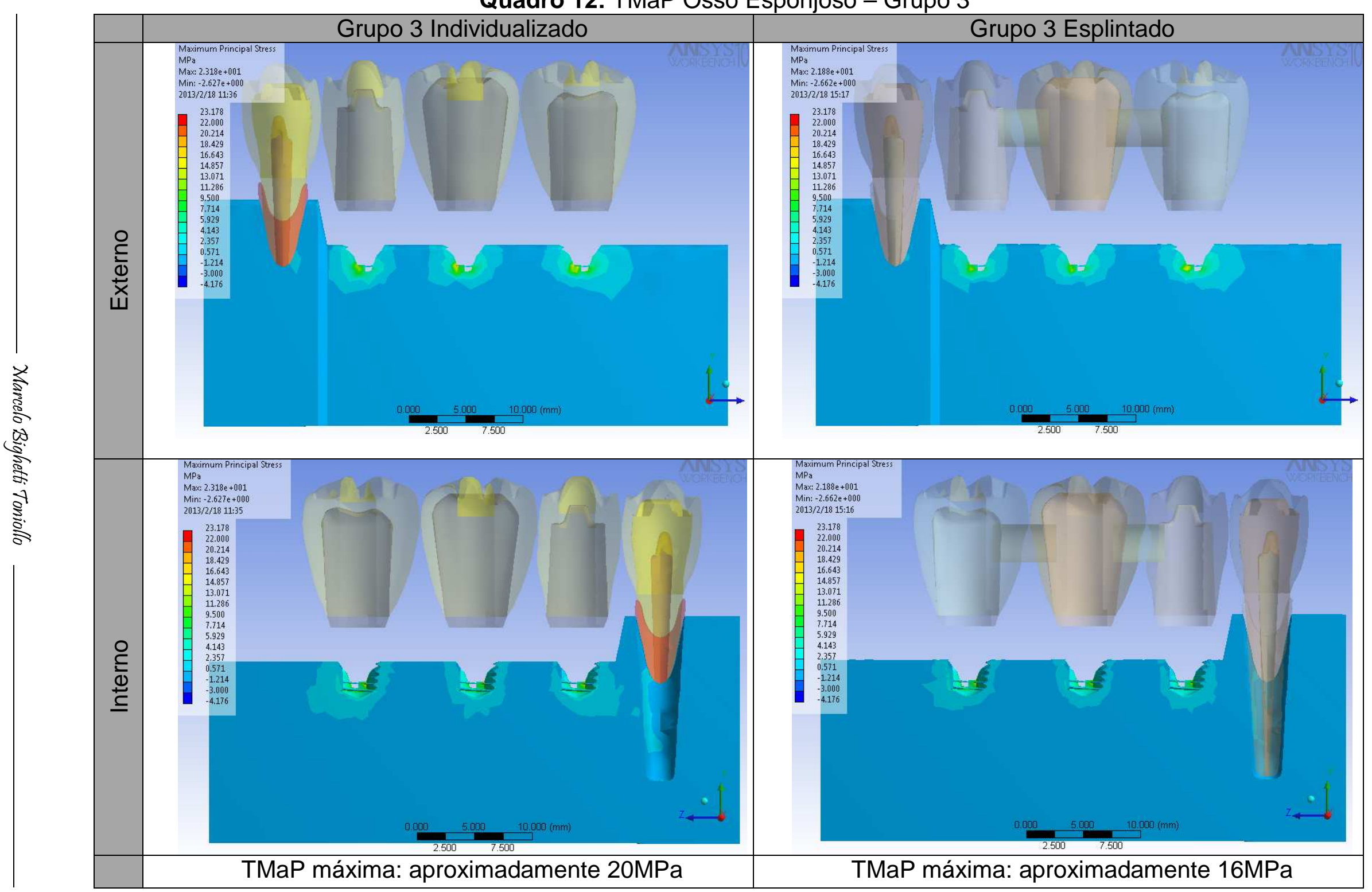




\subsection{Analisando o osso esponioso:}

\section{TMaP osso esponjoso externo:}

- nos grupos controle, houve maior tensão (de tração), com relação à sua abrangência, nas próteses individualizadas, e principalmente no osso circunjacente aos implantes mais distais, porém de forma mínima (Quadro 9).

- nos grupos $1 \mathrm{E}$ e 1I, observou-se maior tensão circunjacente ao implante curto das próteses individualizadas, em abrangência. No entanto, com relação ao implante intermediário, ocorreu maior tensão nas próteses esplintadas (Quadro 10).

- nos grupos 2E e 2I, da mesma forma que nos grupos 1E e 1I, houve maior tensão em abrangência circunjacente ao implante curto distal nas próteses individualizadas. Também se observou maior tensão no osso circunjacente ao implante intermediário para as próteses esplintadas, e, além disso, também para o osso circunjacente ao implante mais anterior (Quadro 11).

- nos grupos 3E e 3l, ocorreram maiores tensões no osso circunjacente a todos os implantes curtos quando do uso de próteses individualizadas 20MPa contra 16MPa, na área apical dos implantes curtos (Quadro 12).

\section{$\underline{\text { TMaP osso esponjoso interno: }}$}

- nos grupos controle, assim como na sua área externa, ocorreu maior tensão, em abrangência, e de forma bastante sutil, no osso circunjacente aos implantes das próteses individualizadas (Quadro 9). 
- nos grupos 1E e 1I, também observou-se maior tensão em abrangência no osso circunjacente ao implante curto das próteses individualizadas (Quadro 10).

- nos grupos 2E e 2I, percebe-se também maior tensão em abrangência no osso circunjacente ao implante curto mais distal das próteses individualizadas (Quadro 11).

- nos grupos 3E e 3I, assim como na sua área externa, ocorreram maiores tensões no osso circunjacente a todos os implantes curtos quando do uso de próteses individualizadas - 20MPa contra $16 \mathrm{MPa}$, na área apical dos implantes curtos (Quadro 12). 
Quadro 13: TMiP Osso Esponjoso - Grupo controle

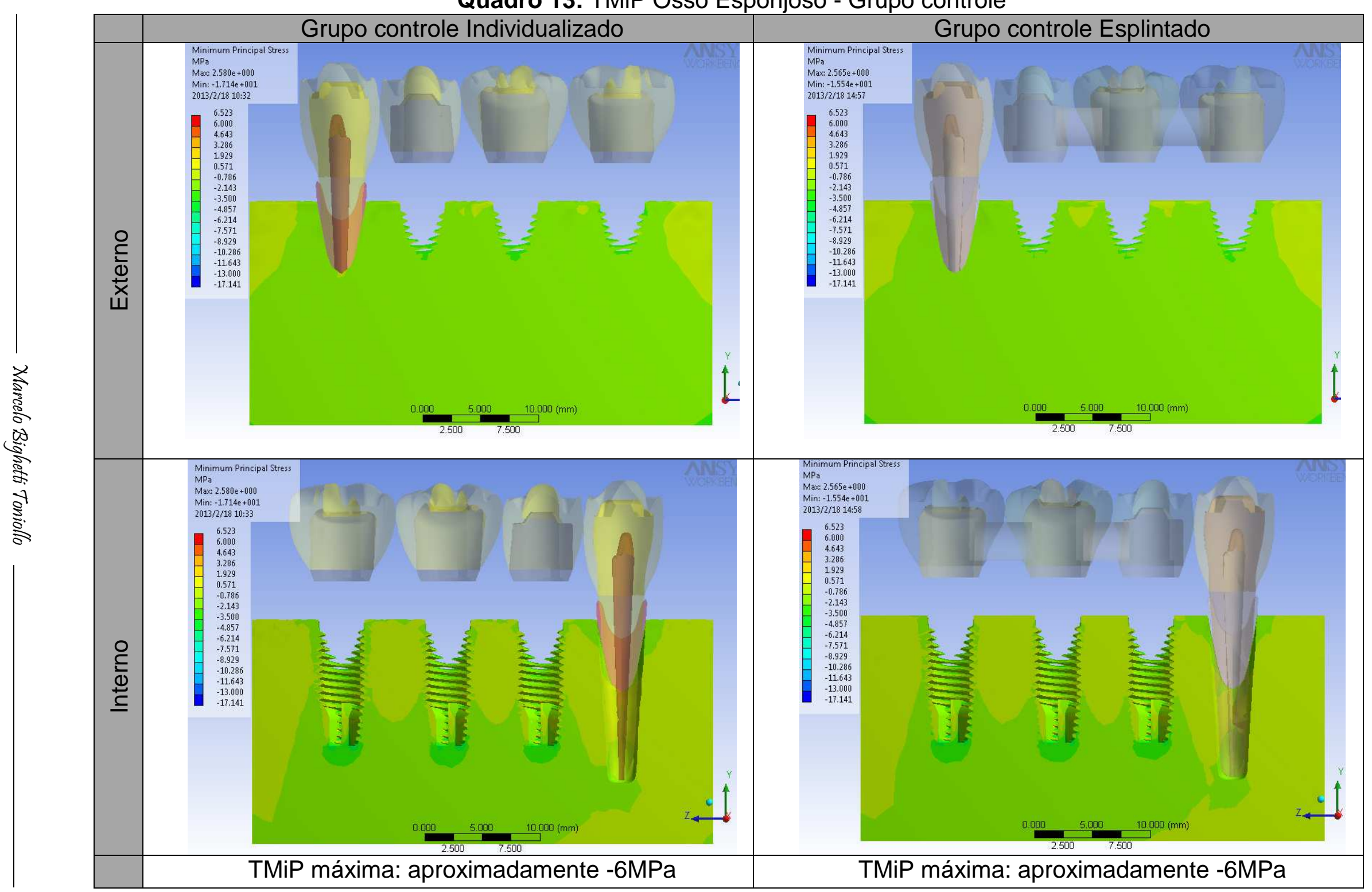

7
0
$\vdots$
2
5
5
5
$\vdots$
0
0 
Quadro 14: TMiP Osso Esponjoso - Grupo 1

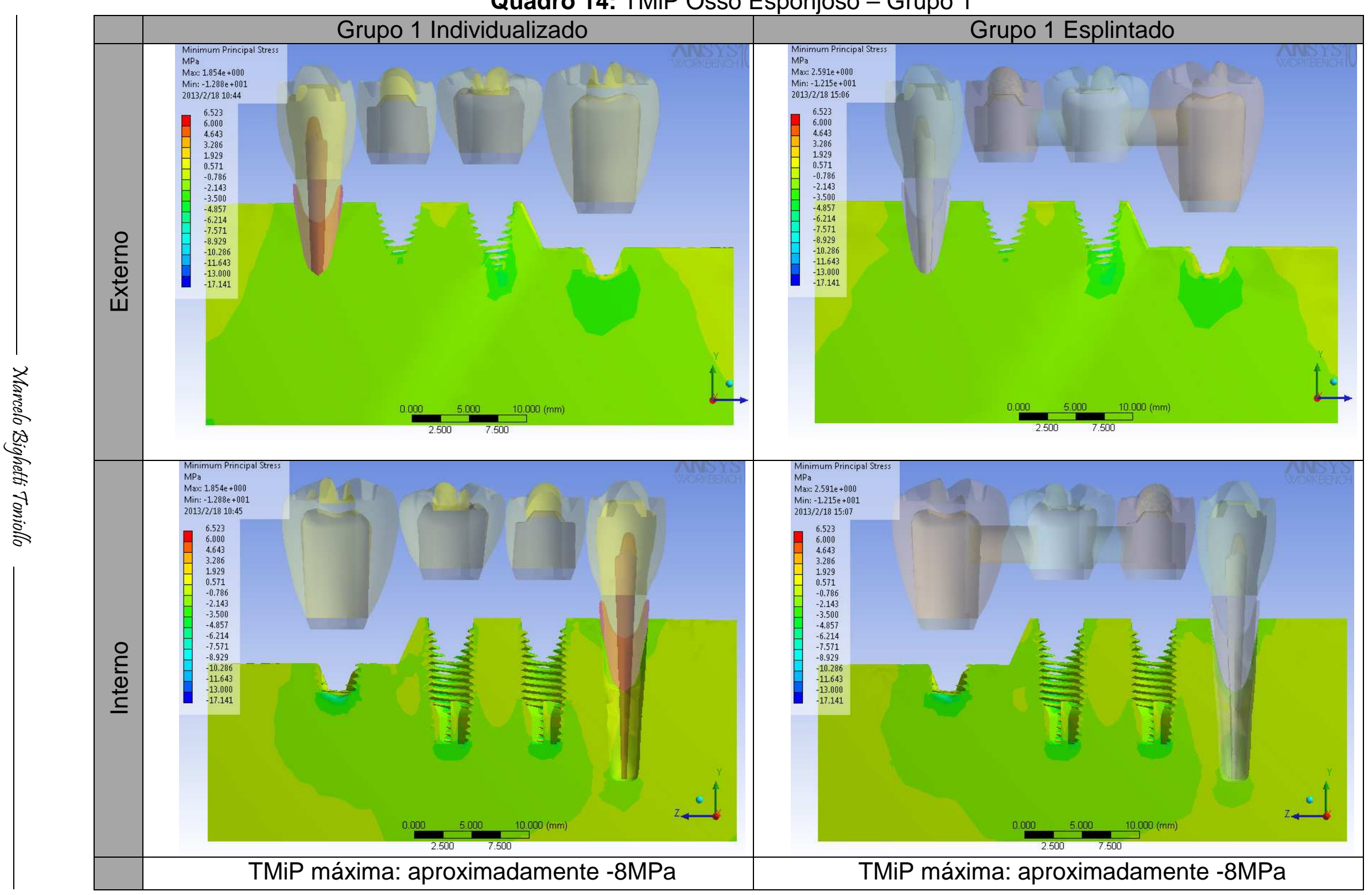


Quadro 15: TMiP Osso Esponjoso - Grupo 2

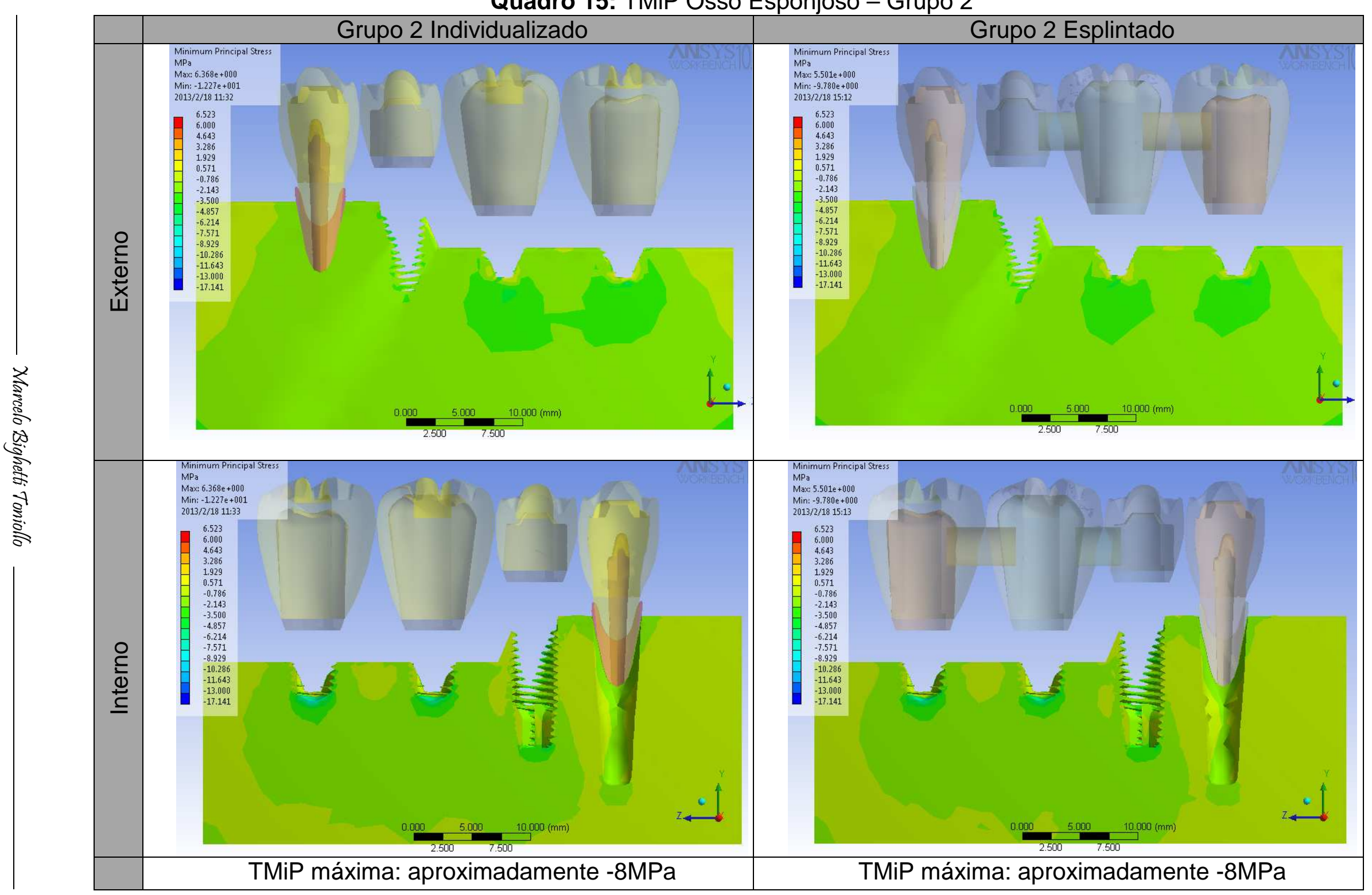


Quadro 16: TMiP Osso Esponjoso - Grupo 3

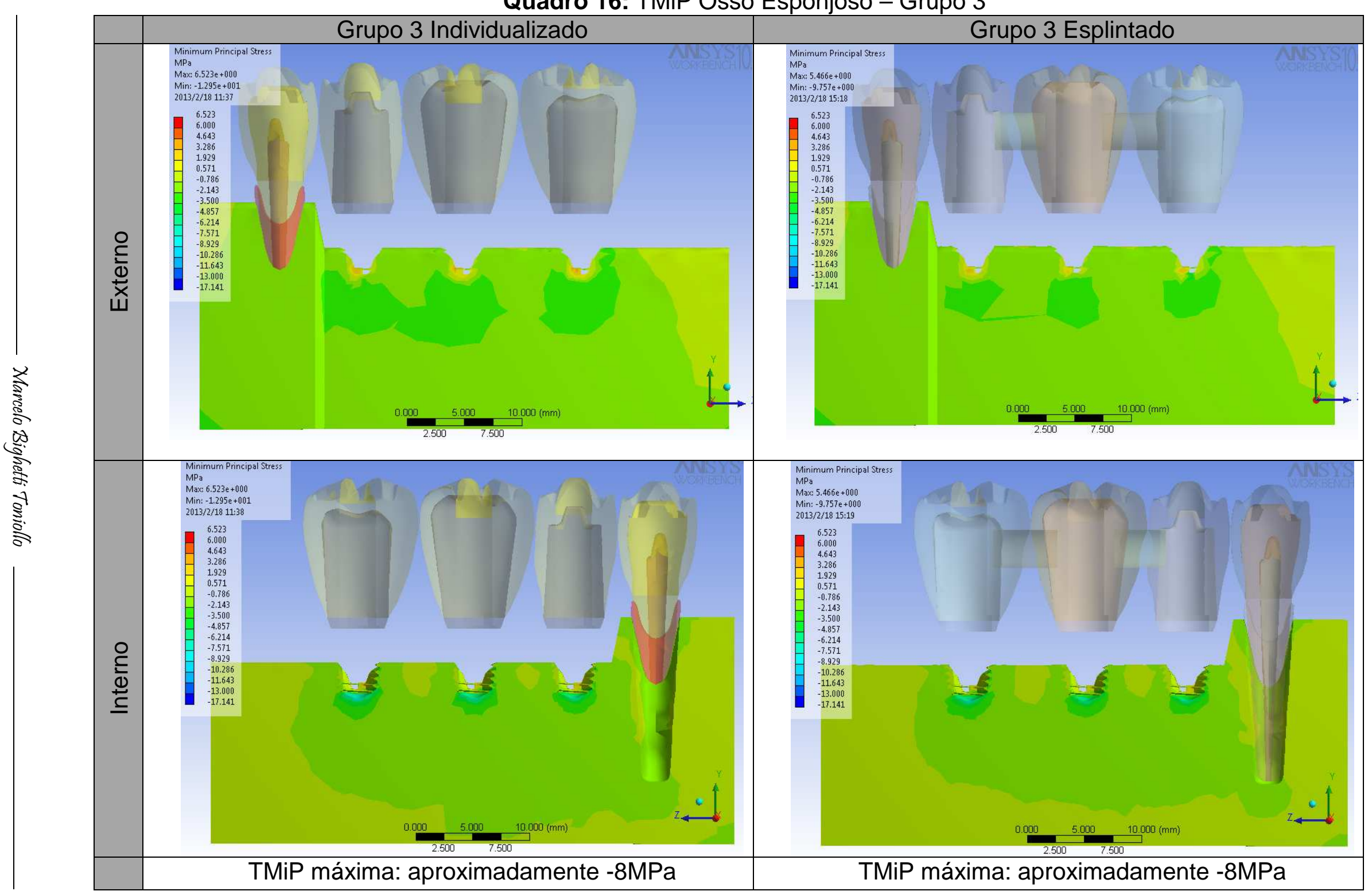




\section{$\underline{\text { TMiP osso esponjoso externo: }}$}

- nos grupos controle, percebeu-se de forma geral que a esplintagem das próteses sobre implantes diminui as tensões ósseas em abrangência na área cervical dos implantes, porém de forma sutil (Quadro 13).

- nos grupos 1E e 11, as próteses esplintadas amenizam as tensões em abrangência no osso referente ao implante curto, no entanto elas pioram as tensões no osso circunjacente ao implante regular intermediário (Quadro 14).

- nos grupos 2E e 2I, o mesmo ocorre. A esplintagem das próteses sobre implantes diminui as tensões em abrangência no osso circunjacente aos implantes curtos mais posteriores, no entanto aumenta a tensão no osso do implante regular mais anterior (Quadro 15).

- nos grupos 3E e 3I, ocorreram maiores tensões em abrangência no osso circunjacente a todos os implantes curtos quando do uso de próteses individualizadas, sendo assim a esplintagem das próteses benéfica (Quadro 16).

\section{$\underline{\text { TMiP osso esponjoso interno: }}$}

- nos grupos controle, da mesma forma que externamente, percebeu-se de forma geral que a esplintagem das próteses sobre implantes diminui as tensões ósseas em abrangência na área cervical dos implantes, porém de forma sutil (Quadro 13).

- nos grupos $1 \mathrm{E}$ e 1I, nota-se que a esplintagem das próteses sobre implantes pioram as tensões em abrangência no osso circunjacente ao 
implante regular intermediário (Quadro 14).

- nos grupos 2E e 2I, a esplintagem das próteses sobre implantes diminui de forma sutil em abrangência as tensões cervicais no osso circunjacente aos implantes curtos mais posteriores, no entanto aumenta a tensão no osso do implante regular mais anterior (Quadro 15).

- nos grupos 3E e 3I, ocorreram maiores tensões em abrangência no osso circunjacente a todos os implantes curtos quando do uso de próteses individualizadas, sendo assim a esplintagem das próteses benéfica (Quadro 16). 
Quadro 17: TEVM Implantes - Grupo controle

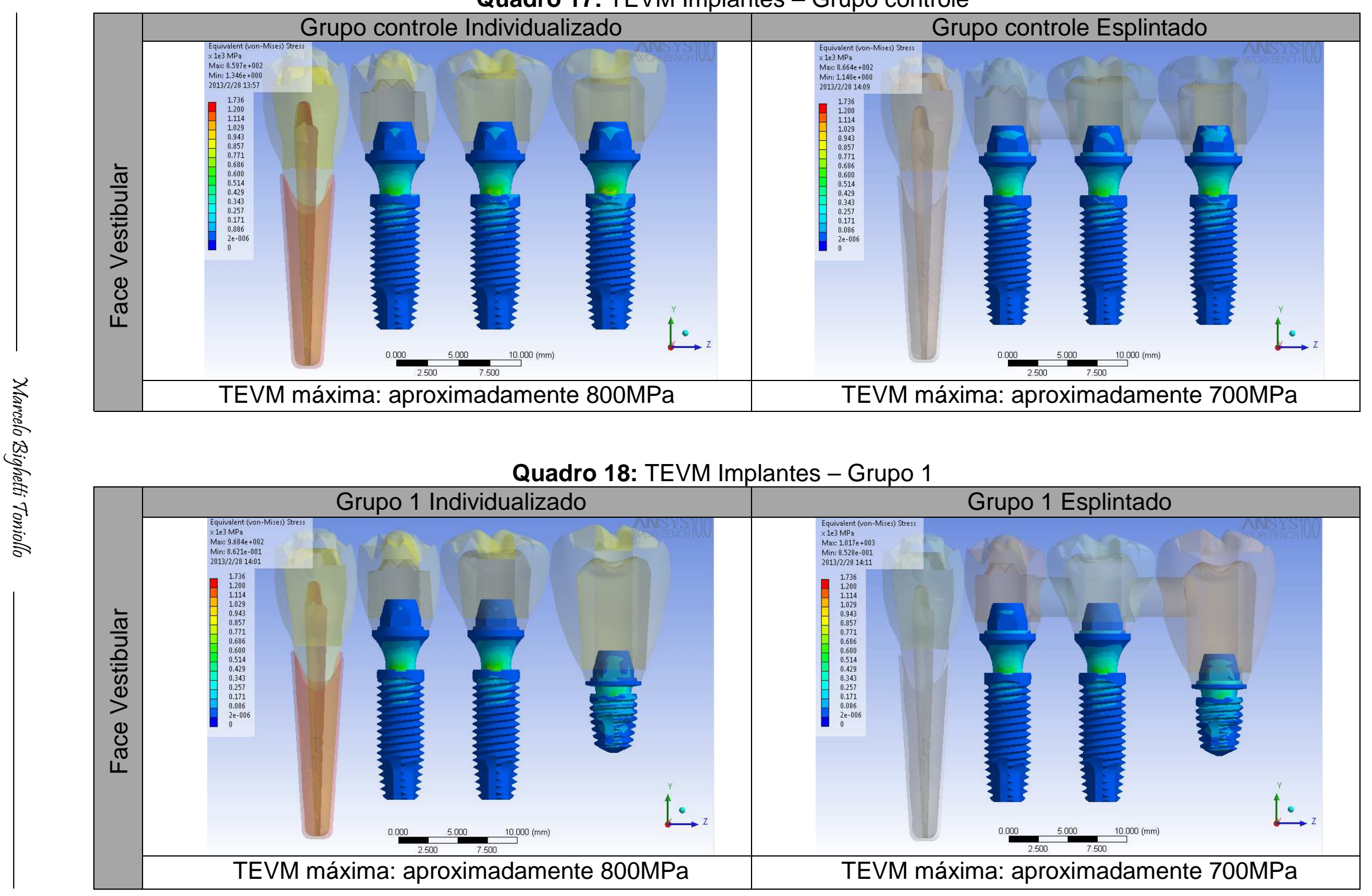


Quadro 19: TEVM Implantes - Grupo 2

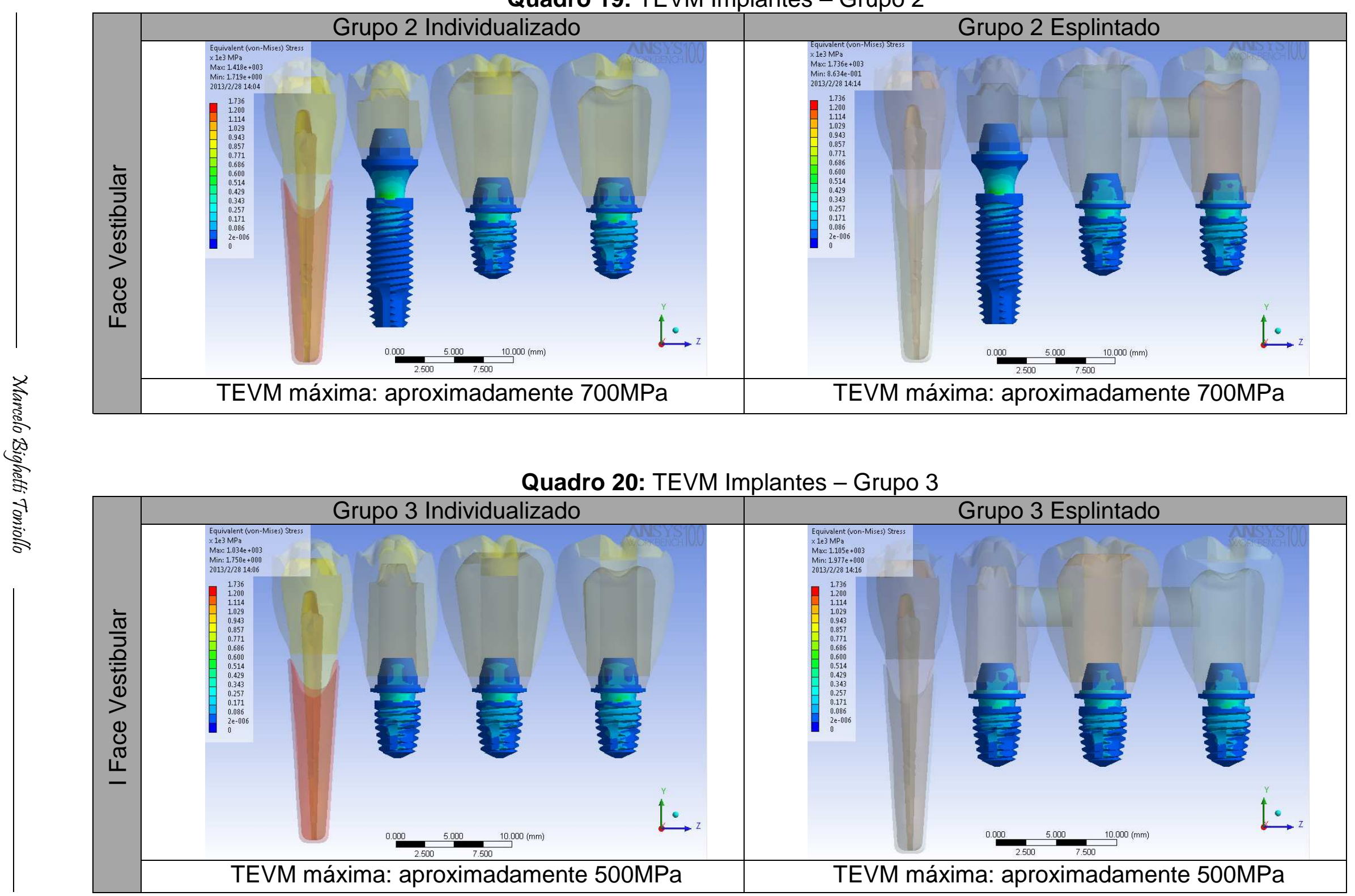




\subsection{Analisando os implantes e componentes:}

Todos os implantes e respectivos componentes comportaram-se de forma similar para todos os grupos. A esplintagem das próteses sobre implantes propiciou menores níveis de tensão à região de transmucoso dos pilares (700MPa contra $800 \mathrm{MPa})$. Além disso, tal esplintagem também gerou, de forma sutil, menor abrangência das tensões na superfície dos implantes. No entanto, para as próteses esplintadas, observaram-se maiores tensões, tanto em valores absolutos como também em abrangência, na parte superior dos pilares, local de assentamento das próteses, e notoriamente maior nos pilares sustentando próteses de maiores dimensões (Quadros 17, 18, 19 e 20). 

Quadro 21: TEVM Infraestruturas - Grupo controle

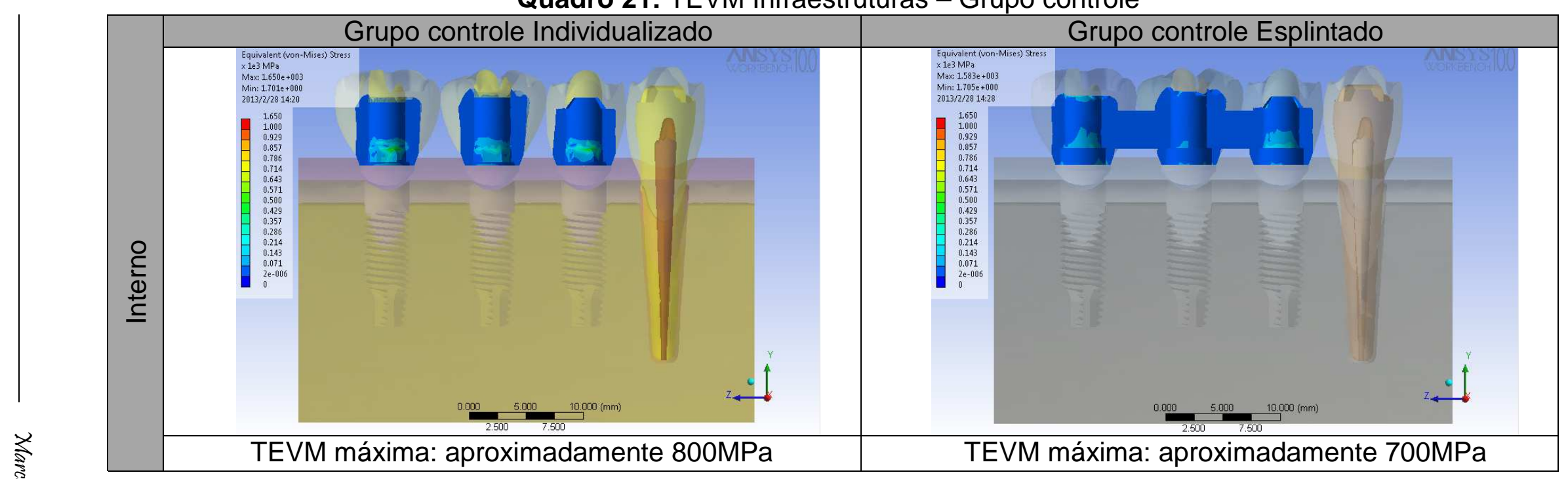

Quadro 22: TEVM Infraestruturas - Grupo 1

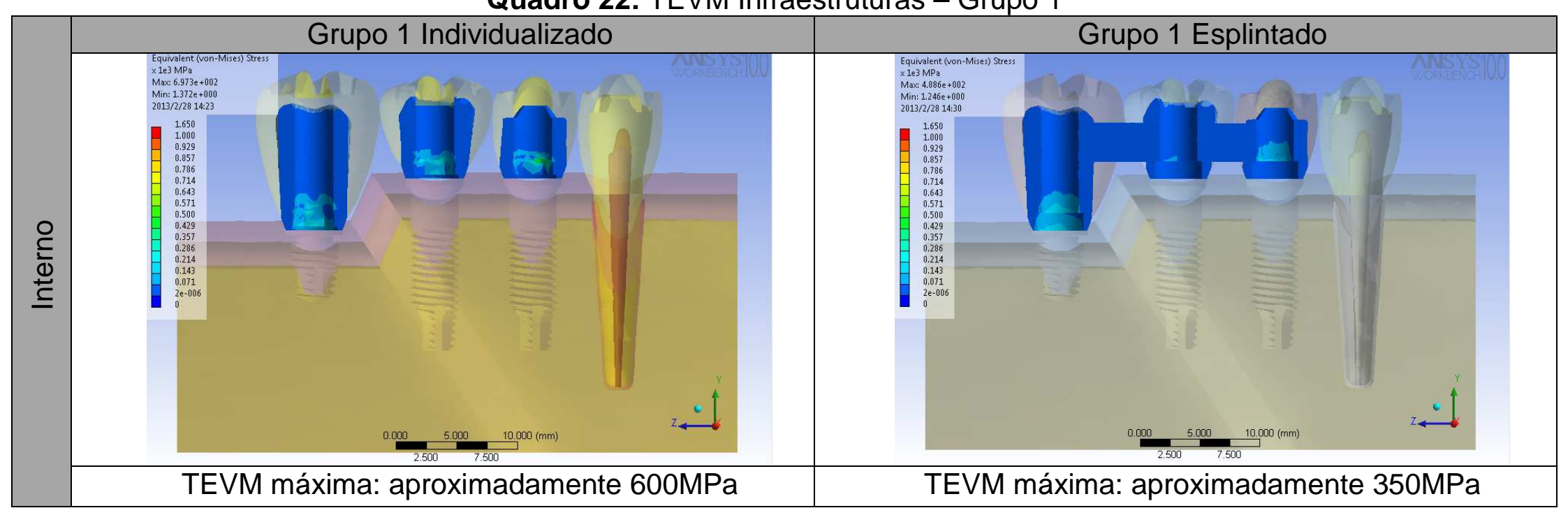


Quadro 23: TEVM Infraestruturas - Grupo 2

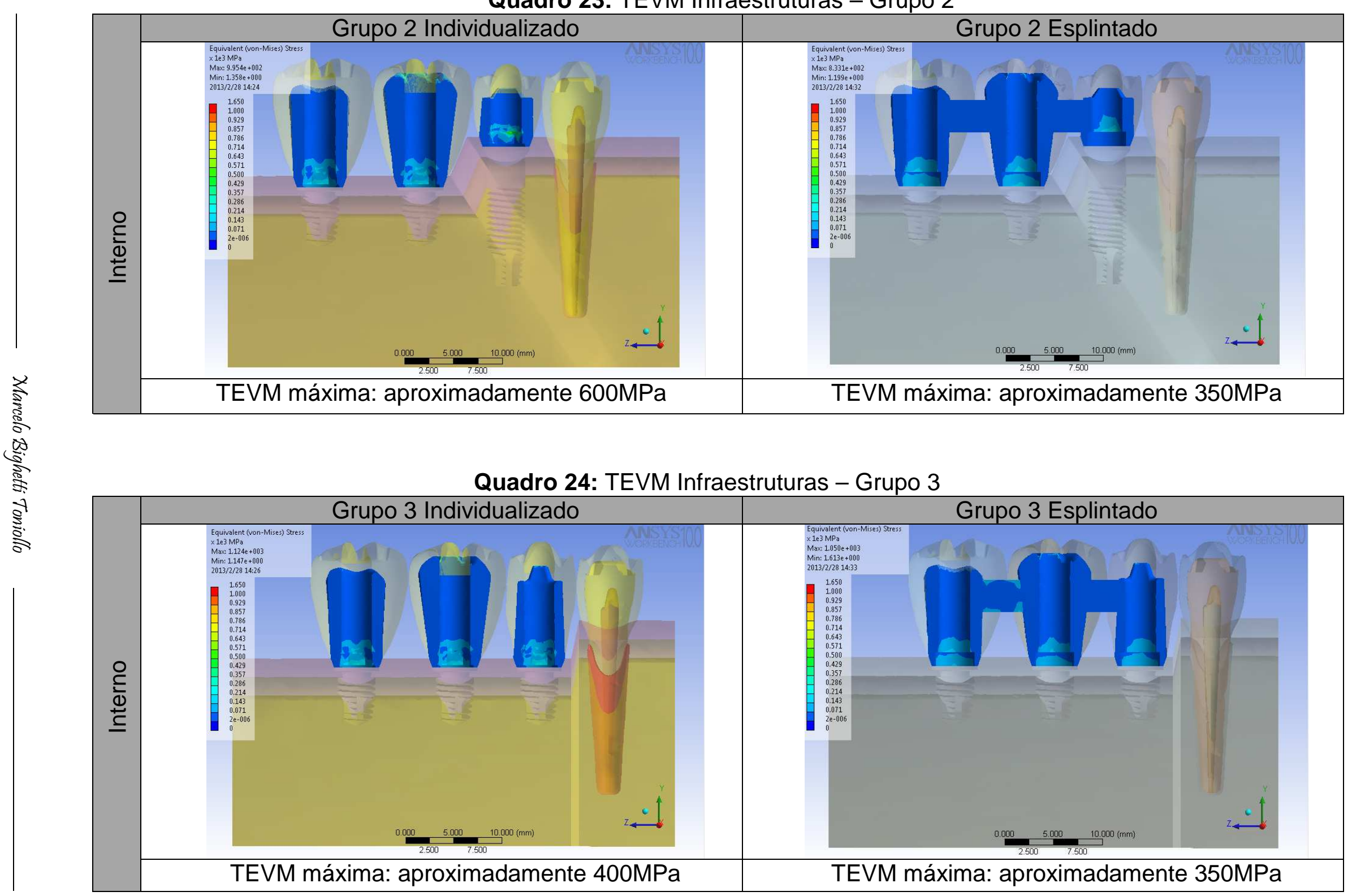




\subsection{Analisando as infraestruturas:}

De forma geral, sempre houve maiores níveis de tensão nas infraestruturas das próteses sobre implantes individualizadas - 600MPa contra $350 \mathrm{MPa}$, e na região interna onde estão presentes os sextavados de travamento das próteses sobre implantes sobre os pilares (Quadros 21, 22, 23 e 24). 

6. Discussão 



\section{DISCUSSÃO}

\subsection{Tensões e suas interferências à interface osso/implante}

O presente estudo teve o objetivo de traçar, em linhas gerais, comparativos das tensões geradas em próteses sobre implantes cone Morse de comprimentos regular e curto, tanto individualizadas como esplintadas, e no osso adjacente após carregamento oclusal distribuído. Tais tensões apresentaram-se diferentes de acordo com os grupos experimentais propostos, tornando possíveis considerações e análises para cada uma das situações de disparidades.

Considerando os resultados deste trabalho, e traçando um comparativo entre as TMaP (representativo das tensões de tração) e TMiP (representativo das tensões de compressão) resultantes, é importante ressaltar a importância da análise criteriosa de ambos os tipos de tensões, já que ambas em demasia podem representar danos à estrutura óssea. Suas associações geram forças de cisalhamento (Turner e Burr, 1993), as quais induzem o deslizamento entre tecido ósseo e implante, tendendo a romper tal interface (Misch, 2009). As forças de cisalhamento têm efeito deletério sobre o osso, uma vez que mesmo em baixas incidências de carga oclusal podem ser suficientes para induzir perda óssea (Rompen et al., 2003).

\subsection{Esplintagem e individualizacão e seus efeitos no tecido ósseo de suporte}

Variados autores corroboram com a ideia que as próteses sobre implantes individualizadas apresentam distribuição de tensão menos uniforme em comparação às próteses esplintadas, mesmo quando submetidas a um 
ajuste oclusal bem balanceado (Skalak, 1983; Guichet et al., 2002; Wang et al., 2002; Menani et al., 2011). No presente estudo pode-se notar que as próteses sobre os implantes de comprimento regular não apresentaram tensões dissipadas no osso de forma significativamente diferente quando do uso de forma individualizada ou esplintada. Porém, já sobre os implantes de comprimento reduzido, a esplintagem das próteses trouxe melhora significativa com redução de tensões transmitidas no osso circunjacente, e também com relação à sua abrangência (Quadros 10 a 12 e 14 a 16). Tiossi et al. (2013), por meio de análise de elementos finitos e correlação de imagem para comparação e validação do método, relataram também os efeitos positivos da esplintagem das coroas sobre implantes e, além disso, a diferença que faz a presença de contato posterior após o último elemento da prótese no intuito da diminuição das tensões em osso.

Nos grupos experimentais com apenas implantes de comprimento curto (grupos 3E e 3I-Quadros 4, 7, 12 e 16) a abrangência das tensões variou mais em comparação aos demais grupos, sendo sempre maior para o uso de próteses individualizadas, sem representar diferenças extremamente relevantes em relação aos valores absolutos, porém acredita-se que pequenas variações de valores possam ser suficientes para causar malefícios, tal como afirmado também por Jofre et al. (2010).

Isso faz crer que quanto mais implantes curtos num mesmo contexto, maior a necessidade em esplintá-los a fim de diminuir a tensão transferida no osso suporte restringindo esta a uma área específica (Quadro 16). No entanto, na presença apenas de implantes de comprimento maior e coroas com proporção coroa/implante normal, mostra-se viável e indicada sua 
individualização (Quadros 1, 8, 9 e 13).

É possível notar que, de forma geral, as tensões encontradas nos ossos entre os grupos individualizados e esplintados varia, na maior parte, apenas em abrangência, e não em valores absolutos relevantes. Assim, frente às variadas vantagens clínicas do emprego das próteses individualizadas, tal como a melhor aceitação do paciente e maior facilidade de higienização, o emprego de próteses sobre implantes não esplintadas, mesmo que sobre implantes de comprimento curto, é uma alternativa viável e interessante a ser considerada no tratamento envolvendo reabilitações implantossuportadas, mas, sobretudo a individualização é mais indicada às próteses sobre os implantes de comprimento regular.

Menani et al. (2011) observaram, por meio de análise fotoelástica, maiores tensões na região coronal das próteses fixas sobre implantes esplintadas, no momento da cimentação, comparativamente às próteses não esplintadas, corroborando com Guichet et al. (2000). Porém, os mesmo autores ainda afirmam que as próteses esplintadas transferem mais tensões nos dentes adjacentes, enquanto que as próteses individualizadas não têm esta capacidade tão acentuada, concentrando as tensões ao redor dos implantes. No presente estudos foram encontrados resultados divergentes a Menani et al. (2011) e Guichet et al. (2000), já que as próteses sobre implantes esplintadas diminuíram as tensões ao osso circunjacente ao dente adjacente, mesmo na presença de proporção coroa/implante aumentada.

Situação interessante encontrada foi a concentração de tensão aumentada no osso circunjacente aos implantes intermediários em situações de esplintagem entre implantes regulares e curtos. Nos Quadros 10 e 14, em 
que estão os grupos 1E e 1I, observa-se maior tensão no osso circunjacente ao implante intermediário em 1E. Isso mostra uma provável situação desfavorável ao sistema, pois se acredita que esta tensão seja gerada pelo maior braço de alavanca observado ao se esplintar a prótese gerando maior tensão sobre o implante intermediário. O mesmo ocorre nas análises dos Quadros 11 e 15, para os grupos $2 \mathrm{E}$ e 2l, com maiores tensões em abrangência no osso circunjacente aos implantes intermediário e mais anterior em 2E, mostrando que a esplintagem com associação de elementos fixados em implantes com grande diferença de altura pode representar uma situação desfavorável no osso circunjacente dos implantes mais anteriores. Nesse contexto é necessário que o profissional pondere o que há de ser mais importante: unir as próteses e preservar o osso circunjacente ao implante curto posterior, ou individualizar as próteses a fim de não gerar maiores tensões circunjacentes aos implantes regulares.

A estrutura óssea, segundo Lekholm e Zarb (1985), pode ser dividida em 4 classificações (osso tipo I a IV, sendo o tipo I mais cortical e o tipo IV mais trabecular), em que a quarta representa a pior qualidade, com a maior proporção de osso trabecular. Na maxila, a fina camada de osso cortical prejudica a estabilidade primária dos implantes, sendo esta considerada essencial para o sucesso da ósseointegração.

Assim sendo, fator importante a ser lembrado é a diferença de implantação dos implantes regulares (2 mm infra-ósseo) e dos curtos (ao nível ósseo), sendo que os regulares ficam praticamente todo implantado em osso esponjoso, e os curtos com quase metade do corpo em osso cortical, conforme recomendado pelo fabricante. Associado a isso há a diferença dos módulos de 
elasticidade dos ossos cortical e esponjoso, a qual naturalmente gera comportamentos diferentes. Pode-se observar que isso interferiu na distribuição das tensões no osso, sendo que elas se dissiparam até o osso circunjacente à cervical dos implantes curtos (Quadros 10, 11, 14 e 15).

A união ou esplintagem dos implantes visa justamente sua ação de forma conjunta, levando à hipótese de que as tensões transmitidas no tecido ósseo são mais bem distribuídas e por isso apresentam menor intensidade localizada, levando a uma melhor estabilidade e cicatrização em comparação aos implantes individualizados. Como exemplo temos os achados de Bergkvist et al. (2008), que demonstraram que a esplintagem dos implantes diminui fortemente os níveis de tensões no tecido ósseo, especialmente quando estes são expostos a forças oblíquas. No entanto, em nossa análise pelo método dos elementos finitos, não foi encontrada variação drástica de valores, mas sim apenas variações de abrangência das tensões.

Forças oclusais em implantes ósseointegráveis são citadas também como importantes fatores na questão do sucesso e longevidade das próteses sobre implantes (Skalak, 1983; Brunski et al., 2000).

Kim et al. (2005) relataram que é comum na prática clínica realizar a união das próteses implantossuportadas visando a resistência e retenção, além de favorecer a distribuição de forças axiais, minimizando sua transferência para a infraestrutura e osso suporte. Tal prática vem dos conceitos convencionados da união entre dentes, em que se acredita haver o aumento da resistência coletiva do sistema (Faucher et al., 1983).

Rokni et al. (2005) encontraram resultados polêmicos e que causam dúvidas e controvérsias. Em seu estudo clínico envolvendo 199 implantes 
obtiveram resultados revelando que o uso de implantes com maiores comprimentos causa maiores perdas da crista óssea em comparação aos implantes curtos; da mesma forma, implantes reabilitados com próteses sobre implantes esplintadas leva a maiores perdas ósseas comparativamente a implantes individualizados. No entanto, os autores afirmam que mais estudos são necessários a fim de maiores esclarecimentos.

Já Jofre et al. (2010) sugerem que o comportamento biomecânico do sistema envolvendo implantes esplintados é melhor devido à união da infraestrutura, a qual aumenta a área de ancoragem osso-implante e diminui a perda óssea diante de cargas funcionais. Além disso, os autores afirmaram que quando um implante isolado é submetido a forças, tensões compressivas excessivas podem ser geradas e ultrapassar o limiar fisiológico do osso; por outro lado, em casos de esplintagem do sistema, há melhor comportamento e menores tensões são desenvolvidas. De fato isso foi observado do ponto de vista da infraestrutura, superfície dos implantes e área de transmucoso dos pilares.

Diferentes estudos têm demonstrado que o aumento do diâmetro do implante diminui as tensões na crista alveolar (Himmlova et al., 2004; Petrie e Williams, 2005), não sendo encontrados achados controversos, como no caso do comprimento. No entanto, juntamente da importância do diâmetro do implante deve-se avaliar o remanescente ósseo em seu entorno, já que o ganho no diâmetro pode se contrapor à quantidade e/ou qualidade das paredes ósseas que, quando limitadas, também representam possíveis fatores de concentração de tensões (Holmes e Loftus, 1997; Tada et al., 2003; Petrie e Williams, 2005). Essa situação fica bem clara no estudo de Kim et al. (2014), 
em que numa simulação de elementos finitos percebe-se a importância do volume ósseo preservado no entorno do implante quando este é diminuído.

No presente estudo também notamos que, no caso dos implantes curtos, posicionados ao nível ósseo, ocorre maior concentração de tensões ósseas cervicais, que pode ter origem pelo menor comprimento do implante e, além disso, menor espessura de remanescente ósseo em seu entorno justamente pelo implante estar posicionado na margem. Porém, do ponto de vista clínico, em que tais implantes são utilizados em situações extremas de debilidade óssea, tal fato não limita sua utilização, até porque tais tensões desenvolvidas não chegaram a limiares lesivos ao osso.

\subsection{Esplintagem e individualização e seus efeitos à infraestrutura, implantes e componentes}

Nota-se que, muitas vezes, a preocupação inicial com relação à concentração indevida de tensões recai sobre a condição óssea e sua manutenção de forma fisiológica. Mas pode-se notar que a preocupação com relação às altas tensões deve ocorrer tanto no osso como também nos implantes e componentes, visando a minimização de falhas, fraturas ou soltura de parafusos.

No entanto, existem múltiplos fatores a serem levados em conta. Um deles é a deformação inerente numa confecção de próteses fixas, pelo método de cera perdida, em que contrações da estrutura, inerentes à técnica, juntamente com maior volume de metal, refletem em maiores tensões resultantes no osso quando são instaladas com assentamento não totalmente passivo. 
Brunski et al. (2000) afirmaram que para cada prótese sobre implante há um coeficiente de erro inerente devido ao desajuste dos componentes envolvidos (coroa/pilar e pilar/implante) resultando em pré-tensões. Assim, sugeriram que quando essas próteses são unidas, há uma somatória destes desajustes devido à esplintagem, resultando na transferência de tensões nos implantes e estruturas de suporte. Isso poderia explicar os resultados de tensões encontradas por Nissan et al. (2010) na cervical dos implantes, em que encontraram valores de tensão significativamente maiores para as próteses esplintadas comparativamente às próteses individualizadas.

Porém, tal somatória de erros relatada por Brunski et al. (2000) aplica-se em estudos de procedimentos clínicos diretos, e no presente estudo não se simulou este desajuste nas próteses esplintadas, como em outros estudos (Silva et al., 2012).

Tem sido documentado na literatura odontológica que a esplintagem dos implantes aumentaria a resistência frente às cargas laterais, diminuindo o risco da fratura de componentes e reduzindo a perda de retenção do parafuso dos componentes (Balshi e Wolfinger, 1997; Misch, 2008). No entanto, segundo Nissan et al. (2010), variados relatos in vitro, na literatura, apresentam resultados conflituosos, tais como Guichet et al. (2002) e Kim et al. (1999). Guichet et al. (2002), em análise fotoelástica, concluíram que restaurações sobre implante de três elementos esplintadas apresentaram melhores resultados do que as não esplintadas. Já Kim et al. (1999) compararam próteses cimentadas e parafusadas esplintadas por meio de análise fotoelástica e strain-gauges, obtendo menores níveis de tensões para as próteses unitárias cimentadas. Bender, em 1995, em estudo clinico de 4 anos, 
relatou maiores taxas de sucesso para próteses sobre implantes cimentadas e individualizadas quando comparadas com as cimentadas esplintadas. Em seus achados observaram que as restaurações não esplintadas permitiram melhor distribuição das tensões à infraestrutura de suporte. Tais achados contradizem os obtidos neste trabalho quando se trata das tensões na infraestrutura das próteses, já que houve menos tensões quando estas estavam esplintadas.

Assim, a esplintagem no presente estudo foi benéfica a fim de preservar os pilares/componentes, implantes e região interna das infraestruturas. A tensão aumentada nas infraestruturas das próteses individualizadas, em torno de $70 \%$ maior que nas esplintadas, revela e exige atenção a fim de se evitar possível dano do componente e/ou da conexão sextavada da prótese e do pilar intermediário, ou mesmo soltura de parafusos por concentração de tensão e necessidade de maiores retornos periódicos (Quadros 21, 22, 23 e 24). Especificamente para os grupos 3E e 3l, ocorreu maior tensão na porção distal da infraestrutura esplintada comparada às demais, provavelmente devido ao efeito alavanca exacerbado pelas próteses de maior proporção coroa/implante (Quadro 24).

Foi observada maior tensão na área de assentamento das próteses esplintadas sobre os pilares, e tal fato pode se justificar pelo maior volume de toda a prótese unida, somado também ao maior dimensionamento da infraestrutura das próteses sobre os implantes curtos, gerando maior braço de alavanca. Outro fator a ser ponderado é que, com o uso das próteses sobre implantes esplintadas, há maior travamento de todo o sistema e consequente aumento das tensões no assentamento sobre os pilares, enquanto que nas próteses individualizadas há possibilidade de diminuição destas tensões pela 
micromovimentação unitária de cada prótese, além da possibilidade de ajustes dos contatos proximais. Além disso, com o uso das próteses esplintadas, há a necessidade do emprego de suas bases internas sem o dispositivo de travamento anti-rotacional, fazendo com que haja menor travamento lateral e distribuição das forças de forma mais acentuada na base de assentamento do pilar (Quadros 17, 18, 19 e 20).

O titânio e suas ligas apresentam boa resistência mecânica à tração (entre 200 e 1370MPa), e o titânio comercialmente puro (Ti cp) grau IV (geralmente usado na confecção de implantes dentários) apresenta a maior resistência mecânica dentre os graus de titânio puro. No entanto existem inúmeras empresas que também utilizam a liga Ti6Al4V para confecção de seus implantes e componentes, buscando valores ainda maiores de resistência. O Ti cp, apresenta tensão limite de resistência ao escoamento próximo a 895MPa (Donachie, 1988; Boyer et al., 1994; Lutjering e Williams, 2003). No caso do titânio utilizado nos implantes do presente trabalho, grau IV, trabalhado por técnica denominada "cold work", possui resistência aumentada em torno de 50\%, atingindo aproximadamente 2050MPa. A amplitude de valores de resistência ao escoamento relatada na literatura é grande (Donachie, 1988; Boyer et al., 1994; Lutjering e Williams, 2003), porém os valores de tensões obtidos neste trabalho não chegam a atingir os valores mais altos sugeridos nos relatos. Pita et al., em 2013, estudou o comportamento biomecânico, por meio do MEF, de parafusos protéticos convencionais e modificados. No referido estudo é relado o limite de escoamento dos parafusos usados em torno de $870 \mathrm{MPa}$, os quais são compostos também de titânio. Foi obtido no estudo de Pita et al. (2013), tensões médias em alguns parafusos 
desde $900 \mathrm{MPa}$ até $3000 \mathrm{MPa}$. No entanto, a área onde tais tensões extremas apareceram é extremamente limitada, de tal forma que efeitos relacionados às tensões podem não ser significativos e problemáticos do ponto de vista mecânico (Merz et al., 2000). O mesmo ocorre no presente estudo, em que as tensões extremas relatadas de $800 \mathrm{MPa}$ e $700 \mathrm{MPa}$ encontram-se em áreas limitadas. Vale lembrar que a metodologia usada (MEF) demonstra de forma bastante fidedigna, mais do que os valores absolutos de tensão, o padrão e distribuição das tensões, e áreas possíveis de falha, elucidando se uma situação é melhor ou pior do que a outra. Assim, nota-se que a esplintagem das próteses pode ser benéfica a fim de preservar toda a estrutura, assim como os elementos mais susceptíveis a falha, como, por exemplo, parafusos de fixação, o que levaria a menor necessidade de retornos periódicos dos pacientes, como já afirmado por Balshi e Wolfinger, 1997 e Misch, 2008.

\subsection{Proporcão coroa/implante}

Implantes dentários sempre estão sujeitos às cargas oclusais quando colocados em função (Bidez e Misch, 2008). Assim, há a transferência destas forças nos tecidos circunjacentes (Mlsch e Bidez, 2008). Extensões em cantilever, altura aumentada de coroa e supraoclusão podem agir como alavancas e ampliar as tensões (Bidez e Misch, 1992). Quanto maior a altura da coroa, maior será o momento de força ou braço de alavanca frente a qualquer força obliqua, segundo Misch, 1999 e Bidez e Misch, 2008. A cada aumento de $1 \mathrm{~mm}$ na altura da coroa há acréscimo de $20 \%$ nas forças atuantes (Bidez e Misch, 1992). Em nosso estudo, pela simulação de reabsorção vertical do alvéolo, simulamos aumento de dimensão da coroa, resultando em 
proporção coroa/implante de 2,8 (Tabela 2). Tal fato, associado ao uso do implante de menor comprimento, aumentou as tensões na região, no entanto não chegando a níveis de tensões percentualmente tão altas quanto as relatadas por Bidez e Misch, 1992. Uma vez que o material suporte é biológico, o seu comportamento, muitas vezes, não é completamente descrito pela teoria, uma vez que não conseguimos simular a remodelação óssea, e como exemplo temos estudos realizados por Celletti et al.,1995; Lindquist et al., 1996; Wennstrom et al., 2004; Blanes et al., 2007. Estes fatores caracterizam-se como limitações do estudo (material isotrópico, linearmente elástico e homogêneo).

Blanes et al. (2007), em seu estudo prospectivo, obtiveram resultados em que próteses sobre implantes com alta proporção coroa/implante apresentaram menor perda da crista óssea do que aquelas com proporção coroa/implante pequena. Tais resultados contradizem o conceito que coroas com dimensão vertical aumentadas são contraindicadas para reabilitação de áreas posteriores, tal como dito por Rangert et al., 1997 e Glantz e Nilner (2000). Ao mesmo tempo, o estudo de Blanes et al. (2007) corrobora com os achados de Celletti et al. (1995), Lindquist et al. (1996) e Wennstrom et al. (2004), em que todos eles não veem problemas em se utilizar reabilitação com grande proporção coroa/implante. Neste trabalho foram encontradas tensões maiores na infraestrutura, para a combinação de implante curto e prótese sobre implante de maior proporção, principalmente nas individualizadas. Porém não houve grandes diferenças em se unir ou não tais próteses com relação aos valores absolutos de tensões no osso circunjacente, mas sim diferenças apenas com relação à abrangência das tensões neste. Mas como a 
abrangência das tensões em osso também é importante fator a se avaliar recomenda-se, portanto a esplintagem das próteses sobre os implantes curtos para redução de tais tensões.

Segundo Blanes et al. (2007) a alta proporção coroa/implante resultou em menor perda da crista óssea pela estimulação natural das tensões no osso. No entanto, deve-se ressaltar alguns fatores relativos ao estudo: foram avaliados 192 implantes em que o número de casos com proporção coroa/implante maior que 3 foi relativamente baixo (4.2\%). Além disso, a maioria dos implantes analisados estavam esplintados (81.3\%), o que poderia sugerir que tal fato ajudaria numa melhor distribuição das tensões. Os autores também consideram que a esplintagem das próteses sobre implantes é recomendada em reabilitações em área posterior de mandíbula a fim de se evitar fatores de risco, perda de crista óssea e possíveis fraturas de componentes e metal. No entanto, afirmam que o uso de reabilitações unitárias oferece maior conforto, menores passos laboratoriais, melhor perfil de emergência e assentamento passivo e melhor higiene, tal como sugerido por Henry et al. (1996), Scheller et al. (1998), Mericske-Stern et al. (2001), Fugazzotto et al. (2004), Glauser et al. (2005) e Renouard e Nisand (2005).

No presente estudo, os achados a esse respeito não foram tão evidentes, já que as tensões encontradas nos grupos controle, que possuem apenas próteses com proporção coroa/implante igual a 1, foram praticamente iguais ao redor do dente quando usadas próteses individualizadas e esplintadas. Isso sugere que, com a presença de próteses menores e a geração de menor braço de alavanca, o comportamento biomecânico das próteses individualizadas é bastante interessante, sendo até mesmo superior 
ao das próteses esplintadas (Quadro 8), tendo em vista também suas vantagens clínicas. Já numa situação em que há a maior desproporção na relação coroa/implante essa situação se inverte, uma vez que se aumenta o braço de alavanca e a dissipação de tensão no dente, fazendo-se assim interessante a esplintagem das próteses a fim de se minimizar as tensões transmitidas no osso circunjacente do dente (Quadros 5, 6 e 7). Portanto, apenas na presença de próteses com proporção coroa/implante grande, a esplintagem das infraestruturas demonstrou melhor comportamento biomecânico com relação à transmissão de tais tensões no dente adjacente.

\subsection{Sugestões e possibilidades futuras}

Situação que foi notada e sugere viabilidade de utilização, tanto em estudos futuros como em aplicação clínica, seria, numa situação de existência de implantes regulares e curtos num mesmo contexto, a esplintagem apenas das próteses sobre os implantes curtos e deixando individualizada a prótese sobre o implante regular, já que a união das próteses de maior proporção juntamente com as próteses de menor proporção coroa/implante causaria maior braço de alavanca e prejuízo no osso circunjacente ao implante mais anterior (de comprimento regular), que apresentou sempre mais tensões em seu entorno quando esplintado aos curtos.

Além disso, numa situação de existência de apenas um implante curto e dois implantes regulares, realizar a esplintagem apenas da prótese sobre o implante curto com a prótese sobre o implante regular mais posterior, a fim de

diminuir o volume da infraestrutura e a desproporção que poderia vir a prejudicar o osso circunjacente aos implantes mais anteriores. 
Portanto, como anteriormente observado, as disparidades nos resultados e conclusões dos estudos mundiais mostram a necessidade de maiores averiguações, coletânea de dados e observações, a fim de ser possível qualquer tipo de afirmação absoluta. Aliás, dificilmente se chagará a um consenso universal sobre tal assunto, pois envolve inúmeros fatores associados, sendo que um deles não é passível de controle: a característica individual de cada paciente. O importante é que se esclareçam ao máximo todos os detalhes envolvidos no comportamento biomecânico dos implantes e respectivas próteses, para que assim nos aproximemos do que seria a situação ideal do comportamento de todo o sistema numa reabilitação. 



\section{Conclusões}





\section{CONCLUSÕES}

Assim, de acordo com os dados obtidos pela análise tridimensional pelo método dos elementos finitos deste trabalho, e levando-se em conta também os estudos relatados presentes na literatura, pode-se traçar algumas conclusões.

O uso de próteses sobre implantes esplintadas propiciou uma série de vantagens e benefícios com relação à distribuição de tensões nos elementos envolvidos no sistema, sendo possível afirmar que tal esplintagem:

- foi benéfica a todos os grupos experimentais do presente estudo, notoriamente ao grupo com presença apenas de implantes curtos, diminuindo as tensões no osso circunjacente aos implantes, principalmente em sua abrangência.

- diminuiu as tensões na superfície dos implantes e na área de transmucoso dos pilares/componentes, além da diminuição das tensões na região interna das infraestruturas.

- amenizou as tensões e sua abrangência ao osso circunjacente aos implantes curtos nos grupos com implantes regulares e curtos. No entanto, nesse mesmo contexto, gerou maior tensão ao osso circunjacente aos implantes regulares intermediários comparativamente aos grupos individualizados, sendo assim necessário ponderar sobre qual situação escolher.

- favoreceu a diminuição das tensões ao osso circunjacente ao dente adjacente, quando na presença de proporção coroa/implante aumentada. 
O uso de próteses sobre implantes individualizadas apresentou-se vantajosa:

- para a diminuição das tensões na parte superior dos pilares, local de assentamento das próteses sobre implantes, principalmente nas de proporção coroa/implante aumentada.

- na área de conexão entre coroas, que é ausente, já que, especificamente no uso de infraestrutura esplintada com proporção coroa/implante aumentada, ocorreu maior tensão em sua área de conexão distal.

- no grupo controle, apenas com implantes regulares e próteses de proporção normal, sendo viável sua utilização frente às vantagens clínicas não oferecidas pelas próteses esplintadas. 


\section{Referências Bibliográficas}





\section{REFERÊNCIAS BIBLIOGRÁFICAS}

Akça K, Cehreli MC. Biomechanical consequences of progressive marginal bone loss around oral implants: a finite element stress analysis. Med Bio Eng Comput. 2006 44(7):527-35.

Anusavice KJ. Phillips' Science of Dental Materials. Editora Saunders; 2003.

Assif D, Marshak B, Horowitz A. Analysis of load transfer and stress distribution by an implant-supported fixed partial denture. J Prosthet Dent. 1996 75(3):28591.

Baggi L, Cappelloni I, Girolamo MD, Maceri F, Vairo G. The influence of implant diameter and length on stress distribution of osseointegrated implants related to crestal bone geometry: A threedimensional finite element analysis. The Journal of Prosthetic Dentistry. 2008 100(6):422-31.

Bal BT, Cağlar A, Aydin C, Yilmaz H, Bankoğlu M, Eser A. Finite element analysis of stress distribution with splinted and nonsplinted maxillary anterior fixed prostheses supported by zirconia or titanium implants. Int $\mathrm{J}$ Oral Maxillofac Implants. 2013 28(1):e27-38.

Balshi TJ, Wolfinger GJ. Two-implant-supported single molar replacement: Interdental space requirements and comparison to alternative options. Int J Periodontics Restorative Dent 1997 17:426-435.

Barão VAR, Assunção WG, Tabata LF, Delben JA, Gomes EA, Sousa EAC, Rocha EP. Finite Element Analysis to compare complete denture and implantretained overdentures with different attachment systems. The Journal of Craniofacial Surgery. 2009 20(4):1066-1071.

Bender MF. Unsplinted crowns on implants in subantral augmented region: an evolution. J Oral Implantol. 1995; 2:121-131.

Bergkvist G, Simonsson K, Rydberg K, Johansson F, Dérand T. A finite element analysis of stress distribution in bone tissue surrounding uncoupled or splinted dental implants. Clin Implant Dent Relat Res. 2008 10(1):40-6.

Bidez MW, Misch CE. Clinical biomechanics in implant dentistry. In: Misch CE (ed). Contemporary Implant Dentistry, ed 3. St. Louis: Mosby, 2008:543-555.

Bidez MW, Misch CE. Force transfer in implant dentistry. Basic concepts and principles. Oral Implantol 1992;18:264-274.

Blanes RJ, Bernard JP, Blanes ZM, Belser C. A 10-year prospective study of ITI dental implants placed in the posterior region. II: Influence of the crown-toimplant ratio and different prosthetic treatment modalities on crestal bone loss. Clin Oral Impl. 2007 18:707-14.

Boyer R, Welsch G, Collings EW. Materials properties handbook: titanium 
alloys. ASM International: USA. 1994.

Bozkaya D, Mufta S, Muftu A. Evaluation of load transfer characteristics of five different implants in compact bone at different load levels by finite element analysis. J Prosthet Dent. 2004 92:523-30.

Brunski JB, Puleo DA, Nanci A. Biomaterials and biomechanics of oral and maxillofacial implants : current status and future developments. Int $\mathrm{J}$ Oral Maxillofac implants. 2000;15:15-46.

Carlson B, Carlsson GE. Prosthodontic complications in osseointegrated dental implant treatment. Int J Oral Maxillofac Implants. 1994 9(1):90-4.

Celletti R, Pameijer $\mathrm{CH}$, Bracchetti G, Donath K, Persichetti G, Visani I. Histologic evaluation of osseointegrated implants restored in non-axial functional occlusion with preangled abutments. International Journal of Periodontics Restorative Dentistry. 199515: 563-573.

Chun HJ, Cheong SY, Han JH, Heo SJ, Chung JP, Rhyu IC, Choi YC, Baik HK, $\mathrm{Ku} \mathrm{Y}$, Kim MH. Evaluation of design parameters of osseointegrated dental implants using finite element analysis. Journal of Oral Rehabilitation. 2002 29(6):565-74.

Çiftçi $Y$, Canaya S. The effect of veneering materials on stress distribution in implant-supported fixed prosthetic restorations. The International Journal of Oral e Maxillofacial Implants. 2000 15(4):571-82.

Cosme DC, Baldisserotto SM, Canabarro SA, Shinkai RS. Bruxism and voluntary maximal bite force in young dentale adults. The International Journal of Prosthodontics. 2005 18(4):328-32.

Craig RG. Restorative dental materials. 10th edition. Mosby-year book, inc., 1997.

Cunha LDAP, Pellizzer EP, Verri FR, Pereira JA. Evaluation of the influence of location of osseointegrated implants associated with mandibular removable partial dentures. Implant Dentistry. 2008 17(3):278-87.

Das Neves FD, Fones D, Bernardes SR, Prado CJ, Neto AJF. Short implants an analysis of longitudinal studies. Int J Oral Maxillofac Implants. 2006 21(1):8693.

Dibart S, Warbington M, Su MF, Skobe Z. In vitro evaluation of the implantabutment bacterial seal: the locking taper system. Int J Oral Maxillofac Implants. 2005 20(5):732-7.

Donachie MJ. Titanium - a technical guide. ASM International: Ohio. 1988.

Eckert SE, Meraw SJ, Cal E, Ow RK. Analysis of incidence and associated 
factors with fractured implants: a retrospective study. Int J Oral Maxillofac Implants. 2000 15(5):662-7.

Ekfeldt A, Carlsson GE, Borjesson G. Clinical evaluation of single-tooth restorations supported by osseointegrated implants: a retrospective study. Int $\mathrm{J}$ Oral Maxillofac Implants. 1994 9(2):179-83.

Eskitascioglu G, Usumez A, Sevimay M, Soykan E, Unsal E. The influence of occlusal loading location on stresses transferred to implant-supported prostheses and supporting bone: A three-dimensional finite element study. The Journal of Prosthetic Dentistry. 2004 91(2):144-50.

Falcón-Antenucci RM, Pellizzer EP, Carvalho PSP, Silva JVL, Moraes SLD. Evaluation of stress distribution on the implant/crown interface. Rev Cir Traumatol Buco-Maxilo-fac. 2008 8(3):49-56.

Faucher RR, Bryant RA. Bilateral fixed splints. Int J Perio Rest Dent. 1983;3:837.

Fereguetti $P$, Martins JF. Aplicações do critério de resistência de von Mises para materiais dúcteis sem usar as tensões principais. In: Anais do PET Civil UFOP, 2008. Disponível em:< http://www.em.ufop.br/petcivil/index.php?option= com_content\&view=article\&id=111\&ltemid=98\&limitstart=1 >. Acesso em: 04/04/2013.

Friberg B, Gröndahl K, Lekholm U, Brånemark PI. Long-term follow-up of severely atrophic edentulous mandibles reconstructed with short Brånemark implants. Clin Implant Dent Relat Res. 2000 2(4):184-9.

Fugazzotto PA, Beagle JR, Ganeles J, Jaffin R, Vlassis J, Kumar A. Success and failure rates of $9 \mathrm{~mm}$ or shorter implants in the replacement of missing maxillary molars when restored with individual crowns: preliminary results 0 to 84 months in function. A retrospective study. Journal of Periodontology. 2004 75(2):327-332.

Geng J, Tan KBC, Liu G. Application of finite element analysis in implant dentistry: A review of the literature. The Journal of Prosthetic Dentistry. 2001 85(6):585-98.

Geng J, Yan W, Xu W. Application of the Finite Element Method in Implant Dentistry. Editora Springer; 2008, 137 p.

Geng JP, Ma QS, Xu W, Tan KBC, Liu GR. Finite element analysis of four thread-form configurations in a stepped screw implant. Journal of Oral Rehabilitation. 2004 31(3):233-9.

Glantz PJ, Nilner K. Biomechanical aspects of prosthetic implant-borne reconstructions. Periodontology. 2000 17: 119-124.

Glauser R, Ruhstaller P, Windisch S, Zembic A, Lundgren A, Gottlow J, 
Hammerle $\mathrm{CH}$. Immediate occlusal loading of Branemark System Ti-Unite implants placed predominantly in soft bone: 4-year results of a prospective clinical study. Clinical Implant Dentistry Related Research 7 (Suppl. 1). 2005 S:52-S59.

Goodacre CJ, Bernal G, Rungcharassaeng K, Kan JYK. Clinical complications with implants and implant prostheses. The Journal of Prosthetic Dentistry. 2003 90(2):121-32.

Grossmann Y, Finger IM, Block MS. Indications for splinting implants restorations. Journal of Oral Maxillofacial Surgery. 2005 63(11):1642-52.

Guichet DL, Caputo AA, Choi $\mathrm{H}$, et al. Passivity of fit and marginal opening in screw- or cement-retained implant fixed partial denture designs. Int $\mathrm{J}$ Oral Maxillofac Implants. 2000;15:239Y246

Guichet DL, Yoshinobu D, Caputo AA. Effect of splinting and interproximal contact tightness on load transfer by implant restorations. The Journal of Prosthetic Dentistry. 2002 87(5):528-35.

Henry PJ, Laney WR, Jemt T, Harris D, Krogh PH, Polizzi G, Zarb GA, Herrmann I. Osseointegrated implants for single-tooth replacement: a prospective 5-year multicenter study. Int J Oral Maxillofac Implants. 1996 $11(4): 450-5$.

Himmlova L, Dostalova T, Kacovsky A, Konvickova S. Influence of implant length and diameter on stress distribution: A finite element analysis. J Prosthet Dent. 2004;91:20-25.

Holmes DC, Loftus JT. Influence of bone quality on stress distribution for endosseous implants. Journal of Oral Implantology. 1997 23:104-111.

Holmgren EP, Seckinger RJ, Kilgren LM, Mante F. Evaluating parameters of osseointegrated dental implants using finite element analysis--a twodimensional comparative study examining the effects of implant diameter, implant shape, and load direction. J Oral Implantol. 1998 24(2):80-8.

Huang H, Huang J, Ko C, Hsu J, Chang C, Chen MYC. Effects of splinted prosthesis supported a wide implant or two implants: a three-dimensional finite element analysis. Clin. Oral Impl. Res. 2005 16:466-472.

Isidor F. Loss of osseointegration caused by occlusal load of oral implants. A clinical and radiographical study in monkeys. Clin Oral Implants Res. 1996 7:143-152.

Isidor F. Influence of forces on peri-implant bone. Clin Oral Impl Res. 2006 17(2):8-18.

Jofre J, Cendoya P, Muños P. Effect of splinting mini-implants on marginal bone loss: a biomechanical model and clinical randomized study with mandibular 
overdentures. Int J Oral Maxillofac Implants. 2010 25(6):1137-1144.

Johns RB, Jemt T, Heath MR, Hutton JE, McKenna S, McNamara DC, van Steenberghe D, Taylor R, Watson RM, Herrmann I. A multicenter study of overdentures supported by Brånemark implants. Int J Oral Maxillofac Implants. 1992 7(4):513-22.

Kaukinen J, Edge M, Lang B. The influence of occlusal design on simulated masticatory forces transferred to implant-retained prostheses and supporting bone. The Journal of Prosthetic Dentistry. 1996 76(1):50-5.

Kim WD, Jacobson Z, Nathanson D. In vitro stress analyses of dental implants supporting screw-retained and cementretained prostheses. Implant Dent. 1999 $8: 141-150$

Kim Y, Oh TJ, Misch CE, Wang HL. Occlusal considerations in implant therapy: clinical guidelines with biomechanical rationale. Clin Oral Implants Res. 2005;16:26-35.

Kim SJ, Kim S, Choi H, Woo D, Park YB, Shim JS, Kim HS, Lee KW. A threedimensional finite element analysis of short dental implants in the posterior maxilla. Int J Oral Maxillofac Implants. 2014 29(2):155-64.

Ko CC, Kohn DH, Hollister SJ. Micromechanics of implant/tissue interfaces. J Oral Implantol. 1992 18(3):220-30.

Lan $\mathrm{TH}$, Pan $\mathrm{CY}$, Lee HE, Huang $\mathrm{HL}$, Wang $\mathrm{CH}$. Bone stress analysis of various angulations of mesiodistal implants with splinted crowns in the posterior mandible: a three-dimensional finite element study. Int $\mathrm{J}$ Oral Maxillofac Implants. 2010 25(4):763-70.

Lekholm U, Zarb G. Patient selection and preparation. In: Brånemark P-I, Zarb G, Albrektsson T, eds. Tissueintegrated prosthesis. Osseointegration in clinical dentistry. Chicago, IL: Quintessence, 1985:199-209.

Lin C, Wang J, Chang W. Biomechanical interactions in tooth-implant-supported fixed partial dentures with variations in the number of splinted teeth and connector type: a finite element analysis. Clin Oral Impl. 2008 19(1):107-17.

Lindh T, Gunne J, Tillberg A, Molin M. A meta-analysis of implants in partial edentulism. Clin Oral Impl. 1998 9:80-90.

Lindquist LW, Carlsson GE, Jemt T. A prospective 15-year follow-up study of mandibular fixed prostheses supported by osseointegrated implants. Clinical results and marginal bone loss. Clinical Oral Implants Research. 1996 7: 329336.

Lops D, Bressan E, Pisoni G, Cea N, Corazza B, Romeo E. Short implants in partially edentuolous maxillae and mandibles: a 10 to 20 years retrospective evaluation. Int J Dent. 2012:351793. 
Lutjering G, Williams JC. Titanium - Engineering Materials and Processes, Springer, New York, 2003.

Mangano C, Mangano F, Piatelli A, lezzi G, Mangano A, La Colla L. Prospective clinical evaluation of 307 single-tooth morse taper-connection implants: a multicenter study. Int J Oral Maxillofac Implants. 2010 25:394-400.

Menani LR, Tiossi R, Torres EM, Ribeiro RF, Almeida RP. Photoelastic stress analysis of different designs of cement-retained fixed partial dentures on morse taper oral implants. The Journal of Craniofacil Surgery. 2011 22(2):674-8.

Mericske-Stern R, Grutter L, Rosch R, Mericske E. Clinical evaluation and prosthetic complications of single tooth replacements by non-submerged implants. Clinical Oral Implants Research. 2001 12: 309-318.

Merz BR, Hunenbart S, Belser UC. Mechanics of the implant-abutment connection: an 8-degree taper compared to a butt joint connection. Int J Oral Maxillofac Implants. 2000 15(4):519-526.

Misch CE. Dental evaluation: Factors of stress. In: Misch CE (ed). Contemporary Implant Dentistry, ed 2. St. Louis: Mosby, 1999: 123-129.

Misch CE. Implantes dentários contemporâneos. In: Reações do osso às cargas mecânicas. São Paulo: Editora Santos [s.d.] 2009:317-28.

Misch CE. Treatment plans related to key implant positions and implant number. In: Misch CE (ed). Contemporary Implant Dentistry, ed 3. St Louis: Mosby, 2008:147-159

Misch CE, Bidez MW. Scientific rationale for dental implant design. In: Misch CE (ed). Contemporary Implant Dentistry, ed 3. St. Louis: Mosby, 2008:202225.

Misch CE, Steigenga J, Barboza E, Misch-Dietsh F, Cianciola LJ, Kazor C. Short dental implants in posterior partial edentulism: a multicenter retrospective 6-year case series study. J Periodontol. 2006 77(8):1340-7.

Misch CE. Prótese sobre implantes. In: Biomecânica clínica na implantodontia. $1^{\mathrm{a}}$ ed. Editora Santos, 2007. p.312-313.

Monteith BD. Minimizing biomechanical overload in implant prostheses: a computerized aid to design. J Prosthet Dent. 1993 69(5):495-502.

Morand $\mathrm{M}$, Irinakis $\mathrm{T}$. The challenge of implant therapy in the posterior maxilla: providing a rationale for the use of short implants. Journal of Oral Implantology. 2007 33(5):257-66.

Naert I, Koutsikakis G, Duyck J, Quirynen M, Jacobs R, van Steenberghe D. Biologic outcome of implant-supported restorations in the treatment of partial edentulism. Part 1: A longitudinal clinical evaluation. Clin Oral Impl Res. 2002 
Naert I, Koutsikakis G, Quirynen M, Duyck J, van Steenberghe D, Jacobs R. Biologic outcome of implant-supported restorations in the treatment of partial edentulism. Part 2: A longitudinal radiographic evaluation. Clin Oral Impl Res. 2002 13:390-5.b

Nissan J, Ghelfan O, Gross M, Chaushu G. Analysis of load transfer and stress distribution by splinted and unsplinted implant-supported fixed cemented restorations. Journal of Oral Rehabilitation. 2010 37(9):658-62.

Ogawa T, Dhaliwal S, Naert I, Mine A, Kronstrom M, Sasaki K, Duyck J. Effect of tilted and short distal implants on axial forces and bending moments in implants supporting fixed dental prostheses: an in vitro study. The International Journal of Prosthodontics. 2010 23(6):566-73.

Okumura N, Stegaroiu R, Kitamura E, Kurokawa K, Nomura S. Influence of maxillary cortical bone thickness, implant design and implant diameter on stress around implants: A three-dimensional finite element analysis. Journal of Prosthodontic Research. 2010 54(3):133-42.

Papavasiliou G, Kamposiora P, Bayne SC, Felton DA. Three-dimensional finite element analysis of stress-distribution around single tooth implants as a function of bony support, prosthesis type, and loading during function. J Prosthet Dent. 1996 76(6):633-40.

Petrie CS, Williams JL. Comparative evaluation of implant designs: Influence of diameter, length and taper on strains in the alveolar crest. A three-dimensional finite-element analysis. Clin Oral Implants Res. 2005 16:486-494;

Pierrisnard L, Renouard F, Renault P, Barquins M. Influence of implant length and bicortical anchorage on implant stress distribution. Clinical Implant Dentistry and Related Research. 2003 5(4):254-62.

Pita MS. Estudo biomecânico de conexões implante/pilar com parafusos convencionais e parafusos modificados tipo Cone Morse: análise tridimensional pelo método dos elementos finitos. [Tese de Doutorado em Reabilitação Oral]. Faculdade de Odontologia de Ribeirão Preto, Universidade de São Paulo; 2013.

Queiroz TP, Aguiar SC, Margonar R, Faloni APS, Gruber R, Luvizuto ER. Clinical study on survival rate of short implants placed in the posterior mandibular region: resonance frequency analysis. Clin Oral Implants Res. 2014 16:doi:10.1111/clr.12394.

Rangert BR, Sullivan RM, Jemt TM. Load factor control for implants in the posterior partially edentulous segment. International Journal of Oral Maxillofacial Implants. 1997 12: 360-370.

Reinhardt RA, Krejci RF, Pao YC, Stannard JG. Dentin stress in post- 
reconstructed teeth with dimishing bone support. J Dent Res. 1983 62(9):10028.

Renouard F, Nisand D. Short implants in the severely resorbed maxilla: a 2year retrospective clinical study. Clinical Implant Dentistry \& Related Research 7 (Suppl. 1). $2005: 104-110$.

Rokni S, Todescan R, Watson P, Pharoah M, Adegbembo AO, Deporter D. An assessment of crown-to-root ratios with short sintered porous-surfaced implants supporting prostheses in partially edentulous patients. Int $\mathrm{J}$ Oral Maxillofac Implants. 2005 20:69-76.

Rompen E, Touati B, Van Dooren E. Factors influencing marginal tissue remodeling around implants. Pract Proced Aesthet Dent. 2003 15(10):754-7759-61.

Rubin C, Krishnamurthy N, Capilouto E, Yi H. Stress analysis of the human tooth using a threedimensional finite element model. J Dent Res. 1983 $62(2): 82-6$.

Sahin S, Cehreli MCC, Yalcin E. The influence of functional forces on the biomechanics of implant-supported prostheses - a review. Journal of Dentistry. 2002 30(7/8):271-82.

Scheller H, Urgell JP, Kultje C, Klineberg I, Goldberg PV, Stevenson-Moore P, Alonso JM, Schaller M, Corria RM, Engquist B, Toreskog S, Kastenbaum F, Smith CR. A 5-year multicenter study on implant-supported single crown restorations. International Journal of Oral Maxillofacial Implants. 1998 13: 212218.

Sertgoz A. Finite element analysis study of the effect of superstructure material on stress distribution in an implant-supported fixed prosthesis. Int $\mathrm{J}$ Prosthodont. 1997 10(1):19-27.

Schwarz MS. Mechanical complications of dental implants. Clin Oral Implants Res. 2000 11:156-8.

Silva RCP. Avaliação de próteses fixas sobre implantes com diferentes níveis de ajuste pilar/prótese: efeito da ciclagem termomecânica sobre diferentes parafusos protéticos e análise fotoelástica da transmissão de tensões. [Dissertação de Mestrado em Reabilitação Oral]. Faculdade de Odontologia de Ribeirão Preto, Universidade de São Paulo; 2012.

Skalak R. Biomechanical considerations in osseointegrated prostheses. $\mathrm{J}$ Prosthet Dent. 1983 49(6):843-8.

Steigenga JT, Al-Shammari KF, Nociti FH, Misch CE, Wang HL. Dental implant design and its relationship to long-term implant success. Implant Dentistry. 2003 12(4):306-17. 
Shillingburg HT, Hobo S, Whitsett LD, Brackett SE. Fundamentals of Fixed Prosthodontics. $3^{\text {rd }}$ edition. Capítulo 19 - Wax Patterns, Quintessence, 1997. p.335-354.

Tabata LF, Assunção WG, Barão VAR, Gomes EA, Delben JA, Sousa EAC, Rocha EP. Comparison of single-standing or connected implants on stress distribution in bone of mandibular overdentures: a two-dimensional finite element analysis. The Journal of Craniofacial Surgery. 2010 21(3):696-702.

Tada S, Stegaroiu R, Kitamura E, Miyakawa O, Kusakari H. Influence of implant design and bone quality on stress/strain distribution in bone around implants: a 3-dimensional finite element analysis. International Journal of Oral \& Maxillofacial Implants. 2003 18:357-368.

Tawil G, Younan R. Clinical evaluation of short, machined-surface implants followed for 12 to 92 months. Int J Oral Maxillofac Implants. 2003 18(6):894901.

Teixeira MF, Ramalho SA, Sartori IAM, Lehman RB. Finite Element Analysis of 2 Immediate Loading Systems in Edentulous Mandible: Rigid and Semirigid Splinting of Implants. Implant Dentistry. 2010 19(1):39-49.

Tesmer M, Wallet S, Koutouzia T, Lundgren T. Bacterial colonization of the dental implant fixture-abutment interface: an in vitro study. J Periodontol. 2009 80:1991-7.

Thomé G, Golin AL, Castro CG, Salatti RC, Valgas L, Bernardes SR. Considerações mecânicas e a importância do uso de implantes cone Morse para o sucesso em implantodontia. Jornal Ilapeo. 2011 5(4):126-130.

Tiossi R, Vasco MAA, Lin L, Conrad HJ, Bezzon OL, Ribeiro RF, Fok ASL. Validation of finite element models for strain analysis of implant-supported prostheses using digital image correlation. Dental Materials. 2013 29:788-796.

Toniollo MB, Macedo AP, Rodrigues RSC, Ribeiro RF, Mattos MGC. ThreeDimensional Finite Element Analysis of Stress Distribution on Different Bony Ridges With Different Lengths of Morse Taper Implants and Prosthesis Dimensions. J Craniofac Surg. 2012 23(6):1888-1892a.

Toniollo MB, Macedo AP, Palhares D, Calefi PL, Sorgini DB, Mattos MGC. Morse taper implants at different bone levels: a finite element analysis of stress distribution. Braz J Oral Sci. 2012 11(4):440-444b.

Turner $\mathrm{CH}$, Burr DB. Basic biomechanical measurements of bone: a tutorial. Bone. 1993 14:595-608.

Urdaneta RA, Rodriguez S, McNeil DC, Weed M, Chuang S. The effect of increased crown-to-implant ratio on single-tooth locking-taper implants. Int $\mathrm{J}$ Oral Maxillofac Implants. 2010 25(4):729-43. 
Wang $\mathrm{T}$, Leu L, Wang J, Lin L. Effects of prosthesis materials and prosthesis splinting on peri-implant bone stress around implants in poor-quality bone: A numeric analysis. Int J Oral Maxillofac Implants. 2002 17(2):231-7.

Weber HP, Sukotjo C. Does the type of implante prosthesis affect outcomes in the partially edentulous patient? Int J Oral Maxillofac Implants. 2007 22(Suppl):140-172

Weng D, Jacobson Z, Tarnow D, Hürzeler MB, Faehn O, Sanavi F, Barkvoll P, Stach RM. A prospective multicenter clinical trial of $3 \mathrm{i}$ machined-surface implants: results after 6 years of follow-up. Int J Oral Maxillofac Implants. 2003 18(3):417-23.

Wennstrom J, Zurdo J, Karlsson S, Ekestubbe A, Grondahl K, Lindhe J. Bone level change at implant-supported fixed partial dentures with and without cantilever extension after 5 years in function. Journal of Clinical Periodontology 2004 31: 1077-1083.

Verri FR, Pellizzer EP, Rocha EP, Pereira JA. Influence of length and diameter of implants associated with distal extension removable partial dentures. Implant Dentistry. 2007 16(3):270-6.

von Mises, R. Mechanik der festen Körper im plastisch deformablen Zustand. Göttin. Nachr. Math. Phys. 1913. vol.1, p.582-592.

Yang $\mathrm{H}$, Lang LA, Felton DA. Finite element stress analysis on the effect of splinting in fixed partial dentures. J Prosthet Dent 1999 81:721-8.

Yokoyama S, Wakabayashi N, Shiota M, Ohyama T. Stress analysis in edentulous mandibular bone supporting implant-retained 1-piece or multiple superstructures. Int J Oral Maxillofac Implants. 2005 20(4):578-83. 